\title{
The Comparative Morphology of the Embryo and Seedling in the Gramineae.
}

\author{
BY
}

\author{
ETHEL SARGANT, F.L.S.
}

AND

AGNES ARBER, D.Sc., F.L.S.

\section{With Plates IX and $\mathbf{X}$ and thirty-five Figures in the Text.}

$7 \mathrm{HE}$ embryo of the Grasses is sufficiently unlike that of most Mono1 cotyledons to render exact comparison difficult. No question arises concerning the stem-bud and primary root; they are particularly clear in the Grass embryo, because it is more completely differentiated in the ripe seed than that of most Monocotyledons. But the parts which feed and protect them - the scutellum, coleoptile, coleorhiza, and epiblastretain these non-committal names because botanists are not yet agreed on their respective homologies.

Before 1872 the only evidence considered was the structure of the embryo within the seed, or immediately on germination. At that age the vascular tissue is not sufficiently differentiated to be traced with certainty.

In 1872 Van Tieghem published a paper in which he compared the vascular skeletons of many seedling Gramineae with each other, and with those of certain other selected monocotyledonous seedlings. He interpreted the structure of the embryo within the seed in the light of its later development. In a subsequent paper (I897), the same author pursues the subject. Publishing no new figures, he accepts a correction of fact made by Miss Lewin ('87), Bruns ('9.2), and Schlickum ('96), but otherwise depends mainly on the evidence published in 1872 . His interpretation of that evidence is, however, quite different.

Since that date the method then introduced by Van

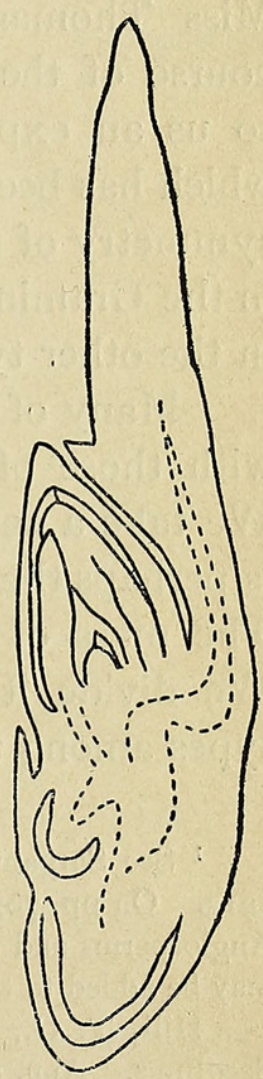

TEXT-FIG. I. Avena sativa, L. Embryo in median section. $\times$ I 8 . Tieghem has been applied to seedlings from many families, with a precision impossible before the introduction of the microtome. Indications of race

[Annals of Botany, Vol. XXIX. No. CXIV. April, 1915.]

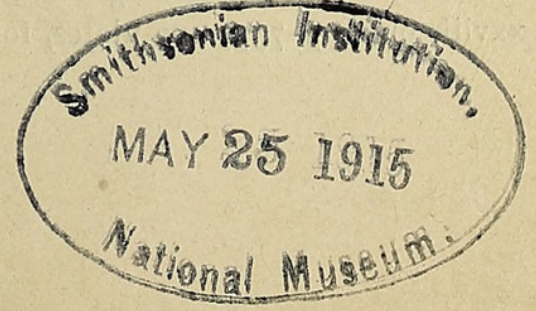




\section{I62 Sargant and Arber. - The Comparative Morphology of}

history have been traced in the vascular system of seedlings belonging to other monocotyledonous families, to Dicotyledons, and to Gymnosperms. ${ }^{1}$ The Grasses, however, have been neglected of late years, and we felt it desirable to repeat and extend Van Tieghem's observations on them with improved methods, and in the light of wider experience. This task we began together at Reigate in 1902, but owing to various interruptions it has only just been finished.

We wish to express our thanks here to Miss E. N. Thomas, D.Sc., for permission to use her preparations, notes, and drawings of the Zingiberaceae (see p. 209) ; to Mrs. G. R. Taylor for the loan of her preparations from Triticum and Hordeum; to Dr. O. Stapf, F.R.S., for various suggestions and criticisms; and to Mr. R. I. Lynch, M.A., of the Botanic Garden, Cambridge, for the gift of seeds and other material.

Besides the various types of Grasses, we have examined seedlings from other monocotyledonous families, choosing those in which the cotyledonary sheath is a prominent feature; and we have continued a detailed study of certain seedlings belonging to the Zingiberaceae which had been begun by Miss Thomas in the laboratory at Reigate. Her observations on the course of the bundles in the cotyledonary sheath of Elettaria suggested to us an explanation of the vascular skeleton in the coleoptile of Avena, which has been confirmed by further research. We think that the vascular symmetry of the seedling in this genus approaches that of the Avena type in the Gramineae, and gives a clue to the homologies of seedlings included in the other types.

Many of the conclusions which we draw from these studies are identical with those of Van Tieghem in 1872 , of Schlickum in 1896 , and others. We take a new view of the morphological nature of the mesocotyl, and this is perhaps the chief contribution which we make to the theory of the subject. The mass of evidence examined is considerable, and much of it is new. We divide it under two heads; first the description of certain seedling types among the Grasses themselves, and then that of a few selected species

1 See Sargant, E., Presidential Address, Section K, Botany, Brit. Assn. Report, Birmingham, 1913. On pp. 703 and 704 will be found a list of references to papers dealing with the seedlings of Angiosperms and Gymnosperms from an anatomical standpoint. The following additional references may be added to this list :

Hill, T. G., and de Fraine, E. : A Consideration of the Facts relating to the Structure of Seedlings. Ann. of Bot., vol. xxvii, pp. 257- $7^{2}$, four text-figs., I9I 3 .

Hill, T. G., and de Fraine, E. : On the Classification of Seed-Leaves. Ann. of Bot., vol. xxviii, pp. 359-62, 1914.

Lee, E.: Observations on the Seedling Anatomy of certain Sympetalae. II. Compositae. Ann. of Bot., vol. xxviii, pp. $303^{-2}$, thirteen text-figs., I9I4.

Mellor, A. E. : The Seedling Structure of Dryas octopetala. The Naturalist, I9I I, pp. 3ro-I2, six text-figs.

Thomas, E. N.: Seedling Anatomy of Ranales, Rhoeadales, and Rosales. Ann. of Bot., vol. xxviii, pp. 695-733, two plates, forty-three text-figs., I914. 
from other Monocotyledons for comparison. But before describing our own researches, we will outline the points in dispute.

The members of doubtful homology are shown in the diagram of a seedling Avena (Text-fig. 2). The same parts are present in the embryo with the exception of the mesocotyl. This appears first on the elongation of the axis during germination (compare Text-figs. I and 2).

In the young seedling of a hypogeal Monocotyledon, two members are distinguished externally: the cotyledon, and the main descending axis. The plumular bud is present, but is commonly concealed within the expanded base of the cotyledon. This expanded base, with or without an appendage, forms the sheath, which protects the plumule during germination. The apex of the hypogeal cotyledon becomes the sucker, absorbing food from the endosperm. Sucker and sheath are usually connected by a stalk, which may be very short or absent. For instance in Tigridia (Text-fig. 8, p. 8) the seed appears to cling to the sheath, but on removal of the seed-coats a short neck is found between sheath and sucker.

The scutellum of Avena seems perfectly comparable with the sucker of Tigridia for example, and the coleoptile re-

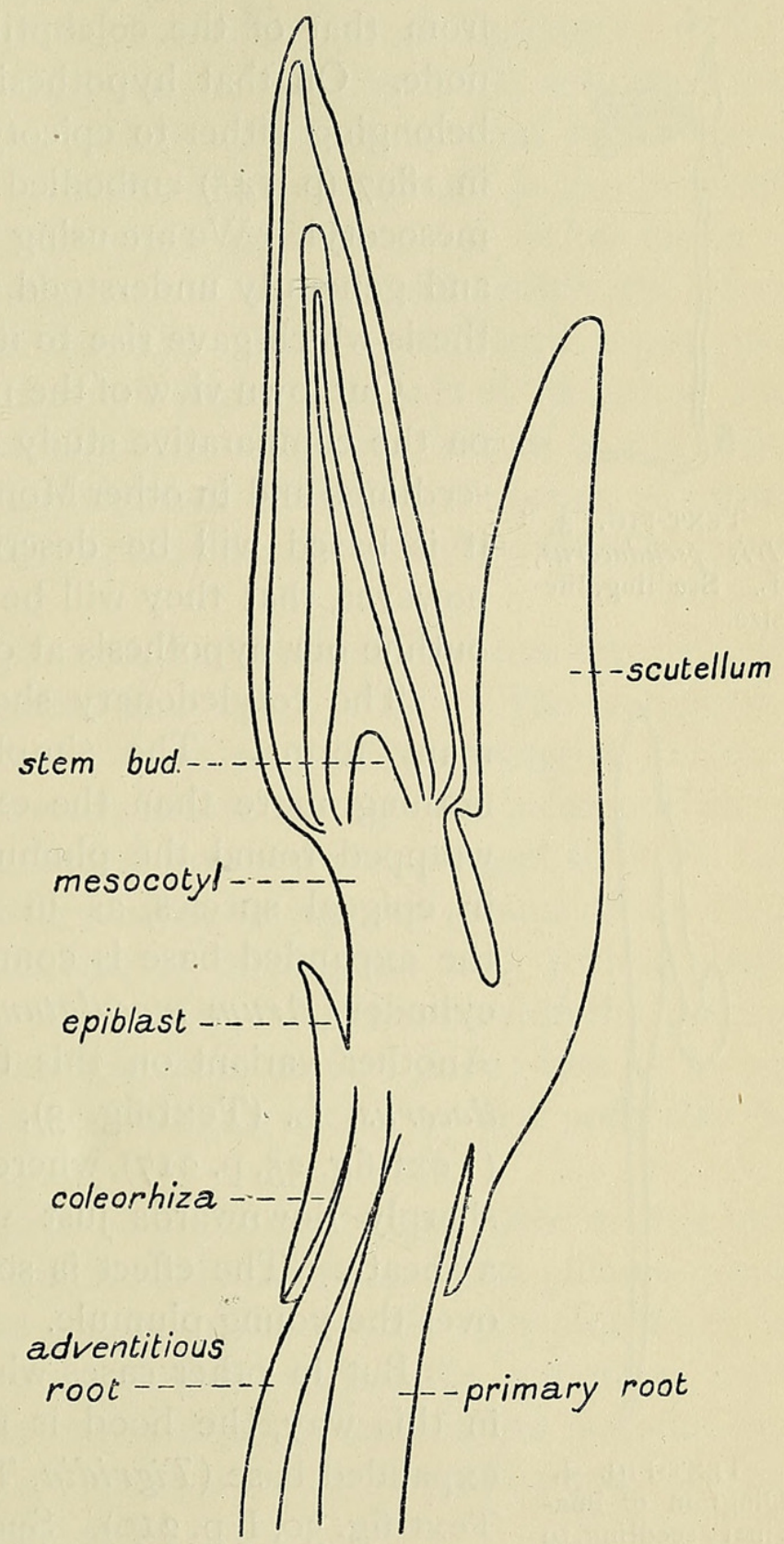

Text-FIG. 2. Avena sativa, L. Diagram of part of very young seedling in median section. sembles such sheaths as those of Tigridia, Crocus, Colchicum, and Elettaria. But in Avena and similar forms, as in the $Z e a$ type also, scutellum and coleoptile are separated from each other by the mesocotyl, which is sometimesvery long (Text-fig. I 8, p. I79). If this were not so-that is, if throughout the Gramineae the coleoptile and scutellum were inserted on the axis at the same level (as in Hordeum and 


\section{I64 Sargant and Arber.-The Comparative Morphology of}

Triticum, for instance)-botanists would probably have found no difficulty in considering the scutellum as the sessile sucker of the cotyledon, and the coleoptile as its sheath. Van Tieghem, indeed, did take this view in 1872 , and justified it by a bold morphological fiction. He treated the whole of

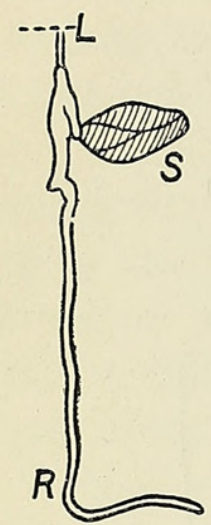

TEXT-FIG. 3. Iris psendacorus, L. Seedling, lifesize.

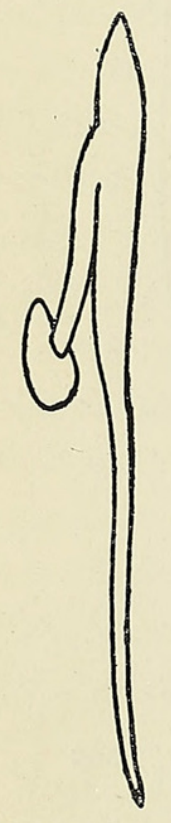

TEXT-Fig. 4 Diagram of imaginary seedling, to illustrate how the stalk of the cotydon might fuse with the hypocotyl.

is well developed (Kniphofia).

Now suppose a seedling with a pronounced upper sheath to its cotyledon, and no basal sheath at all, the stalk of the cotyledon pointing downwards and in close contact with the axis (Text-fig. 4). If we imagine from that of the coleoptile as an elongation of the first node. On that hypothesis it could not be considered as belonging either to epicotyl or hypocotyl, and Celakovský in 1897 (p. I45) embodied Van Tieghem's view in the term mesocotyl. We are using this term because it is convenient and generally understood, but we do not accept the hypothesis which gave rise to it.

Our own view of the nature of the mesocotyl is founded on the comparative study of the vascular skeleton in Grass seedlings and in other Monocotyledons. The facts on which it is based will be described in detail later. We think, however, that they will be followed with greater ease if we outline our hypothesis at once.

The cotyledonary sheath of Monocotyledons assumes many forms. The simplest case is that in which it is nothing more than the expanded base of the cotyledon wrapped round the plumular bud. This is very common in epigeal species, as in Allium. In hypogeal seedlings the expanded base is commonly transformed into a closed cylinder (Arum maculatum, L., Veratrum nigrum, L., \&c. Another variant on this type is illustrated by Iris pseudacorus, L. (Text-fig. 3), and Commelina coelestis, Willd. (Text-fig. 35, p. 2I7), where the stalk of the cotyledon is bent sharply downwards just where it begins to expand into a sheath. The effect is sometimes to form a sort of hood over the young plumule.

But in other cases when the stalk is bent downwards in this way, the hood is formed by an appendage to the expanded base (Tigridia, Text-fig. 8, p. I68, and Elettaria, Text-fig. 30, I, p. 210). Such a hood often suggests a pair of stipules united along one margin or both. Van Tieghem ('72, p. 27I) distinguished this structure as the upper or stipular sheath from the lower or basal sheath. Occasionally the latter is almost wholly suppressed, while the upper sheath

the axial region separating the insertion of the scutellum 
stalk and axis to become completely united, the sucker will appear sessile on the axis at one level, while the sheath is inserted higher up. These are precisely the relative positions of scutellum and coleoptile in Avena. As far as external structure goes, the mesocotyl may have been derived in some such way from a fusion of cotyledonary stalk with hypocotyl. What influence would such an ancestry be likely to have on the internal anatomy?

In such an ancestor the stalk, before it became fused with the axis, would contain at least one bundle; and every bundle present would travel upwards within the stalk to the first node, where the sheath is also inserted. At the first node each stalk-bundle would enter the axis. After fusion of stalk and axis all the stalk-bundles would be enclosed within the same compound structure as the stele of the axis. They would to all appearance be traces lying side by side with the stele during this part of its course, and on reaching the first node they would enter either the sheath or the stele. We have compared this imaginary skeleton with that of Avena, or rather with that of the Avena type, which we consider the primitive form of Grass seedling.

The Avena skeleton is complicated, but its main features can perhaps be followed with the aid of a diagram (Text-fig. 6, p. I66). The scutellum is sessile, and its single massive bundle turns upwards on entering the axis without joining the stele. Transverse sections through the mesocotyl show the scutellum trace outside the stele, and inverted with respect to it (Pl. IX, Fig. 4). The inverted trace is clearly double, having two groups of soft bast, and in older seedlings two formations of metaxylem also, with a single group of protoxylem elements. Here, then, is a trace outside the stele of the mesocotyl, and travelling from scutellum to first node; just as in our imaginary case a trace or traces travelled from sucker to first node side by side with the stele of the hypocotyl.

Reference to Text-fig. 6 shows that the scutellum trace divides into two parts at the first node while still outside the stele. The phloem group on either side becomes a phloem group of the double coleoptile trace on that side, and half the xylem goes with it. Thus the scutellum trace ceases to exist at the first node, but each of its two halves maintains its identity within one of the two coleoptile traces. The other half of each coleoptile trace is supplied from the stele.

The peculiar connexion between scutellum trace and coleoptile traces can be equally well described from above downwards ; that is, by following the coleoptile traces through the first node.

The structure of the first node is symmetrical about a plane which bisects the first leaf, and when prolonged downwards also bisects the scutellum trace and the scutellum itself. It is the plane of the paper in Text-fig. 2. In Text-figs. I 6 and I7, pp. I74 and I75, it is represented by the shorter axis of the elliptical diagram, which always bisects both $s c$., the scutellum trace, 
I66 Sargant and Arber.-The Comparative Morphology of
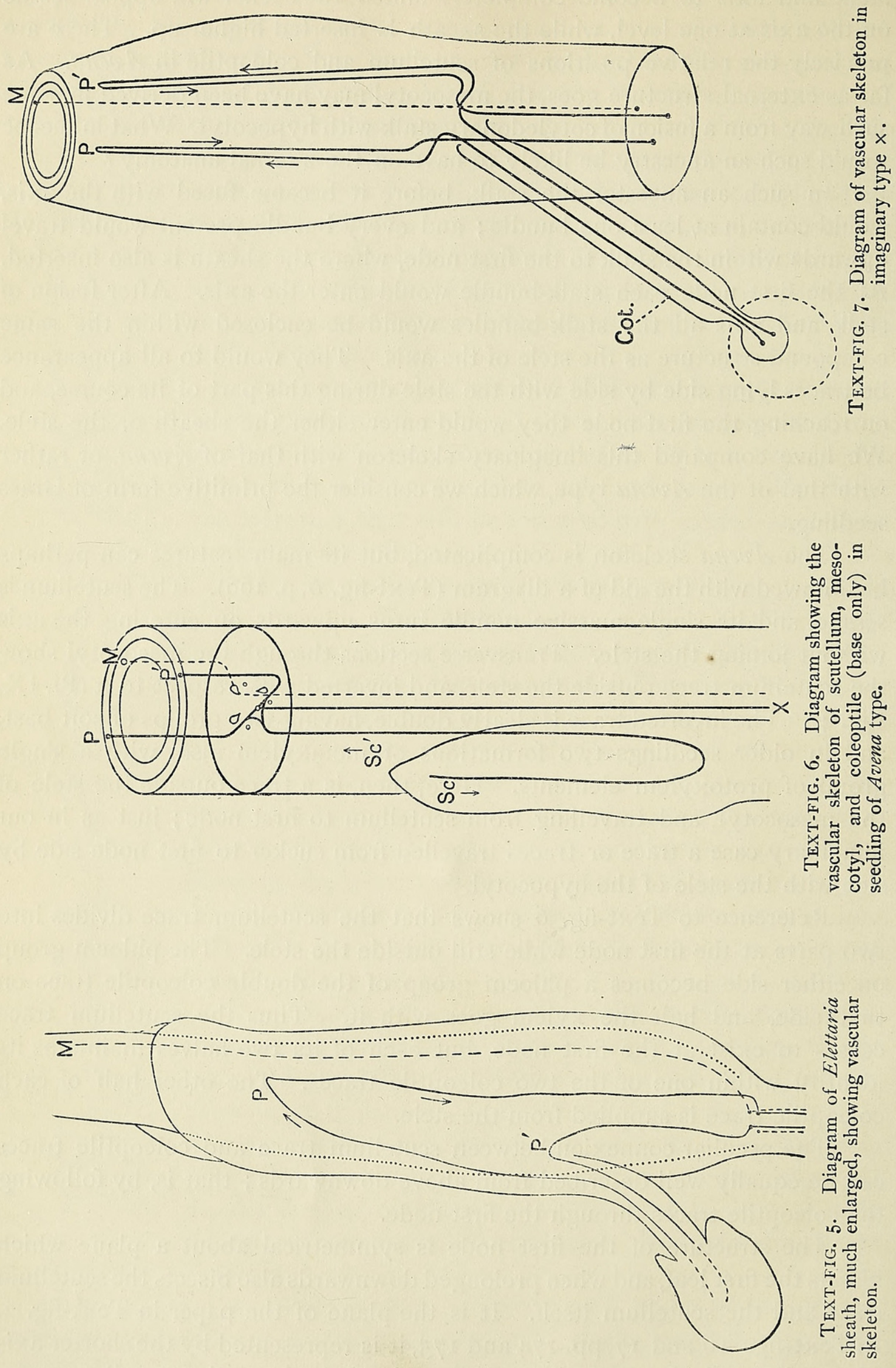
and also $M$, the midrib trace from the first leaf. The coleoptile bundles are bisected by the long axis at right angles to this. They enter the stele at opposite sides, and the adjacent plumular traces are inserted on them. Then each coleoptile trace divides. The phloem groups separate, one turning outwards and carrying some xylem elements with it, while the other continues within the stele, and meets the corresponding branch from the opposite coleoptile trace there. These united branches turn downwards, and constitute the bundle $x$ within the stele (Text-figs. 6, p. I66, and I6, p. I74). The outward branches meet too, but outside the stele. Together they build up the scutellum trace. ${ }^{1}$

The direct connexion between scutellum trace and coleoptile bundles is the most striking feature in the Avena type, and we have therefore searched for some special relation between sucker and sheath in the vascular structure of other monocotyledonous seedlings. The comparison which we think most instructive is with the seedling of Elettaria cardamomum, one of the Zingiberaceae. In this species the sucker of the cotyledon remains within the seed, and is connected with the axis by a fairly long stalk. The sheath is partly above the insertion of the stalk, and partly below it. The stalk runs up to its insertion, and in that neighbourhood is commonly almost parallel with sheath and axis (Text-fig. 5). The two bundles of the cotyledon are symmetrically placed within the stalk, the xylem of each being internal. On entering the sheath, however, they diverge to right and left. One travels upwards, and approaches the apex of the sheath before turning sharply down. The other turns down almost as soon as it enters the sheath (Text-fig. 5). In the end they enter the stele of the hypocotyl from opposite sides. The traces which separate them are plumular.

We have constructed an imaginary vascular skeleton to link the symmetry of the Avena type with that of Elettaria (Text-fig. 7). The stalk of the cotyledon contains two independent bundles. These enter the axis at the first node, where each turns outwards into the cotyledonary sheath, and then upwards within it. Near the apex each turns sharply

1 The vascular skeleton described above is that of the Avena type, generalized from Avena and from other genera resembling it in seedling structure, notably from Zizania. It differs in one important respect from the vascular skeleton of Avena itself. In describing the latter we shall show later on that the scutellum trace is directly connected with the stele by a massive xylem arch (p. I 78 ). We have come to the conclusion that this feature is adaptive, not primitive; perhaps a device for supplying the scutellum with water from the lower roots in the most direct way. For in Zizania, although, as usual in an aquatic species, the whole xylem skeleton is very much reduced, it is still identical with that of Avena except in this one respect. No general reduction of xylem elements would account for the complete disappearance of a massive xylem arch between scutellum and stele. But the submerged scutellum of Zizania needs no short cut to secure an adequate supply of water, and this species has no lower system of cauline roots.

There are some independent grounds for considering Zizania as a genus with primitive features, particularly its floral structure. 
downwards, doubling on itself in such a way that in transverse section two double bundles appear on opposite sides of the sheath. When the downward bundles approach the first node they leave their companions and enter the stele among the plumular traces.

This imaginary type $X$ resembles Elettaria in possessing two distinct bundles in the cotyledon, which make an acute angle in the sheath before entering the stele of the hypocotyl from opposite sides. To derive it from Elettaria the stalk of the cotyledon must be inserted on the axis rather than on the sheath; both bundles must approach the top of the sheath before they turn down, and they must double on themselves so closely that

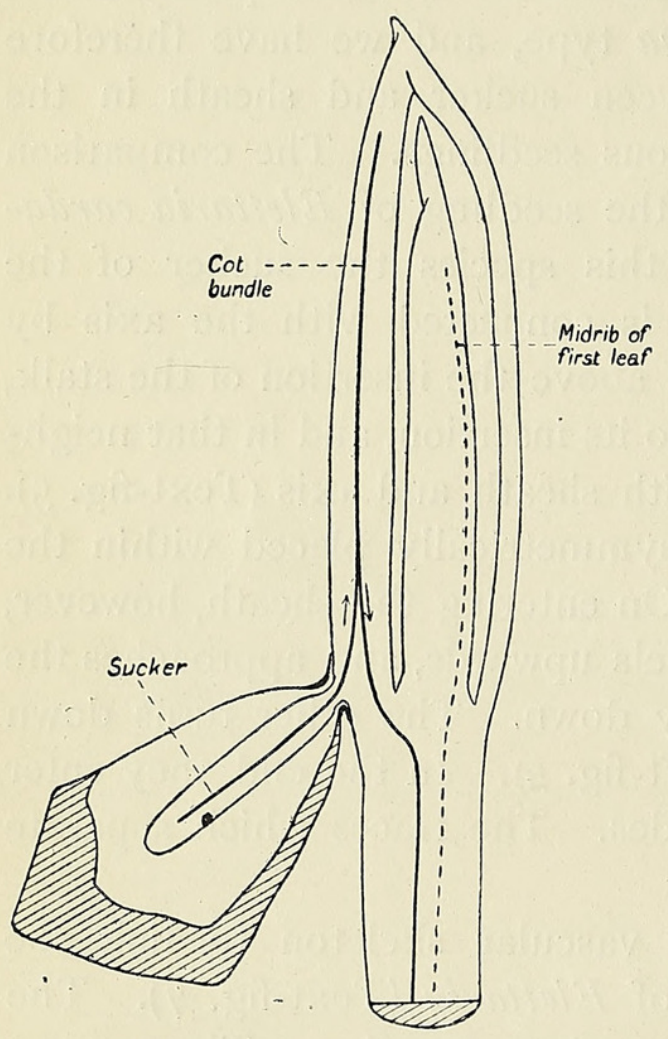

TeXT-FIG. 8. Diagram of bundles in sucker and sheath of Tigridia. the upward and dow nward segments of each bundle are in contact throughout the upper part of the sheath.

For such close doubling of a bundle there is a precedent in the seedling of Tigridia (Text-fig. 8, p. I68). A single bundle enters the sheath from the cotyledon, travels up the dorsal spine of the sheath, and doubles on itself near the top. It appears in transverse section as a double bundle with two external xylem groups, dorsal and ventral, for some distance below the turn (Pl. X, Fig. I5). This unusual orientation of xylem and phloem depends on the median position of the bent bundle in the Tigridia sheath, and would not occur in the lateral bundles of the $X$ sheath, however closely each might bend on itself.

To derive the vascular skeleton of the Avena type from that of $X$, four modifications are necessary. (I) The two bundles of the cotyledon must unite with each other throughout their course in sucker and stalk. Examples of such union are not uncommon among Monocotyledons. ${ }^{1}$ The distinct bundles of one species may be represented by a double bundle in another species within the same genus. (2) The stalk of the cotyledon must unite with the hypocotyl so completely that the sucker appears sessile on the axis at a level below that of the first node. Thus a mesocotyl is formed by fusion of the cotyledonary stalk with part of the hypocotyl.

1 Sargant, E. ('03) : A Theory of the Origin of Monocotyledons founded on the Structure of their Seedlings. Ann. of Bot., vol. xvii, pp. 20-I, I903. Scilla sibirica has two separate bundles in the cotyledon, and $S$. peruviana a double bundle. Cf. also the case of Colchicum autumnale mentioned below, p. 2 I 8 . 
The effect of these two structural alterations is that the stalk bundles are represented in the mesocotyl by a trace, distinct from the stele and parallel with it. The origin of this trace in Avena is suggested by its double structure and inverted orientation.

(3) In the sheath the upward and downward segments of each lateral bundle must be united to the very base. (4) The downward segments on entering the stele must fuse with each other to form trace $x$ (IV in Textfig. I6, p. I74).

These four modifications are sufficient to transform the imaginary type $X$ into a vascular skeleton, with all the features which we consider as essential to the Avena type. Three more would be necessary to complete the resemblance to the actual Avena seedling. The sucker of $X$ must become the scutellum of Avena; the sheath-bundles must be capped with xylem elements; and a xylem arch must be thrown from the scutellum trace to the mesocotylar stele.

All these characters are in our opinion adaptive, and therefore of secondary importance for our present purpose. The greater differentiation of the scutellum, as compared with the sucker, is closely related to the rapid growth of the Grass seedling in comparison with that of other Monocotyledons. The xylem caps to the coleoptile bundles are doubtless organs for the excretion of water. We have already referred to the probable function of the xylem arch as a water-carrier.

Our interpretation of the doubtful members of the Avena seedling is thus as follows:

The scutellum is the sucking apex of the cotyledon.

The coleoptile is the cotyledonary sheath-perhaps equivalent to a pair of stipules.

The mesocotyl is the fusion of the cotyledonary stalk with the hypocotyl.

The coleorhiza and the epiblast we consider as outgrowths from cotyledon or axis, or both, and of little morphological importance.

The reconstruction of the missing link $X$, through which the Grass embryo and seedling are connected with those of hypogeal Monocotyledons in general, is intended to demonstrate how the following exceptional features of the Avena seedling may have arisen: the double scutellum trace and its inversion; its indirect connexion with the bundles of the stele through the coleoptile traces; the double structure of the coleoptile bundles. Later on, the reconstruction of $X$ will be shown to throw light on the $Z e a$ type also, with its more specialized mesocotyl. 


\section{Comparative Anatomy of Grass Seedlings.}

\section{A. Avena type.}

Avena sativa, L. The structure of the embryo within the seed is well known. Only such details as are important for our purpose need be described here. A median section is outlined in Text-fig. I, p. I6I.

The scutellum is fleshy, but leaf-like in outline. It has a well-developed dorsal ridge (Text-fig. I3), and a ventral scale (Text-fig. I4). Whatever the morphological nature of this scale may be, its function is quite clear. The endosperm - which encloses the upper part of the scutellum like a capfits into the furrow between scutellum and scale, and ends there. Thus the plumule, which lies immediately below the scale, is quite clear of the endosperm, and is not impeded by it when growth begins. The scale is at some

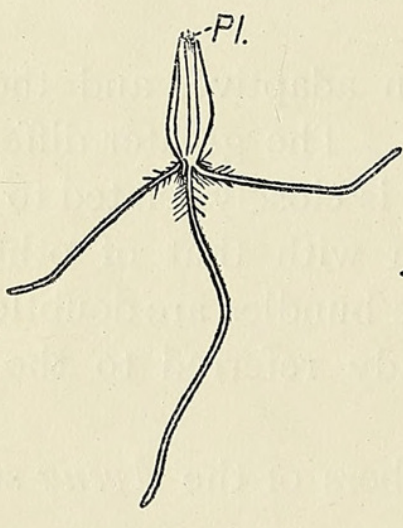

Fig. 9.

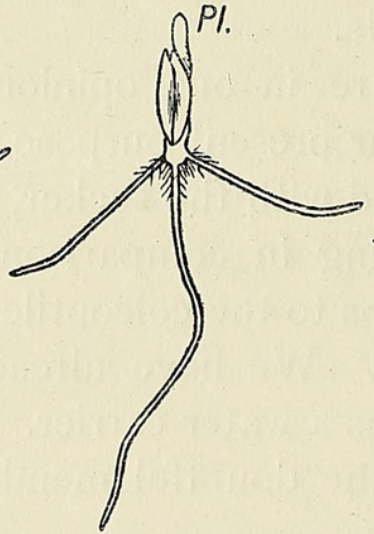

Fig. I0.

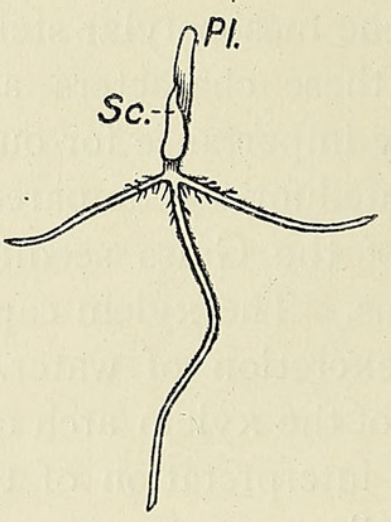

Fig. II.

TeXt-Figs. 9-II. Avena sativa, L. 9. Whole seedling, life-size. Io. Same seedling with husks of grain removed. II. Same seedling with scutellum laid bare.

distance above the insertion of the scutellum on the axis, and the scutellum itself is prolonged below its insertion.

The first region of the axis to elongate is the mesocotyl, but the primary root is the first member to show externally in the germinating grain. In Text-fig. 9, the primary root is an inch and a half long, while the tip of the stem-bud can hardly be perceived among the glumes. Two cauline roots from the zone of insertion are also well developed.

The mesocotyl bears the stem-bud enclosed in the coleoptile, a stiff conical sheath with a sharp point. In terrestrial Grasses the coleoptile serves to force a way upwards through the soil, while protecting the stembud within it.

The mesocotyl may continue to grow for a considerable time. When grains are scattered on the ground in the usual way, the ascending axis of each grows upwards as soon as it can get clear of the glumes, making an angle of about $90^{\circ}$ with the long axis of the grain. The length of the mesocotyl is then very variable. Growth appears to cease when the base 
of the plumule is in a position favourable for the cauline roots it throws out. In a seedling produced from a grain which had been planted with the glumes pointing upwards, the mesocotyl ceased to grow when it had just overtopped them. Two foliage leaves were expanded at that time, and a third was appearing from the sheath of the second. The upper limit of the mesocotyl was clearly defined in this seedling by the sudden increase in diameter of the epicotyledonary axis with its sheathing leaves, and also by the appearance of rudimentary cauline roots at the first node (Textfig. I5). By this time the food reserves of the endosperm are exhausted

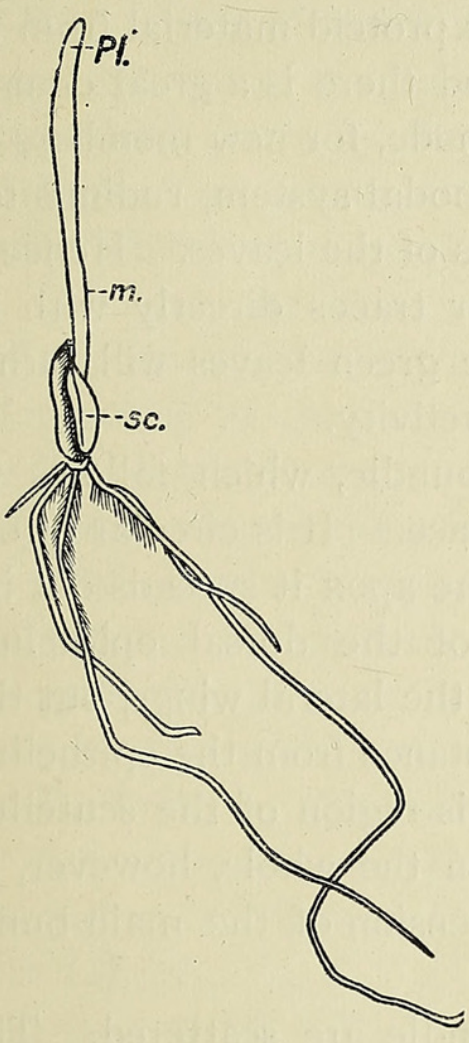

Fig. I2.

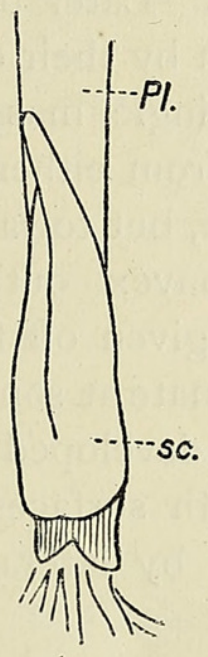

Fig. 13 .

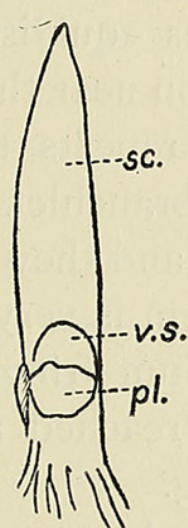

Fig. I 4.

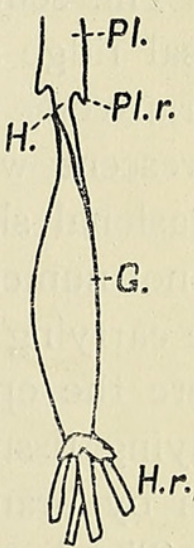

Fig. I5.

TeXT-FIgS. I2-I4. Avena sativa, L. I2. Whole seedling, life-size. Part of grain is removed, exposing half scutellum. I3. All grain removed. Scuteilum and adjacent parts from back. $\times 4$. I4. Scutellum from front, showing ventral scale (v.s.). The scar pl. shows place whence plumule has been removed. $\times 4$.

Text-FIG. I5. Avena sativa, L. From much older seedling, which showed three leaves. Grain with median region of axis attached. The mesocotyl is surrounded by the husks of the grain. Nodal roots show as rudiments. $\times 3$.

and the scutellum is functionless. The young plant will depend in the future on its green leaves only for supplies of food, and these leaves are developing a root-system of their own. The older root-system perishes by degrees ; the cauline roots first, and then the primary root. In time all the lower members of the seedling-scutellum, mesocotyl, primary and insertion roots-having served their purpose, will disappear and leave the mature plant rooted at the first node.

We are concerned here, however, with the structure of the seedling in its early stages, before the epicotyledonary members have become functional. 


\section{I72 Sargant and Arber. - The Comparative Morphology of}

At this period-that is, up to the time when the foliage leaves burst through the coleoptile-the seedling may be considered as an expanded embryo. Its ascending axis is the mesocotyl, crowned by coleoptile and stem-bud. The scutellum is inserted at the base of the mesocotyl, just where it passes into the primary root or descending axis. From the zone of this insertion spring several cauline roots (Text-figs. 9, IO, II).

In a seedling of this age the plumule must depend on the primary rootsystem until it has developed its own roots. The first two leaves draw their water at first from the lower roots through the mesocotyl into which their traces are prolonged. Similarly, they draw their proteid material from the endosperm through the scutellum. At this period there is a great demand for proteids in the neighbourhood of the first node, for new members are constantly being formed there-the roots of the nodal system, rudimentary leaves at the growing point, and buds in the axils of the leaves. Hence no doubt the necessity for connecting the plumular traces directly with the vascular system of the scutellum. Later on the green leaves will furnish a supply of proteids to this region by their own activity.

The scutellum contains a single massive bundle, which follows the dorsal ridge and is equidistant from either surface. It is circular or oval in transverse section near the base, but towards the apex it spreads out into a crescent which repeats the convex outline of the dorsal epithelium. Occasional short branchlets are given off from the lateral wings, but they are not numerous, and they terminate at some distance from the epithelium. The carrying system is very well developed in this region of the scutellum, where the epithelium fringes both surfaces. On the whole, however, the outlying tissue is reached rather by lateral extension of the main bundle than by branching.

The lignified elements of the extended bundle are scattered. They are most numerous in the median zone, where they often appear as a band of lignified tissue with protoxylem elements at either extremity. The bulk of the phloem fringes this band on the dorsal or convex edge. But groups of elements with thick contents, which probably represent phloem too, are found among scattered lignified elements on the ventral side of the xylem band. Lower down, where the bundle is oval or circular in outline, the xylem elements are collected on the ventral side of it, the phloem on the dorsal.

At the apparent insertion of the scutellum, its bundle turns sharply upwards within the axis, but does not enter the stele (Text-fig. 6). Transverse sections through the mesocotyl show the slender stele in the centre, and on one side of it a massive inverted bundle--the scutellum trace (Text-fig. I6, p. I74, and Pl. IX, Fig. 5). They run upwards side by side to the real insertion of the scutelium at the first node.

Throughout its upward course in the axis, the scutellum trace is clearly 
double (P1. IX, Fig. 5). In seedlings of the age drawn in Text-fig. I2, p. I7 I, the two groups of soft bast can be distinguished very clearly by their contents. At this period the vessels of the phloem are crammed with proteids, which they are conveying from the endosperm to the first node. The two groups of soft bast are injected as it were with thick contents, which take up most stains readily, and then appear in transverse sections as two highly coloured patches within the trace (P1. IX, Fig. I). They are separated from each other by a partial sheath of bast fibres, and by the xylem group. In serial sections through the mesocotyl of older seedlings the bast vessels of the scutellum trace are nearly empty. The two phloem groups, however, are still defined by the greater differentiation of the bast fibres which partially sheathe them. The xylem also is better lignified, and shows two metaxylem groups with a common cluster of protoxylem elements between them (PI. IX, Fig. 2).

In short, the structure of the scutellum trace is undoubtedly double as it approaches the first node. Here it will meet traces from the coleoptile and plumule as they enter the stele of the mesocotyl. From this region also the plumular or nodal roots will be given off later, and their rudiments are present even in the youngest seedlings we have cut.

The vascular complex at the first node is best attacked from above. The stele of the mesocotyl is built up of traces from the plumule and coleoptile; these must therefore be followed downwards until they are joined by the scutellum trace. Considerable disturbance is caused at and near the node, by the insertion of cauline roots.

A transverse section taken just above the first node shows twelve traces arranged as in Diagram I, Text-fig. 16, p. I74. Seven of the ten plumular traces $\left(M ; L_{1}, L_{2}, L_{3} ; L_{1}^{\prime}, L_{2}^{\prime}, L^{\prime}{ }_{3}\right)$ belong to the first leaf; three $\left(m, l_{2}\right.$, $\left.l_{2}^{\prime}\right)$ to the second. They are arranged in two concentric circles. $M$ and $m$ are midrib traces, and they face each other on the same diameter. The coleoptile bundles $P$ and $P^{\prime}$ are bisected by a line perpendicular to this diameter.

The midrib trace $M$ from the first leaf passes through the node unchanged. No other trace is inserted on it, nor does it contribute vascular elements to any cauline root. The midrib trace $m$ from the second leaf behaves differently. It divides into two branches, one of which unites with the lateral traces $l_{2}$ and $L_{1}$, the other with $l_{2}^{\prime}$ and $L_{1}^{\prime}$ (Diagram II, Textfig. I6, p. I74). This occurs at the very top of the node, just as the coleoptile traces $P$ and $P^{\prime}$ run into the stele. The gap left by $m$ is clear in several consecutive sections below this level.

The union of $L_{1}$ with half of the three principal traces from the second leaf gives rise to a lateral plate of internal xylem and external phloem. A similar plate is formed on the other side of $M$ by the union of $L^{\prime}{ }_{1}$ with the other second-leaf traces. The steles of the two first-formed nodal roots 


\section{I74 Sargant and Arber.-The Comparative Morphology of}

will be inserted on these two plates respectively. But in such seedlings as those drawn in Text-figs. 9 (p. I 70) and I 2 (p. I7 I), where the stem-bud is still enclosed in the coleoptile, these roots are mere rudiments in which the vascular tissue is not differentiated, and the lateral plates are so far embryonic too, that xylem cannot be clearly distinguished from phloem. Their presence, however, affects the mesocotylar stele even at this age, and

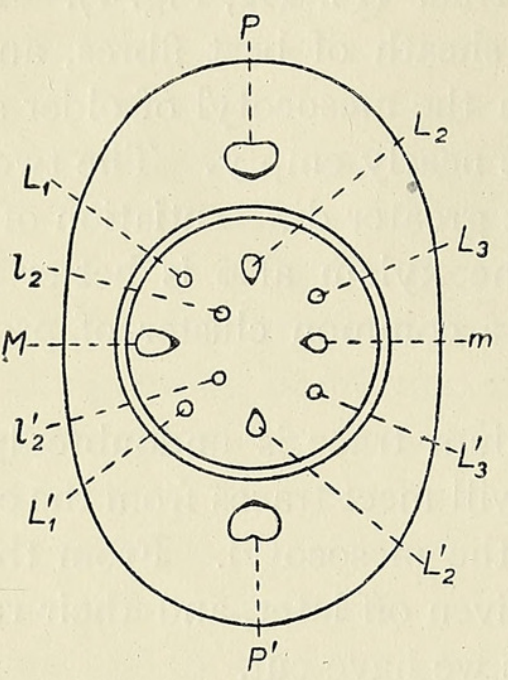

I.

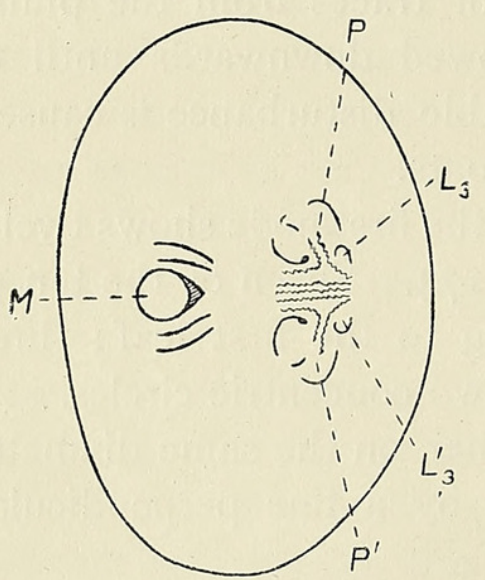

III.

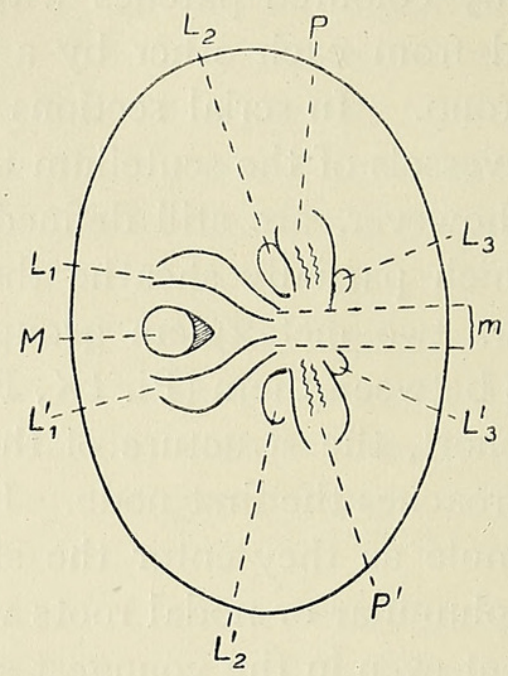

II.

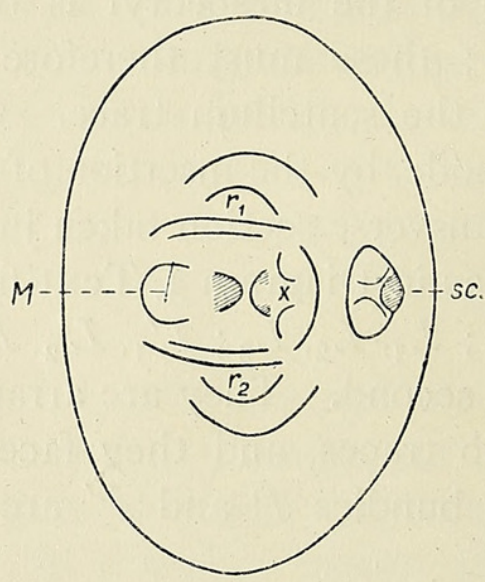

IV.

Text-Fig. 16. Avena sativa, L. Structure of axis in seedling about age of that drawn in Textfig. I2, p. I 7I. Shown in a series of diagrams representing transverse sections from above downwards. I. Plumule surrounded by coleoptile. II. Top of first node. III. Base of first node. IV. Mesocotyl.

they are later of great functional importance. The anatomy of the young node is obscure until the structure of these plates is thoroughly understood, and it is therefore worth while to describe them in an older seedling where they are better differentiated.

In the oldest seedling examined, the third foliage leaf is just unfolding, and the second internode of the plumule is $2 \mathrm{~mm}$. long. It is enclosed within the sheath of the first leaf, which is itself surrounded by the base of 
the coleoptile. The internode contains a circle of twelve traces (Diagram I, Text-fig. I 7$)$ : seven derived from the second leaf $\left(m ; l_{1}, l_{2}, l_{3} ; l_{1}^{\prime}, l_{2}^{\prime}, l_{3}^{\prime}\right)$, and five from the third. The midrib of the third leaf is marked $\mu$ in Diagram I. At the second node seven traces from the first leaf enter the axis, and form an outer circle (Diagram III, Text-fig. I7).

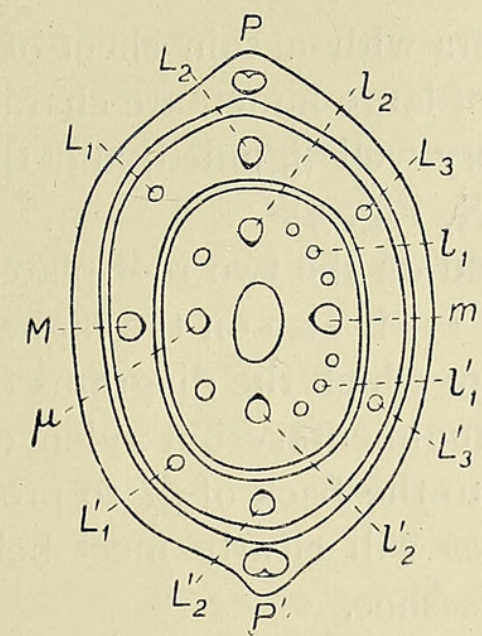

I.

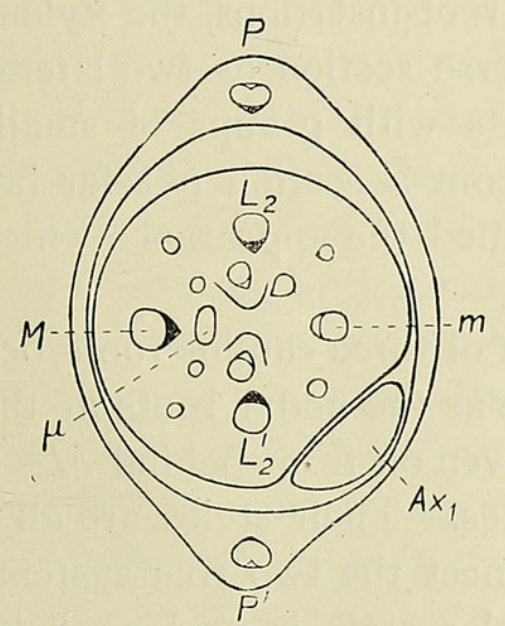

III.

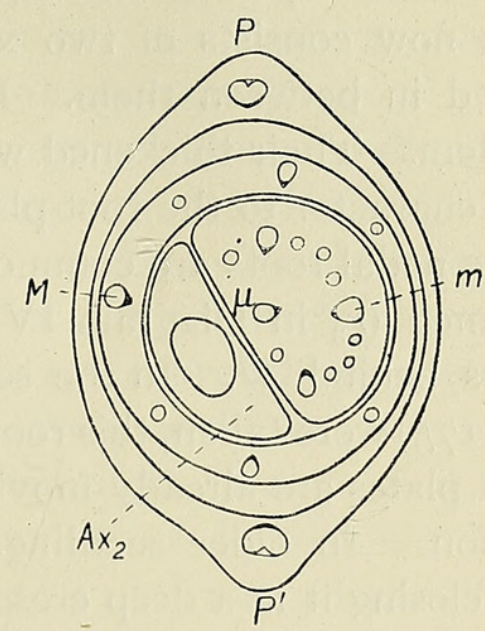

II.

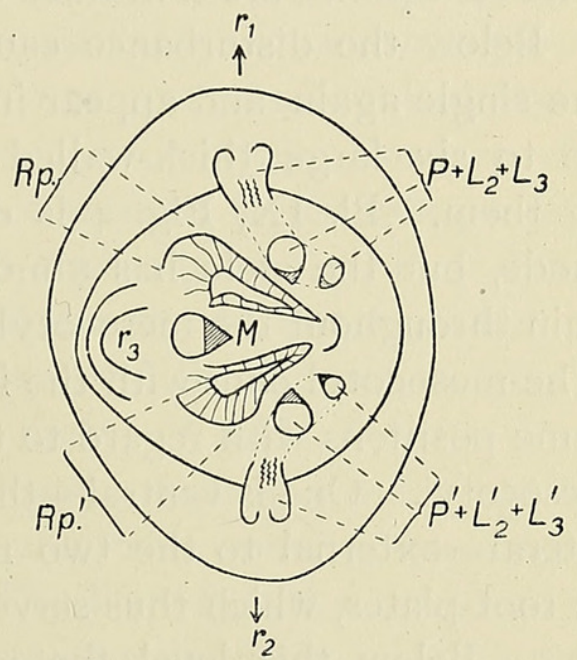

IV.

Text-FIG. I7. Avena sativa, L. Diagrams from much older seedling, showing base of plumule. I. Second internode. Axis sheathed by base of first leaf as well as coleoptile. II. Approaching second node. $A x_{2}$ is bud in axil of first leaf. III. Base of first internode. Axis sheathed by coleoptile only. $A x_{1}$, bud in axil of coleoptile. IV. First node. $R p$., $R p^{\prime}$, , root-plates.

The first internode is undeveloped: there is no interval between the second and the first node. The upper limits of the two nodes are, however, marked by the insertion of two lateral buds, $A x_{2}$ in the axil of the first leaf (Diagram II), and $A x_{1}$ in that of the coleoptile (Diagram III). Both buds are embryonic, and do not yet receive any vascular elements from the stele. 


\section{Sargant and Arber. - The Comparative Morphology of}

Thus nineteen plumular traces enter the second node in a seedling of this age, as against ten in the younger one. Without following the course of the nine new bundles in detail, we may briefly say that they appear to fuse with one or other of the root-insertion plates. The midrib trace $\mu$ divides itself between them. The total effect is to add a massive layer of external xylem to both plates.

Each now consists of two xylem layers with a thin sheet of phloem sandwiched in between them. Elements of large lumen are characteristic of the xylem. Their thickened walls are very well lignified, and they give a distinct character to the root-plates (P1. IX, Fig. 5).

Three nodal roots are commonly inserted on the two root-plates. The latest formed ( $r_{3}$ in Diagram IV, Text-fig. I 7 ) is also on the highest level. It appears behind $M$. In the seedling from which the diagrams of Textfig. I 7 (p. I 75) were taken, this root was still rudimentary, but xylem elements from both plates are already moving round to the back of $M$ to provide for its insertion. In older seedlings the plates will clearly meet behind $M$, almost enclosing it in a deep crescent or horseshoe.

Two older roots, $r_{1}$ and $r_{2}$, are inserted lower down. One is attached to either plate, and their position is indicated by arrows in Diagram IV.

The root-plates are continued down the mesocotyl in a rather simplified form. Below the disturbance caused by root-insertions, the xylem layers become single again, and appear in transverse section as two lateral chains of five to six large thick-walled elements with groups of smaller ones among them. Pl. IX, Fig. 4 is drawn from a section not far below the first node, but the stele has almost assumed the appearance which it will maintain throughout the mesocotyl.

The mesocotyl ends with the insertion of three cauline roots, occupying the same positions with regard to the stele as the nodal roots at the top of the mesocotyl. One is ventral - that is, given off from behind $M$-and two are lateral-external to the two root-plates. Their steles are all inserted on the root-plates, which thus serve to connect the two root-systems of the seedling. Below this level the mesocotylar stele is prolonged into that of the primary root, but the method of transition from stem to root structure is almost completely masked by the disturbance caused by rootinsertions. The root-plates end with the mesocotyl. Some of their larger elements, particularly those on the scutellum or dorsal side of the stele, can be followed into the stele of the primary root.

Before leaving the subject of the root-plates, we may observe that they are built up at the node from the main traces of the second and third leaves, which are thus put into connexion with the nodal roots. But only two minor traces from the first leaf enter the root-plates; the main lateral traces, as well as the midrib, are independent of them, and connect the first leaf with the primary root and the rest of the lower root-system. 
Returning to the first node of the younger seedling, the midrib trace $m$ from the second leaf has only just divided itself between the embryonic root-plates when the coleoptile traces $P$ and $P^{\prime}$ run in from either side. As they do so, traces $L_{2}$ and $L_{3}$ are inserted on $P$, and $L_{2}^{\prime}, L_{3}^{\prime}$ on $P^{\prime}$, in a way which must be described in detail.

The double structure of $P$ and $P^{\prime}$ is clearly indicated, particularly in the neighbourhood of the node. Each has two distinct groups of soft bast (Pl. IX, Fig. I). In young seedlings the common group of protoxylem only is lignified, but in older ones the metaxylem forms two distinct groups (Pl. IX, Fig. 2), and the protoxylem is often torn away, leaving a gap.

As the coleoptile traces enter the stele, the two phloem groups of each are separated by the xylem. One phloem group from $P$ unites with that of $L_{2}$, the other with that of $L_{3}$. Similarly the two phloern groups of $P^{\prime}$ unite with those of $L_{2}^{\prime}$ and $L^{\prime}{ }_{3}$ respectively (Diagram II, Text-fig. I6, p. I74).

The xylem of $P$ divides. One branch turns inwards, that is towards the centre of the stele, and carries the xylem of $L_{2}$ with it: the otherturning outwards-carries off the xylem of $L_{3}$. The xylem of $P^{\prime}$ behaves similarly, the inward branch sweeping off with the xylem of $L^{\prime}{ }_{2}$, and the outward one with that of $L_{3}^{\prime}$ (Pl. IX, Fig. 3).

In the end the ingoing xylem branches unite to form the xylem group $x$., which thereafter occupies the gap opposite $M$, and becomes part of the mesocotylar stele. The corresponding phloem groups accompany the xylem, remaining external to it (Diagram IV, Text-fig. I 6, p. I 74). For some distance below the node the two phloem groups are seen in favourable preparations to be distinct, but before the transitional region is reached they commonly form a single group. Both xylem and phloem can be distinguished in good preparations from other tissues of the mesocotyl throughout its length.

The outgoing branches of xylem from $P$ and $P^{\prime}$ leave the stele altogether, and are followed by the phloem groups $\left(\frac{1}{2} P+L_{3}\right)$ and $\left(\frac{1}{2} P^{\prime}+\right.$ $L_{3}^{\prime}$ ) respectively. United they form a double trace running downwards side by side with the central stele (Diagram IV, Text-fig. I6, p. I74, and P1. IX, Figs. 4 and 5). The two phloem groups remain distinct within the trace until it approaches the scutellum. There are two groups of metaxylem, divided more or less completely from each other. The common group of protoxylem is directed towards the periphery of the mesocotyl (Pl. IX, Figs. 4 and 5).

The trace thus formed loses its double character as it reaches the insertion level of the scutellum, and turns sharply upwards to enter it (Text-fig. 2, p. I63).

This account of the course of the bundles in the first node must be understood to give the ground-plan of its structure as observed in seedlings of different ages. In such a tangle of traces the junctions are not accomplished with mathematical precision. For example, metaxylem elements 
may enter the lateral root-plates from the plumular traces $L_{2}$ and $L_{2}^{\prime}$, though the bulk of their xylem-including all the protoxylem-unites with the ingoing branches of $P$ and $P^{\prime}$ respectively. A more constant and important modification of the ground-plan is the formation of a massive xylem-bridge between the ingoing and outgoing branches of $P$ and $P^{\prime}$ (Diagram III, Text-fig. 16, and Pl. IX, Fig. 3). This bridge is very conspicuous in all the seedlings, and it must be slightly arched, for in serial sections followed downwards xylem elements commonly appear in the gap opposite $M$ at a level higher than that in which the coleoptile traces begin to divide. As no formation of this kind is found in Zizania, where the division of the coleoptile traces between the stele and the scutellum trace is particularly clear, we are inclined to think that the formation of a xylem arch is not a primitive character. We have already (p. I67) suggested a possible function for it in Avena-to supply the scutellum with water from the lower roots by a shorter path than would otherwise be available. In the aquatic Zizania this adaptation is unnecessary.

The stele of the mesocotyl is now complete (Pl. IX, Fig. 5). It is built up of the midrib trace $M$ from the first leaf, of two plates $(r p ., r p$.$) , on$ which the nodal roots have been inserted, and of trace $x$, derived from the ingoing branches of the coleoptile traces. The root-plates when clear of the nodal roots lose their external xylem, but are always distinguished by a chain of large vessels.

As soon as the nodal roots $(r ., r$ in Pl. IX, Fig: 4$)$ have differentiated their steles, they are in direct connexion through the root-plates with the main traces of the second and third leaves-already fully formed at that epoch. The first leaf is connected with the root-plates through a pair of its smaller lateral traces only $\left(L_{1}\right.$ and $\left.L_{1}^{\prime}\right)$, and perhaps by a few stray xylem elements from other traces as mentioned above. The main traces of the first leaf, together with a portion of each coleoptile trace, pass down the stele of the mesocotyl into the primary root. We have already shown how the xylem arch puts the scutellum also into direct communication with the primary root and the lower cauline roots. Thus the scutellum, coleoptile, and first leaf are dependent throughout their lives on the lower root-system, consisting of the primary root and three insertion roots (Text-fig. I 2, p. I7I). The second and third leaves are also connected with this lower root-system through the root-plates, for the latter bear the insertion roots below as well as the nodal roots above. Indeed, since the nodal roots do not become functional until the second and third leaves are unfolded, these leaves too draw water in their youth from the insertion roots.

Little remains to be said concerning the lower root-system. Its relation to the mesocotyl has already been described. The primary root is heptarch or octarch ; the insertion roots hexarch or heptarch. 
Avena itself is, as we have already said, the most complete specimen of its type. Zizania aquatica, L., the Manchurian Water-Rice, deserves special attention on account of the simple structure of its first node, in which we think it approaches the primitive type. We have also described two other Grasses of the Avena type for comparison: Lolium italicum, A. Br., and Leersia oryzoides, Sw.

Zizania aquatica, L. The fruits are long and slender. They will germinate only while quite fresh, and when planted under water. The vascular ground-plan of the seedling is like that of Avena. The numerous differences in detail can generally be referred to the adaptation of Zizania to an aquatic habit.

The endosperm of Zizania is scanty compared with that of Avena sativa, in which-as in all cultivated cereals-it is unnaturally bulky. The scutellum is like a linear leaf in outline. It is separated from the coleoptile by a very long and slender mesocotyl (Text-fig. I8, and Pl. IX, Fig. 6). As in Avena, the scutellum trace runs upwards to the first node side by side with the mesocotylar stele, but is perfectly distinct from it throughout.

The stem-bud is wrapped in a linear leaf-like coleoptile; its margins united into a short tubular sheath at the base (P1. IX, Fig. 6). There is no stiff pointed cap such as that which protects the early leaves of Avena and other terrestrial Grasses. But two bundles run nearly the whole length of the coleoptile, and, seen in transverse section, they occupy the same relative positions as in Avena, and recall the two-nerved 'axillary stipules' found in some species of Potamogeton. ${ }^{1}$

We consider the mesocotyl of Zizania, like

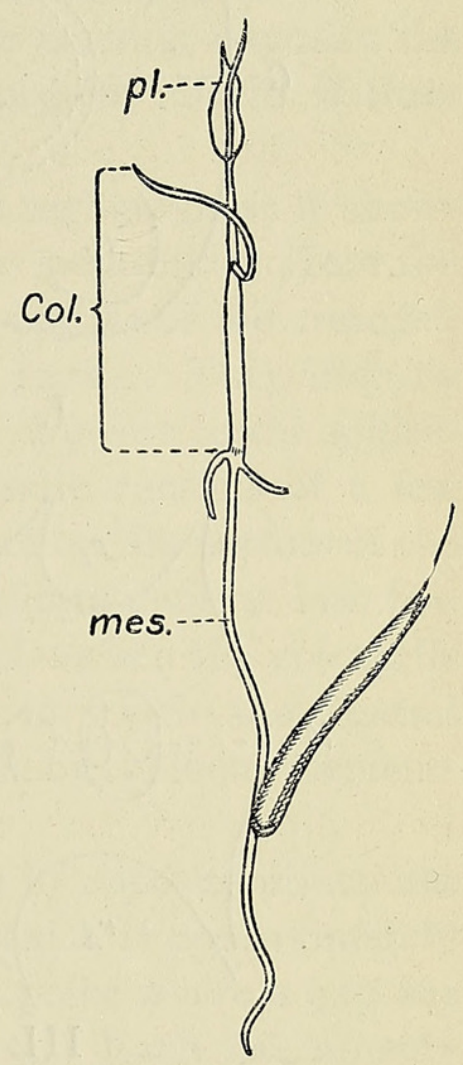

TEXT-FIG. I8. Zizania aquatica, L. Seedling, lifesize.

that of Avena, to represent a fusion of the cotyledonary stalk with the hypocotyl. If we mentally reconstruct a form in which they were separate

1 Cf. the description given by E. Cosson (Note sur la stipule et la préfeuille dans le genre Potamogeton, et quelques considérations sur ces organes dans les autres monocutylées. Bull. de la Soc. Bot. de France, t. vii, p. 7I5, 1860): 'La stipule, dans la plupart des Potamogeton, est constituée par un organe indivis, membraneux, libre, de forme et de longueur variables, inséré à l'aisselle de la feuille, à face supérieure regardant du même côté que la face supérieure de la feuille correspondante, et entourant d'une manière plus ou moins complète la base de l'entre-nœud de la tige... . Cette stipule axillaire présente, surtout dans les espèces à feuilles pétiolées, deux nervures presque parallèles, saillantes, généralement en forme de carène, placées exactement à la limite du point de contact du pétiole. Assez souvent cette stipule n'est binerviée et bicarérée que dans sa partię inférieure, et quelquefois même elle n'est nullement binerviée.' 
members, we find them meeting each other and the coleoptile at the first node. Then the coleoptile of such a form would clearly bear the same relationship to its cotyledon as the 'axillary stipule ' of Potamogeton to its own leaf.

The epiblast is membranous and very well developed (Pl. IX, Fig. 6). The primary root is less vigorous than that of Avena, and no cauline roots

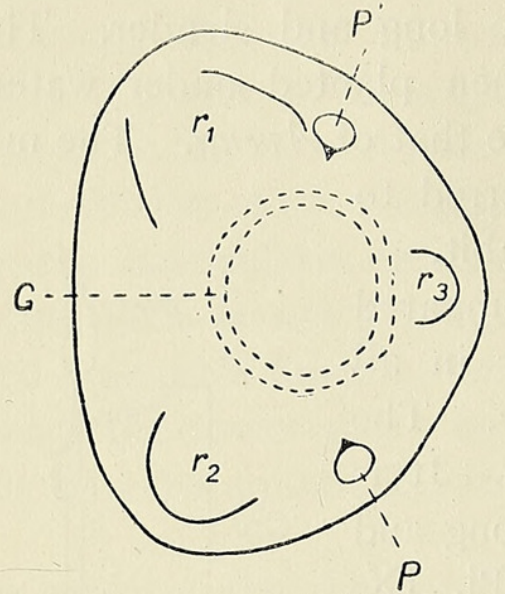

I.

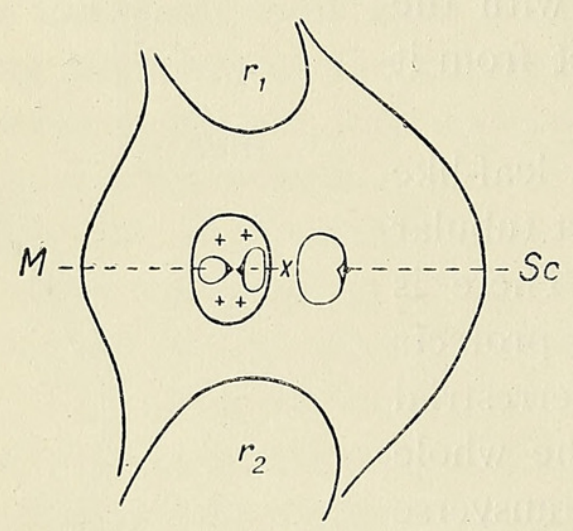

III.

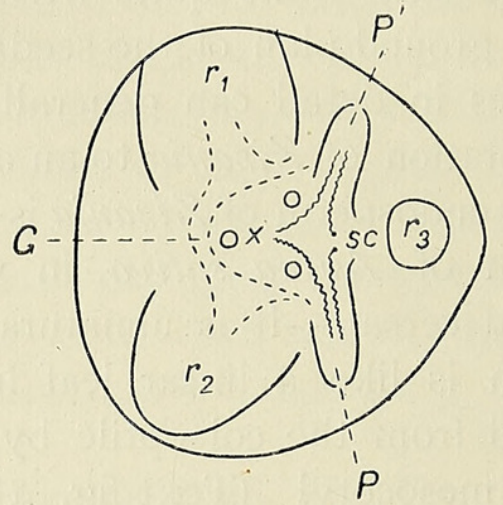

II.

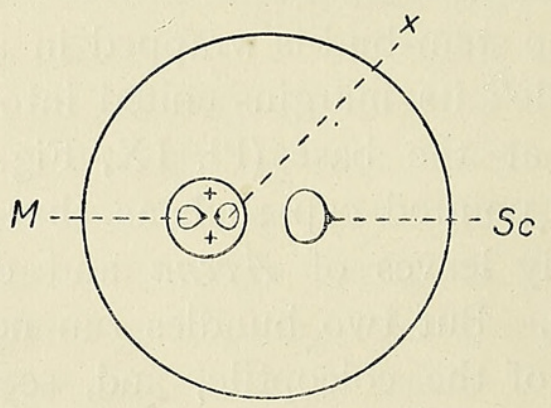

IV.

TeXT-FIG. I9. Zizania aquatica, L. Structure of axis in seedling shown in a series of diagrams representing transverse sections from above downward. I. The coleoptile bundles $P$ and $P^{\prime}$ are shown in the cortex. $G$ = root-girdle; $r_{1}, r_{2}, r_{3}$, adventitious roots. II. The coleoptile bundles are dividing and fusing to form the scutellum bundle $s c$. and the bundle $x$, which passes down the mesocotyl in the stele. III and IV. Mesocotylar stele completely formed. $M=$ midrib of first leaf.

are formed from the insertion zone just above it. They are produced, however, at all the early nodes, which are crowded together at the base of the plumule.

The scutellum contains a single slender bundle, running down the dorsal ridge to the zone of insertion. Here, as in Avena, the scutellum bundle enters the axis and at once turns sharply upwards, travelling to the first node side by side with the stele. Throughout its course in scutellum 
and axis the bundle is enclosed in an endodermis. The single group of xylem is composed of a few tracheides, often hardly lignified at all. They are commonly annular, but occasionally spiral. In the scutellum the xylem group is turned towards the ventral surface; in the axis it is inverted-that is, directed away from the centre (Text-fig. I9, III and IV). The phloem is massive throughout, but appears single except just below the node, where the trace is prepared to branch to right and left as it enters the stele.

The structure of the first node is obscured by the formation of a vascular girdle (P1. X, Fig. 9), on which the cauline roots are inserted ( $G$ in Diagram I, Text-fig. I9). The plumular traces lose their identity in this girdle, but some of them reappear just as the coleoptile traces $P$ and $P^{\prime}$ are entering the stele (Diagram II, Text-fig. I9). One trace is opposite the gap which opens to receive $P$ and $P^{\prime}$, and must represent midrib $M$ from the first leaf.

Above the cylindrical base of the coleoptile is a region where it shows in transverse section as a crescent on one side of the stem-bud. Here the two bundles are symmetrically placed as regards the outline of the crescent, but not at either end of a diameter of the axis as in Avena. They both lie on the same side of this diameter ; that side which is opposite to the midrib of the first leaf. At this level the xylem of each bundle consists of a few narrow elements but little lignified. In transverse section the outline of the phloem is almost kidney-shaped, but there is no definite division into two groups. This structure is continued downwards, and-when the coleoptile traces enter the axis-preparations can be found in which the central xylem strand is seen to be bordered on either side by phloem elements (Diagram II, Text-fig. I9).

The coleoptile traces $P$ and $P^{\prime}$ approach the stele in opposite directions. They commonly travel along the same straight line, which is approximately tangential to the circumference of the stele at the point where a gap has appeared in the root-girdle (Diagram II, Text-fig. I9). Each has already split into two branches, one running outwards, and the other keeping nearly to the original line of approach (Pl. IX, Figs. 7 and 8). In the three younger seedlings examined, the inner branch of $P$ on its way to the gap is seen to unite with the lateral plumular trace adjacent to it, and the inner branch of $P^{\prime}$ carries off the corresponding trace on the other side of the stele. These junctions are masked in the two older seedlings by the insertion of numerous cauline roots. The inner branches unite to form trace $x$, which fills up the gap in the stele. The outward branches form the inverted scutellum trace $s c$. (Diagrams II and III, Text-fig. I9; Pl. IX, Figs. 7 and 8 ).

The reader will naturally conclude from the above description that the node of Zizania resembles that of Avena, except that its structure is less clear, and that this lack of clearness is due partly to the reduction of 
vascular tissue consequent on the aquatic habit, and partly to the complications introduced by the number of roots found at the first node, and by the formation of a vascular girdle on which they are inserted. On the whole this is true, but in one important character the nodal structure is clearer in Zizania than in Avena, namely, in the insertion of the scutellum trace. It divides into two branches before reaching the stele. Each branch joins a coleoptile trace. No xylem arch is formed as in Avena, and there is therefore no direct connexion between the scutellum trace and the stele. One or two xylem elements may perhaps be found by diligent search to go from one to the other, but the rule is that the scutellum trace divides itself completely between the coleoptile bundles $P$ and $P^{\prime}$. The other elements of $P$ and $P^{\prime}$ are prolonged downwards into the stele as the compound trace $x$.

When the mesocotylar stele is fairly formed, it contains the trace $x$ derived from coleoptile traces, and a trace opposite to it which probably represents $M$, the midrib of the first leaf (Diagrams III and IV, TextFig. I9, p. I 80). There are also one or two xylem groups on either side which probably correspond to the lateral xylem plates in Avena. These lateral groups become insignificant as we descend the mesocotyl, and are very soon reduced to two-rarely three or four-lateral vessels of large lumen, placed symmetrically with regard to $M$ and $x$ near the periphery of the stele.

The mesocotylar stele is very little lignified, except just below the first node, and again in the region of transition to a root-structure. Even at this lower level, very accurate staining is required to bring out the xylem elements at all in contrast to surrounding tissues. In two seedlings only among the five examined is it possible to make out the symmetry of the root-steles. In both cases that of the primary root is pentarch, with an inclination to become tetrarch by fusion of two xylem rays. The cauline roots are 6 to Io arch. The method of transition is obscure in all the seedlings.

Thus the vascular structure of Zizania may be described as that of a slender Avena, with imperfect lignification and no cauline roots springing from the insertion level of the scutellum. The imperfect lignification is, no doubt, connected with its aquatic habit. Whether the absence of insertion roots is a consequence of this habit too can hardly be determined without observations on the growth of $Z i z a n i a$ under natural conditions.

The most important anatomical character from our point of view is the very clear way in which the scutellum trace is built up from portions of both coleoptile traces, and the absence of direct connexion between it and the stele of the mesocotyl. If the object of the xylem arch in Avena be to put the scutellum into direct communication with the water-supply from the lower root-system (ante, p. I67), then the absence of this character is readily 
understood. For as the seed of Zizania will only germinate under water, the scutellum does not require special adaptations for rapid water conduction.

Leersia oryzoides, Sw. The three seedlings which we have examined are all about the same age. The first and second leaves are free from the coleoptile, and the second is unrolling as it leaves the shelter of the first leaf. In this species the first leaf is reduced to a membranous sheath, but the second is a fully-formed foliage leaf.

The species is aquatic, and the seedling resembles that of Zizania in general habit. The chief points of difference, excluding the smaller size, are the reduction of the first leaf to a sheathing organ, and the formation of cauline roots from the insertion zone as well as at the first node. It will be seen that the anatomical differences between Leersia and Zizania are correlated to these external features.

The coleoptile is open and unstiffened ; the epiblast leaf-like, and the mesocotyl slender. The primary root is developed much earlier than any cauline root, and is freely branched.

The bundle of the scutellum is slender. It enters the axis at the apparent insertion, and turns sharply upwards without joining the stele, as in all seedlings of this type.

Just above the first node six lignified plumular traces form a single circle in the axis; outside these are the traces from the coleoptile. The three traces from the second leaf are much larger than those from the first, probably because the second is a foliage leaf while the first acts only as a sheath. A xylem girdle is formed here, as in Zizania, in which the identity of all the plumular traces is lost. A gap appears in the girdle just before the coleoptile traces have reached the stele. They run in from either side along a tangent touching the stele at this gap.

As the traces approach the stele, the xylem of each divides; one branch entering the stele, the other remaining outside it. The inward branches unite to form a xylem group within the stele, which does not long retain its identity. The outward branches meet outside. The phloem of each coleoptile trace is already double; one group accompanies the inward, the other the outward branch. Thus a double phloem group is formed within and without the stele, but both become single almost immediately. The complete bundle outside the stele is of course the inverted scutellum trace. As in Zizania it is not directly connected with the stele by xylem elements.

The stele of the mesocotyl just below the first node is slender but very well differentiated. The cells of the endodermis are thickened, especially on the inner and radial walls. The pericycle consists of a single row of thickened elements, some of them lignified. The later xylem plates of 
Avena are represented by one or two large pitted vessels on either side of the stele. Between them is a group of small well-lignified xylem elements common to the two phloem groups. This compound structure, two phloem groups opposite to one another and divided by a common xylem group, represents the two traces $M$ and $x$ in Avena.

Lower down in the mesocotyl the stele loses in differentiation. The endodermis and pericycle are little thickened, and not lignified at all. The central xylem group is only partially lignified. The large lateral vessels are comparatively well differentiated and completely lignified throughout their course, doubtless because-as in Avena-they connect the cauline roots of the insertion region with those of the node.

The process of transition to a root-structure cannot be followed in any of our preparations, nor is the symmetry of the primary root to be made out.

Lolium italicum, A. Br. In the two seedlings examined, the first leaf has lately emerged from the coleoptile, but one of them is rather further developed than the other. The type is that of Avena, but the seedlings are smaller in every dimension; the grain shorter in proportion to its breadth, and the axis more slender. A small epiblast is inserted opposite the scutellum, and at about the same level. Cauline roots are also formed there, and they begin to show externally about the time when the first leaf appears, while at the same epoch the nodal roots are still mere rudiments within the cortex.

The bundle of the scutellum is single. Its xylem is massive, and gives off a few lateral branches near the apex. Below this, the xylem forms a ventral crescent embracing the phloem. At the insertion of the scutellum its trace enters the axis, and at once turns sharply upwards, but it does not join the stele below the first node. A transverse section through any part of the mesocotyl shows the scutellum trace side by side with the main stele, and inverted - that is to say, the xylem of the scutellum trace is directed away from the centre of the stele.

At the first node three plumular traces only can be followed with certainty into the stele of the mesocotyl. They all belong to the first leaf, and represent $M, L_{2}$, and $L_{2}^{\prime}$ in Avena. Five more are present, though unlignified, above the entrance of the coleoptile traces; they represent $L_{1}$. and $L_{1}^{\prime}$ from the first leaf, and $m, l_{2}$, and $l_{2}^{\prime}$ from the second. They behave exactly like the corresponding traces in Avena. $m$ divides into two branches which travel to opposite sides of $M$; one uniting with $l_{2}$ and $L_{1}$ on the way, the other with $l_{2}^{\prime}$ and $L_{1}^{\prime}$. But all these traces disappear before those from the coleoptile run into the stele. In older seedlings they would doubtless persist, and then their connexion with the lateral xylem plates of the mesocotyl would appear. 
Two other plumular strands are perceived in the stele for the first time as the coleoptile traces enter it. They represent $L_{3}$ and $L^{\prime}{ }_{3}$. Trace $P$ makes its way between $L_{2}$ and $L_{3}$, and trace $P^{\prime}$ between $L_{2}^{\prime}$ and $L^{\prime}{ }_{3}$, just as in Avena. Even the xylem arch is present, though far less massive.

The large xylem vessels of the lateral plates make their appearance to right and left of $M$ during the formation of the mesocotylar stele. At first they are numerous and poorly lignified. Lower down, where the stele has assumed its final form, each lateral plate consists of three or four large lignified elements.

The structure of the first node in Lolium italicum is very clear because the nodal roots are mere rudiments without vascular tissue at an age when the stele of the mesocotyl is fully defined, and some of the plumular traces are lignified. The lower cauline root-system is also tardy in development, and the transition from mesocotyl to primary root can therefore be followed better in the stele of Lolium than in that of Avena or Zizania. The details, however, are not very clear. In one seedling--the younger of the two-the xylem breaks up into four crescents, convex towards the centre. Protoxylem elements are found at their extremities, and the result is a pentarch root-stele. In the older seedling there are at first three xylem groups, not definitely crescent-shaped. Here, too, the stele of the primary root becomes pentarch.

\section{B. Zea type.}

Sorghum vulgare, Pers. The seedling structure of this species is clearer than that of $Z e a$, because the formation of cauline roots is delayed until the appearance of the second leaf, both at the first or plumular node, and at the insertion level. We have therefore chosen this species for detailed description, and it will represent the type named from the betterknown genus $Z e a$.

The seedling drawn in Text-fig. $20 \mathrm{~A}, \mathrm{p} .186$, has just reached the age when the first leaf is about to push through the slit near the tip of the coleoptile. This still sheathes the stem-bud, and is borne on a fairly long mesocotyl. The primary root is long and unbranched. There are as yet no cauline roots.

We have examined the vascular skeleton of five seedlings, including that mentioned above. Two of the others are younger, and two older. The oldest shows two foliage leaves, but no cauline roots are visible externally. The vascular structure in all five seedlings is singularly uniform.

The scutellum has a single bundle with massive phloem, but comparatively little lignified xylem. In the upper part, branches are given off freely towards the dorsal surface of the scutellum, which is covered by an active epithelium. In this region the xylem elements are scattered about the periphery of the main bundle, but even here they are far more 
frequent on the ventral side, and lower down - where branches are fewerthey form a ventral crescent. Still lower, no branches are given off from the main bundle, and the xylem elements are collected into a compact ventral group.

The scutellum trace does not run up the mesocotyl side by side with the stele as in Avena or Zizania, but enters it at once. Its elements, however, can be followed within the stele above its insertion. Below that level

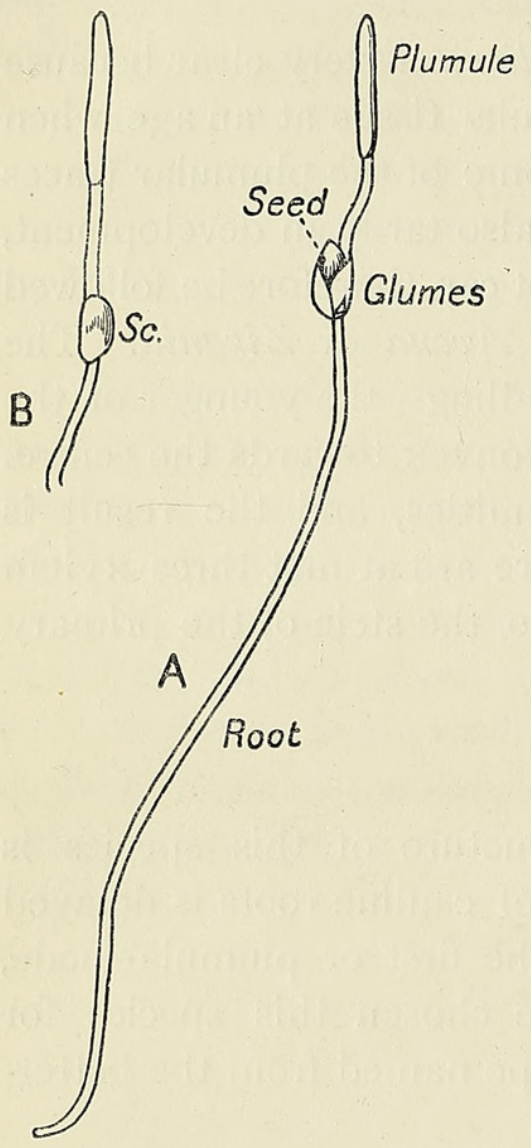

TEXT-Fig. 20. Sorghum vulgare, Pers. A. Seedling, life-size. B. Upper part of same seedling with grain removed to show scutellum. there is a complex formation of xylem and phloem resembling that found in Avena in the region from which the lower cauline roots are given off. The identity of the mesocotylar traces is lost in this plexus, which we have called the insertion plate. In the oldest seedling which we have cut, no cauline roots are formed at this level, but they may be present in seedlings older still. Below the insertion plate, the axis is abruptly transformed into the primary root. Above it, the mesocotylar stele soon acquires its characteristic structure, and preserves it almost unchanged up to the plumular node. For convenience we must first describe the complete stele above the insertion, and return later to the entrance of the scutellum trace, though this reverses the natural sequence of events.

The whole stele is surrounded by a very well-marked endodermis. The internal wall of each cell in this layer is thickened and lignified; but the radial walls are little thickened, though more or less completely lignified (Pl. X, Fig. IO). Within the endodermis are at least two layers of thick-walled but unlignified cells.

The vascular tissue of the stele consists of three phloem centres, each defined internally by a xylem crescent, and externally by the thick-walled peripheral tissues. One of these phloem centres $(M)$ differs from the other two $\left(P, P^{\prime}\right)$ in containing a single group of soft bast. The lignified xylem crescent embracing this phloem group is broken, but clearly indicated. Its protoxylem elements $\left(p x_{3}.\right)$ are distinct, and nearer the centre of the stele than the rest of the crescent. At either extremity are one or two large well-lignified elements, but no trace of protoxylem. The whole structure forms a typical endarch bundle, which we call the median trace to distinguish it from the two lateral traces $P$ and $P^{\prime}$. 
Each of the lateral traces is separated from the median trace by an unthickened element of very large lumen $\left(r x_{0}, r x_{0}\right)$ resembling the large vessels characteristic of monocotyledonous roots. No such element occurs between the lateral traces. They are separated by several layers of ordinary conjunctive tissue. In transverse section this appears as a broad pathway of clear tissue opposite the protoxylem of the median bundle $\left(p x_{3}.\right)$. Within this pathway, near the periphery, is a single lignified element of protoxylem $\left(p x_{1}.\right)$, to which we shall refer later (P1. X, Fig. Io).

The lateral bundles are alike, and each differs from the median bundle chiefly in the fact that its metaxylem crescent embraces two groups of soft bast instead of one. These groups are partially separated from each other by a projection of the peripheral thickened layers. A little group of protoxylem elements $\left(p x_{2}.\right)$, sometimes reduced to a single lignified tracheide, is common to both crescents, and at the extremities of both there are large thick-walled vessels. Such vessels are also found at the ends of the median crescent $M$ (Pl. X, Fig. IO).

The characteristic structure just described is found in the mesocotylar stele of the five seedlings examined. In all of them the scutellum trace is found to be connected with the lateral bundles only. Its scanty xylem is represented in the stele by the isolated element of protoxylem $\left(p x_{1}\right.$.) already described as occurring between the two lateral crescents. It is not always easy to identify this solitary element. When the thickening is annular, it can be picked out only in sections which include a ring or part of one, and the imperfectly lignified rings do not stain deeply. In three of the seedlings examined the whole mesocotyl, from insertion to first node, is included in a single series; and we have satisfied ourselves that the chain of single protoxylem elements can be followed from one end of the series to the other. In the two remaining seedlings, the mesocotyl was divided before microtoming, and accordingly we have two separate series in each: one passing through the insertion of the scutellum, and a second-with different orientation - through the first or plumular node. The scutellum xylem within the mesocotylar stele is represented in both insertion series by a single peripheral tracheide, which is either spiral or annular, and is always isolated in the conjunctive tissue separating the lateral bundles. In both nodal series a similar element is found in the corresponding position, and successive elements can be followed upwards to the plumular node.

The phloem of the scutellum trace is massive. It divides, travelling to right and left of its scanty xylem on entering the stele. Below this level all traces are confounded in the insertion plate, but it is pretty clear that the scutellum trace contributes only a sharp elbow of tissue to this structure. Its real course lies up the stele, as already described for its xylem. The phloem branch on either side is absorbed in a lateral phloem centre of the mesocotyl. During the junction there is no clear division between the two 
groups of soft bast which constitute a centre. The outline of the double group is kidney-shaped, but the phloem elements of the scutellum trace seem to run chiefly into the nearer of the two segments. When these have finally separated, the xylem crescents are also defined, and the mesocotylar stele has assumed its characteristic structure (Pl. X, Fig. Io).

Thus the scutellum trace supplies a single isolated element of protoxylem $\left(p x_{1}.\right)$ to the mesocotylar stele, and also contributes at least half of the phloem to each of the two lateral centres. It does not account for all the lateral phloem, nor for any part of the lateral xylem crescents, and it is quite unconnected with the median bundle.

Below the scutellum insertion the vascular symmetry of the mesocotyl is sharply separated from that of the primary root by the formation of a plate of vascular tissue. In the upper part of this region the phloem of the median bundle can still be traced distinctly. Opposite to it is a single phloem group, representing the elbow of the scutellum trace as it turns on itself. The massive xylem crescents which define these two groups internally embrace and nearly meet round them. The centre of the stele is occupied by a plate of metaxylem uniting the crescents with each other. This formation recalls a similar structure in the transitional region of Fritillaria imperialis, ${ }_{1}^{1}$ L. It persists through a few sections only. Below these the phloem and xylem become inextricably mingled, and finally settle down into normal root-structure.

The primary root is polyarch, with nine or ten xylem rays. Just within the protoxylem of each ray is a single well-lignified element of wide lumen. When cut obliquely it is seen to be a vessel with pitted walls. The ray commonly ends with this vessel, but sometimes a few smaller lignified elements lie next it on the inner side.

In the centre of the root-stele are many xylem elements scattered among unthickened cells which probably represent conjunctive tissue. These xylem elements are of different sizes; their walls more or less thickened, and more or less lignified. They do not form a continuous xylem plate, and are distinct from the rays. Among them are always two elements of very large lumen. Their walls are only slightly thickened; but in the older seedlings examined they are completely lignified, and can be seen-where cut obliquely--to be uniformly pitted. Each is bordered by a single row of small elements, mostly unlignified, and some of them thinwalled. The two large vessels can be followed upwards through the insertion node, and are found to be continuous with those which separate the median bundle of the mesocotyl from the lateral bundles ( $r x$. in Pl. X, Fig. Io).

Returning to the stele of the mesocotyl, its structure is slightly

1 Sargant, E. ('03) : A Theory of the Origin of Monocotyledons, founded on the Structure of their Seedlings. Ann. of Bot., vol. xvii, p. 24, and P1. III, Fig. 4, I903. 
modified as it approaches the first or plumular node. All its elements become less differentiated. The cells of the endodermis and conjunctive tissue just below the node are little if at all thickened; the xylem is less lignified. In particular all the vessels of large lumen become quite thinwalled, and are apt to appear crushed in transverse section. Two phloem groups are found in the median trace, so that but for the two sentinel vessels $(r x$. $)$ there would be some difficulty in distinguishing the median from the lateral bundles.

At the node a number of plumular traces combine with the two traces from the coleoptile to form the stele of the mesocotyl. In none of these traces are any elements of wide lumen present, such as those which extend from the root upwards through the mesocotylar stele. All such elements appear suddenly just below the node.

The coleoptile bundles are distinctly double (Pl. X, Fig. II). Each consists of two phloem groups embraced by a common xylem crescent. In places two groups of protoxylem are indicated, corresponding to the two phloem groups. At the node the coleoptile bundles run in from opposite sides of the axis in a straight line, which is perpendicular to that bisecting the midrib of the first leaf. The xylem groups of these bundles meet in the centre of the axis, forming a bridge across the node (P1. X, Fig. I2). The phloem groups of each bundle separate, and one runs in on either side of the xylem.

In the youngest seedling cut, numerous plumular traces are differentiated just above the node. Of these, ten possess at least one lignified xylem element. Five lignified traces are on one side of the xylem bridge, and five on the other. The stele is not quite symmetrically divided however, as on one side the traces are larger than on the other, and more unlignified strands are present. The median trace in the larger segment represents the midrib of the first leaf ; it is commonly the largest trace, and always the best lignified. Though at one point its xylem just touches the xylem bridge, it forms a centre independent of the coleoptile traces. Several unlignified strands are inserted on it at the node, and together they form the median bundle of the mesocotylar stele ( $M$ in Pl. X, Fig. IO). Of the bundles on the same side as the midrib trace, several of the strands, and all four lignified traces, are inserted on the coleoptile bundles; and so are all the traces-lignified and unlignified-on the other side.

In the older seedlings the nodal structure is essentially similar, but the discrepancy in number and size of the traces on either side of the xylem bridge is greater.

The coleoptile traces form the lateral bundles of the mesocotylar stele. The two phloem groups of either lateral bundle are derived from those of a single coleoptile trace. The xylem bridge breaks up into two groups, each of which-supplemented by the large vessels derived from the 
root-forms a lateral xylem crescent. The single element $p x_{1}$, which becomes visible in the peripheral gap between the lateral traces, is derived from the xylem bridge too.

The vascular elements of the mesocotylar stele in Sorghum are thus derived from three distinct sources :

I. The phloem of the median bundle ( $M$ in $\mathrm{Pl}$. X, Fig. Io), and most of its xylem, is plumular; for it is derived from the midrib of the first leaf and the plumular traces inserterd on it above the node.

2. The phloem of the two lateral bundles, and much of their xylem, is derived from the coleoptile bundles, and the numerous plumular traces inserted on them. The symmetry of each lateral bundle reproduces that of a coleoptile bundle; there are two phloem groups and a common xylem crescent in one as in the other. The single element $p x_{1}$. (Pl. X, Fig. IO) also comes from this source.

3. A certain number of large xylem elements, forming part of the lateral crescents, are derived from the root-xylem and disappear at the node. In particular the two 'sentinel' vessels ( $r x_{\text {. }}, r x_{\text {., }}$ in P1. X, Fig. IO), which divide the median from the lateral bundles, can be traced throughout the mesocotyl into the root.

\section{Comparison of Sorghum seedling with that of Avena.}

There is of course no doubt as to the complete homology of scutellum, coleoptile, and primary root in the two seedlings. The real question is whether the mesocotyl of Sorghum is homologous with that of Avena. If it is not, what member or members of a typical monocotyledonous seedling does it represent? We have already explained that we consider the mesocotyl of Avena to represent a fusion of the cotyledonary stalk with the hypocotyl (ante, p. I65). If, on the other hand, the mesocotyl is morphologically equivalent in both seedlings, how account for the differences in vascular anatomy?

Adopting the latter view, we believe that the mesocotyl of Sorghum is equivalent to the mesocotyl of Avena, and we have therefore to explain its anatomy on that assumption. The most obvious difference is that in Avena the scutellum trace joins the stele of the axis at the top of the mesocotyl; that is, at some distance above the apparent insertion of the scutellum. Between these two levels the scutellum trace runs upwards in the cortex of the mesocotyl; side by side with the stele, but quite distinct from it (Text-fig. 6, p. I66). But in Sorghum the scutellum trace goes straight to the stele as soon as it enters the axis; the real insertion appears to lie in the same plane with the apparent. Our explanation is that the fusion of stalk and hypocotyl has proceeded further in Sorghum than in Avena; the cotyledonary trace in the former runs up to the plumular node within the stele, not outside it. 
We have attempted to explain the vascular symmetry of the Avena seedling by supposing that the scutellum trace divides at the plumular node; that one branch runs up one side of the coleoptile, doubles closely on itself near the top, and runs down again, thus forming one of the double coleoptile bundles. The other branch does the same on the other side. When they reach the plumular node again, each downward branch plunges into the stele of the mesocotyl. Here they unite to form a compound bundle opposite the midrib trace $M$ (Pl. IX, Fig. 4, also ante, pp. I67-9, and Text-figs. 6 and 7, p. I66). To explain the vascular skeleton of Sorghum in the same terms, we must consider the solitary element $p x_{1}$. as representing the xylem of the upward scutellum trace in Avena, and the two phloem groups adjacent to it-within the lateral xylem crescents-as its phloem. At the plumular node all these structures are seen to be connected with half of each coleoptile trace, just as in Avena; while the remaining phloem group within each lateral crescent belongs to the other half of the corresponding coleoptile trace, and can be traced downwards through the plumular node into the stele of the mesocotyl.

Those who adopt this view will find that the chief difficulty to be faced is the existence of an insertion plate at the point of junction of the scutellum trace with the stele. For if the scutellum is identified with the cotyledon, the level where its trace is inserted on the stele would appear at first sight to be undoubtedly the cotyledonary node. But then the mesocotyl of Sorghum would represent the first internode of the main axis, and this is contrary to our hypothesis. Nor is it consistent with our observations, for we have shown that the structure of the upper or plumular node of Sorghum is strictly comparable with that of the first or plumular node in Avena, where the scutellum trace first unites with the stele. On the other hand, the insertion 'node' in Sorghum resembles with equal fidelity the region in Avena where the lower cauline roots are given off. We therefore prefer to use the term 'insertion plate', and we continue to regard the node where the coleoptile traces enter the stele as the first node of the axis in Sorghum as in Avena. It is strictly comparable in our opinion with the node which in a typical Monocotyledon divides the hypocotyl from the first internode of the plumule.

Zea Mays, L. We have already described and figured the ramifications of the single bundle in the upper part of the scutellum (Sargant and Robertson ('05)). We may therefore begin here with the structure of that bundle near the base, just before it enters the axis. At this level it is oval in transverse section, with massive phloem (Text-fig. 2I, p. 192). Its xylem is compact and well-lignified. The xylem divides into three parts while passing into the axis, and the phloem into two. The lateral branches of the xylem enter the two cauline roots which are inserted between scutellum and 
axis-the 'wedging' roots as we have called them (1. c., Pl. V, Figs. 6-9, $r^{\prime}$ ). The median segment is the most slender of the three. It goes straight to the axial stele, and at once turns upwards within it. The two phloem strands accompany the scutellum xylem, one on either side of it. Each gives off a considerable portion to the stele of the nearer wedging root on its way to the axial stele. Thus the scutellum xylem enters the latter with a phloem branch on either hand, and they turn upwards side by side with it.

These three strands, one of xylem and two of phloem, can be followed from their entrance into the mesocotylar stele upwards to the first node in

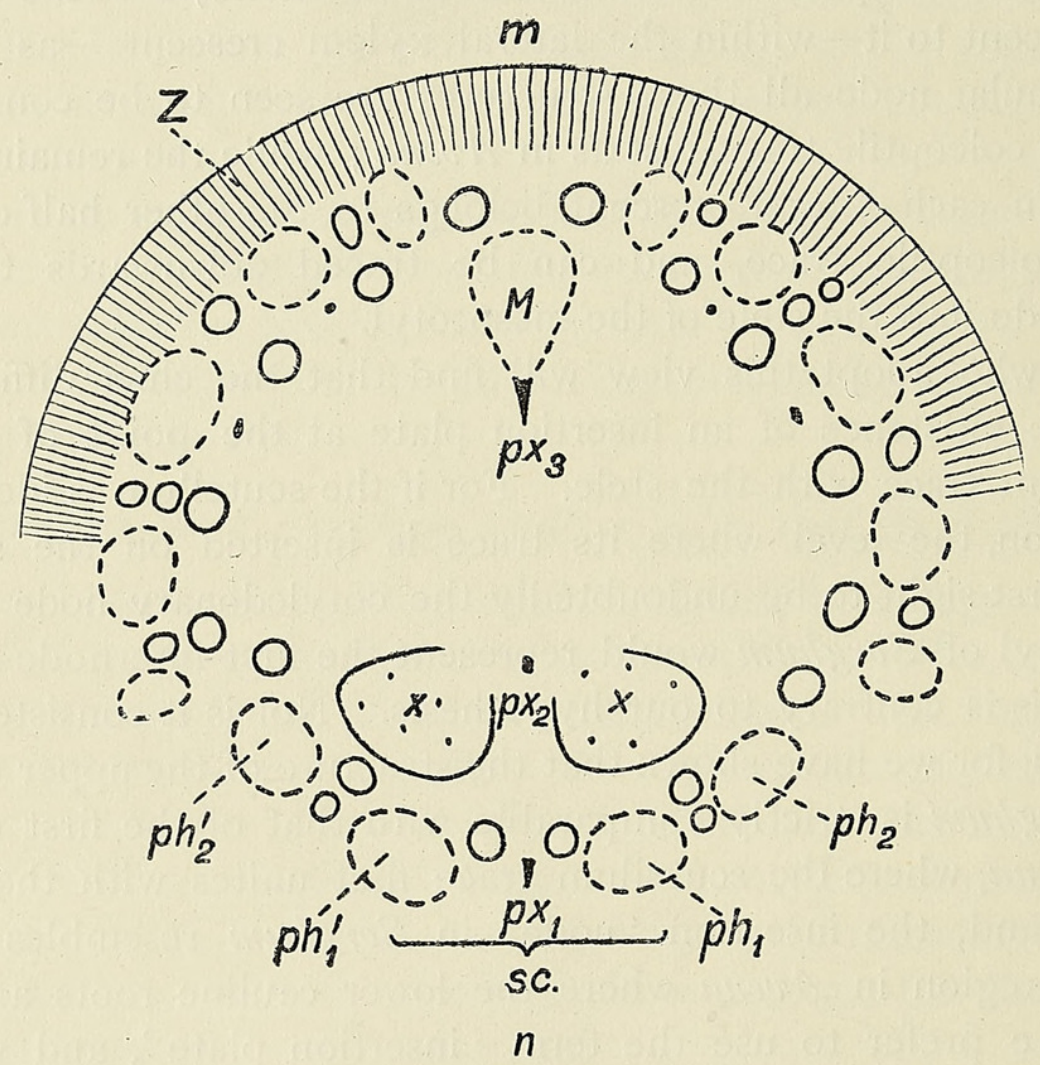

TeXt-FIg. 2I. Zea Mays, L. Diagram of mesocotyl as seen in transverse section.

two seedlings. Both of them are young, with the stem-bud still completely enclosed in the coleoptile. The cauline roots which will be produced later from this node are not present even as rudiments, though a band of meristem partly enclosing the stele suggests the formation of new members there. So far, indeed, the youth of the seedling is an advantage, since it allows the primary structure of the node to be followed without the complications introduced by root-insertions. But on the other hand the mesocotylar stele is very imperfectly differentiated at this age. After very careful inspection of these two complete series, and comparison with several partial ones from seedlings of the same age or older, we found certain landmarks within the stele which enabled us to interpret its structure 
with a fair degree of probability. Only after comparison with the allied case of Sorghum, however, which in some respects is much more favourable for observation, were we fully convinced that this interpretation was sound.

The first fixed point is the little group of protoxylem elements, sometimes even reduced to a single annular tracheide with a phloem group on either hand, which represents the xylem of the scutellum trace. In the diagram (Text-fig. 2I) it is marked $p x_{1}$, and the double bundle consisting of $p x_{1}$ and the adjacent phloem strands is called $s c$., because it answers to the upward scutellum trace in Avena. In series which include the scutellum insertion, this group $\left(p x_{1}\right)$ can of course be determined with absolute certainty. But even in an isolated section of the mesocotyl, the group $p x_{1}$ can be picked out, partly by its position near the periphery of the stele, and with still more certainty by reference to a second fixed point, the midrib trace from the first leaf $(M)$. In Zea Mays, as in the other Grass seedlings examined, the midrib of the first leaf is prolonged almost unchanged into a trace which can be followed with certainty throughout the mesocotyl. It lies a little nearer the centre of the stele than the other traces, and its xylem is better lignified. The group $p x_{1}$ is always at the further end of the diameter bisecting $M$.

The rest of the stele is symmetrical with respect to this diameter. The phloem group on either side of $p x_{1}$ is followed by another phloem group resembling it. Internal to the pair of phloem groups thus lying on one side of $p x_{1}$ is a wedge-shaped area, over which are scattered xylem elements more or less completely lignified. A similar area is found on the other side. The two wedges ( $x, x$ in Text-fig. 2I) are separated by a lane of clear conjunctive tissue, closed at the peripheral end by $p x_{1}$, and between the apices of the wedges by another little group of protoxylem elements $\left(p x_{2}\right)$. Thus the diameter $m n$, which bisects $M$, also passes through three distinct protoxylem groups : $p x_{3}$ belonging to $M ; p x_{2}$ common to the two areas $x, x$; and $p x_{1}$ belonging to the scutellum trace.

The numerous lateral plumular traces lie near the periphery of the stele. They occupy the two arcs which are bounded by $M$ on one side, and on the other by either extremity of the cotyledonary bundles which face it. They are best defined in young seedlings by their phloem groups, for only a xylem element here and there is sufficiently well lignified to show up clearly in transverse section. Nevertheless, the existence of such elements within the larger phloem groups shows conclusively that the lateral traces from the first leaf are endarch, like their medium trace $M$.

Between the phloem groups of plumular and cotyledonary traces alike are large elements, lignified in older seedlings, which clearly correspond to the root xylem found in the mesocotyl of Sorghum. They extend in places to the periphery of the stele. Since these are by far the most conspicuous xylem elements present in the section, and since among them the smaller 
elements are commonly external to the rest, it is not surprising that the mesocotylar stele of Zea has been described as root-like. ${ }^{1}$ This is, however, a mistake. The plumular traces, as well as those connected with scutellum and coleoptile, are certainly of the usual stem-type ; that is, their xylem is centrifugal, and internal to the phloem.

We have now described the anatomy of the mesocotylar stele near its base, and its connexion with the scutellum trace. Following it upwards, we find some changes in a transverse section taken just below the first node. Much of the root xylem has died out, and what is left is thin-walled and unlignified. The two phloem bundles on either side of $p x_{1}\left(p h_{1}, p h_{2}\right.$, $p h_{1}^{\prime}$, and $p h_{2}^{\prime}$ ) sometimes divide into three or four groups. In one seedling two small groups, one on either side of $p x_{1}$, appear to represent a pair of minor plumular bundles whose insertion on $p h_{1}$ and $p h_{1}^{\prime}$ respectively has been delayed for some distance below the node. The two or three groups beyond them represent $p h_{1}$ and $p h_{2}$ on one side, and $p h_{1}^{\prime}$ and $p h_{2}^{\prime}$ on the other.

Here, as in Sorghum, the first node is most easily described from above downwards. The plumular traces are very numerous, even in these young seedlings, but mostly small and unlignified. The midrib $M$ of the first leaf can be traced with certainty through the complications of the node into the mesocotylar stele. The other traces anastomose with each other, and most of them finally settle down into the single semicircle shown in Text-fig. 2I. A few insert themselves on the coleoptile traces at or near the node.

The coleoptile traces themselves are clearly double, with two wellmarked phloem groups side by side, and groups of xylem internal to both. There is a common group of protoxylem, and lignification of the metaxylem seems to start on either side of it, suggesting that in older seedlings the metaxylem will be in two groups like the phloem. The traces do not divide until they have entered the stele. They approach each other from opposite directions in the same straight line; so that the two larger xylem branches, maintaining their original direction, meet to form a massive xylem bridge, which divides the circular stele into two unequal segments. The two smaller xylem branches bend outwards, and meet almost at once to form the peripheral protoxylem group $p x_{1}$.

We have already described the mesocotyl just below the node in one seedling. In this instance the two phloem groups of each trace, together with the plumular phloem inserted on them, give rise to three or four groups in the stele just below the node. Lower down these unite to form the two groups $p h_{1}, p h_{2}$, on one side of $p x_{1}$, and $p h_{1}^{\prime}, p h_{2}^{\prime}$, on the other. We do not doubt that the two groups in each pair represent the two phloem groups of a single coleoptile trace, but they do not seem to maintain their

1 Schellenberg and Kirchner in Kirchner, O. von, Loew, E, and Schröter, C. ('08-'I2), p. 23 I. 
independence completely throughout the nodal region. In the two other seedlings from which we possess complete series of sections through the first node, the phloem groups of each coleoptile trace seem prolonged into two groups in the mesocotyl, and to remain fairly distinct during the complications of the first node.

Thus in Zea, as in Sorghum, the scutellum trace can be followed from its entry into the stele upwards to the first node, where it divides. Each branch forms half one of the coleoptile traces. The other half is prolonged downwards into the stele of the mesocotyl, and is found throughout its course side by side with the upward scutellum trace. Thus from first node to scutellum insertion, a transverse section shows the double scutellum trace, with a trace derived from the coleoptile on either side. Below the scutellum insertion the main axis becomes the primary root. The transition from the stem structure of the mesocotyl to the characteristic structure of the primary root is masked by a very complicated insertion plate. When the stele emerges from this region it is completely root-like.

Coix Lacryma-Fobi, L. Of the four seedlings cut, only one is so young that the first leaf is still enclosed in the coleoptile (Text-fig. 22, p. 196). In the others, two leaves have unfolded. The first $\left(L_{1}\right)$ is only sheathing; the second $\left(L_{2}\right)$ is a foliage leaf (Text-fig. 23 , p. I96).

The scutellum is fleshy and wrapped round the axis. Its apparent insertion is prolonged for some distance, but the single massive bundle enters the axis almost at once, and often joins the mesocotylar stele above the level at which its structure becomes obscured by the entrance of steles from the insertion roots. In such cases the xylem and phloem of the scutellum trace can be followed up the main stele with some accuracy.

From apex to insertion the scutellum bundle branches freely, and even as it enters the axis branches are still given off to supply the lower part of the organ. The main trunk becomes amphivasal from constant insertion of branch bundles, and is still amphivasal at its junction with the axis. The external xylem on its dorsal and lateral faces enters the downward branches for the most part, and the main bundle carries nothing but its compact mass of ventral xylem into the mesocotyl.

The phloem of the scutellum bundle is sometimes clearly double and always massive. Its outline in transverse section is kidney-shaped, at any rate near the insertion; the concavity occupied by ventral xylem. On entering the axis it approaches the stele very gradually, so that a section just above their junction may cut both scutellum trace and stele almost transversely.

In such a section the ventral xylem group of the scutellum trace is easily recognized on its upward course in the stele ( $p x_{1}$ in Text-fig. 24 , p. 197). The phloem groups on either hand $\left(p h_{1}\right.$ and $\left.p h^{\prime}\right)$ represent those of 
the trace. The identity of $p x_{1}$ with the scutellum xylem can be demonstrated by following sections downwards. That of phloem groups $p h_{1}$ and $p h_{1}^{\prime}$ with the scutellum phloem is not quite so clear, because during the traceinsertion, and for some distance above it, the limit between $p h_{1}$ and $p h_{2}$ on one side, and that which divides $p h^{\prime}{ }_{1}$ from $p h_{2}^{\prime}$ on the other, is confused.

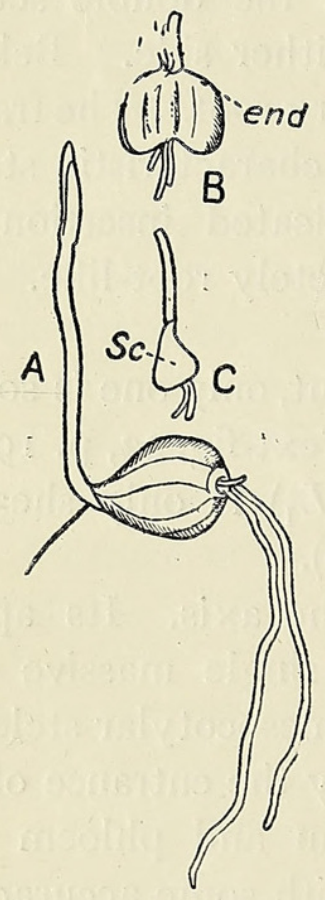

Text-Fig. 22. Coix $L a-$ cryma-fobi, L. A. Outline of young seedling, life-size. B. Husk of grain removed to show endosperm. C. Endosperm removed to show scutellum.

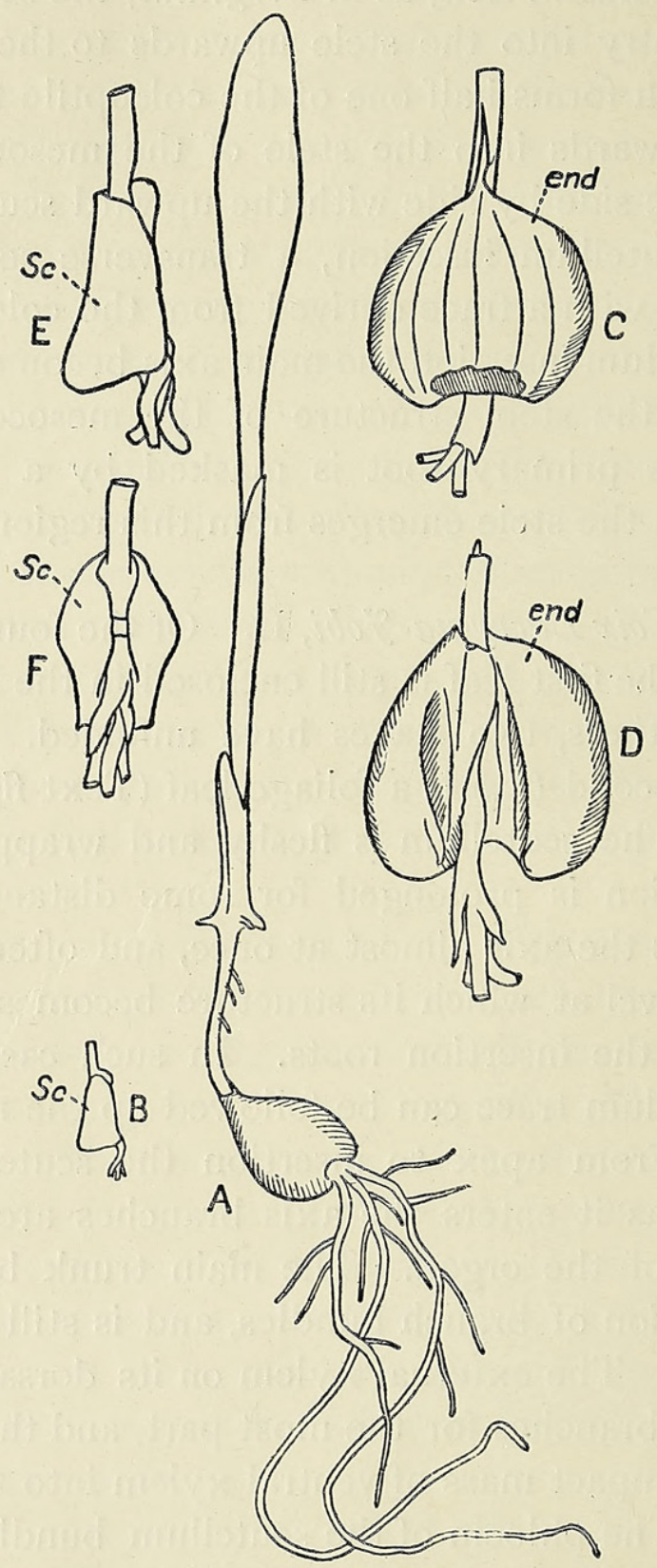

Text-Fig. 23. Coix Lacryma-Fobi, L. A. Outline of older seedling, life-size. B. Scutellum and adjacent parts, life-size. C. Endosperm from back. $\times 2$. D. Endosperm from front. $\times 2$. E. Scutellum from side. $\times 2$. F. Scutellum from front. $\times 2$.

Starting from $p x_{1}$ as a fixed point, the structure of the mesocotylar stele is easily deciphered by reference to that of Sorghum and Zea. It is adequately shown in all four seedlings, and is symmetrical about the 
diameter which passes through $p x_{1}$. This diameter cuts the similar group $p x_{3}$, which lies on the other side of the centre, but nearer to it than $p x_{1}$. As in Sorghum and $Z e a, p x_{3}$ represents the protoxylem of midrib trace $M$, and is similarly situated. But Coix differs from Sorghum and Zea in the absence of an intermediate group of protoxylem on this diameter $\left(p x_{2}\right.$ in Text-fig. 2I). We have interpreted this group in Sorghum and Zea as common to the two groups of metaxylem on either side of $p x_{1}$. In Coix each of these metaxylem groups has its own group of protoxylem, placed just within it, at a considerable distance on either side of the diameter of symmetry. The two groups are marked $p x_{2}$ and $p x_{2}^{\prime}$ in Text-fig. 24.

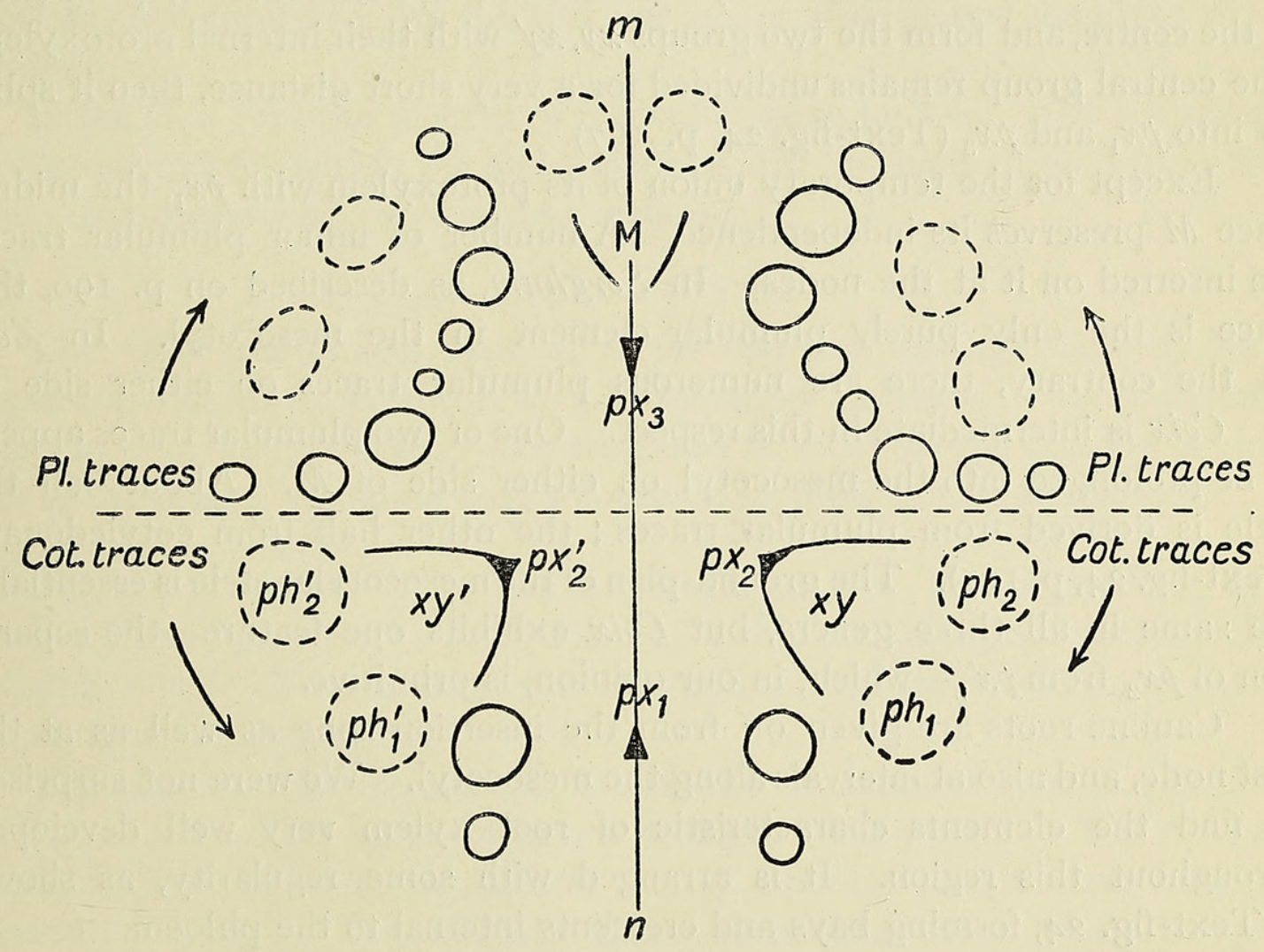

TeXT-Fig. 24 Coix Lacryma-Fobi, L. Diagram of mesocotyl as seen in transverse section.

The contribution of the scutellum trace to the stele of the mesocotyl is therefore the protoxylem group $p x_{1}$, and part of the two phloem crescents on either side of it. When each crescent settles down into two distinct groups, $p h_{1}$ and $p h_{2}$ on one side, $p h^{\prime}{ }_{1}$ and $p h^{\prime}{ }_{2}$ on the other, it is natural to identify $p h_{1}$ and $p h_{2}^{\prime}$ with the two halves of the scutellum phloem. The other constituents of the stele cannot be identified until they have been followed to the first node.

We have series through the first node from two seedlings only, but both of them are complete and well differentiated. Some obscurity is introduced by the insertion of three cauline roots, but the midrib trace $M$ can be followed into the stele of the mesocotyl, and the general course 
of the coleoptile traces laid down. The latter behave, on the whole, very much as in Sorghum. They appear to give rise to $p x_{1}, p x_{2}, p x_{2}^{\prime}$; to the two xylem groups $x y, x y^{\prime}$; and to the phloem groups $p h_{1}, p h_{2}, p h_{1}^{\prime}, p h_{2}^{\prime}$. But minor plumular traces are inserted on them at critical moments, and further complications are introduced by the formation of cauline roots in the neighbourhood; hence the whole process is obscure, and would hardly be explicable but for comparison with Sorghum.

No massive xylem bridge is formed by the union of coleoptile traces. A few elements of protoxylem are pushed forward from either side, and meet in the centre. There they are joined by similar elements from the midrib trace $M$. The mass of xylem elements in both traces stop far short of the centre, and form the two groups $x y, x y^{\prime}$ with their internal protoxylem. The central group remains undivided for a very short distance, then it splits up into $p x_{1}$ and $p x_{3}$ (Text-fig. 24, p. 197).

Except for the temporary union of its protoxylem with $p x_{1}$, the midrib trace $M$ preserves its independence. A number of minor plumular traces are inserted on it at the nodes. In Sorghum, as described on p. I90, this trace is the only purely plumular element in the mesocotyl. In Zea, on the contrary, there are numerous plumular traces on either side of it. Coix is intermediate in this respect. One or two plumular traces appear to be prolonged into the mesocotyl on either side of $M$. About half the stele is derived from plumular traces; the other half from cotyledonary (Text-fig. 24, p. 197). The ground-plan of the mesocotylar stele is essentially the same in all three genera, but Coix exhibits one feature-the separation of $p x_{2}$ from $p x_{2}^{\prime}$-which, in our opinion, is primitive.

Cauline roots are given off from the insertion zone as well as at the first node, and also at intervals along the mesocotyl. We were not surprised to find the elements characteristic of root xylem very well developed throughout this region. It is arranged with some regularity, as shown in Text-fig. 24, forming bays and crescents internal to the phloen.

Euchlaena mexicana, Schrad. We possess but one series of sections from this species. It passes through scutellum and base of mesocotyl downwards to insertion zone and primary root. The mesocotylar stele resembles that of Coix; but the insertion of the scutellum trace on it is much clearer, chiefly owing to the absence of cauline roots in this region. The two phloem groups in the scutellum bundle are quite distinct, and they enter the stele of the mesocotyl on either side of the ventral xylem. As these phloem strands pass up the stele they remain distinct from adjacent strands, and can therefore be identified with certainty as belonging to the scutellum trace. 


\section{Comparison of the Zea type with the Avena type.}

In these two types the scutellum is inserted at some distance below the first node. The region of the main axis which separates them has been called the mesocotyl.

In the Avena type the scutellum trace on entering the axis turns sharply upwards in the cortex and does not join the stele until it has reached the first node. In fact, the trace behaves like the main bundle of a separate stalk running upwards from sucker to node. It is easy to construct stages of development in which such a stalk might become united with the main axis. Avena would then represent the epoch when external union was accomplished, but the vascular systems of the two members were still distinct.

In the $Z e a$ type the process of fusion has gone further. The scutellum trace runs upwards within the stele, but can still be distinguished from the other constituents with more or less certainty.

\section{Triticum type.}

The third anatomical type of Grass seedling distinguished by Van Tieghem possesses no mesocotyl. The apparent insertion of the scutellum takes place at the first node. We have now to examine the relation of this type to the others, assuming that some such relation can be established.

Triticum vulgare, Vill. The external features of the seedling are shown in Text-figs. 25-7, p. 200. The leaf within the coleoptile becomes the first foliage leaf. Two cauline roots are formed very early, and soon equal the primary root in length.

The scutellum is rounded at the apex. It contains slender vascular bundles, which collect lower down into a single bundle-trunk. The epithelium is confined to its dorsal surface, merely tipping the apex and fringing the ventral wings. The bundles either terminate under these fringed margins, or in the neighbourhood of the dorsal epithelium. At a level rather nearer the insertion than the apex, a main trunk is formed by union of all the upper bundles. They approach along lines converging from both margins and from the dorsal surface; their bases in transverse section look rather like the sticks of a fan.

The main bundle-trunk when first formed is much extended laterally. Its xylem is a thin ventral plate, bisected by a few protoxylem elements. Its phloem is shaped in transverse section like a flat plano-convex lens. Just below the apparent insertion of the scutellum, however, the bundle becomes more compact.

The real insertion of the scutellum on the axis can be followed with accuracy in those seedlings only where the plumule lies in a straight line with the primary root, and is fairly parallel to the midrib of the scutellum. 
In such specimens the plumular traces, the stele of the primary root, and the main scutellum bundle are all cut transversely in the same series of sections. In many seedlings, however, the base of the plumule makes a considerable angle with the scutellum and primary root, or is almost perpendicular to them. Such specimens are useless for interpretation of the nodal structure. We are fortunate, however, in having secured series of sections through four straight seedlings, two in which the plumule is still enclosed in the coleoptile, and two rather older-the first leaf having pushed its way

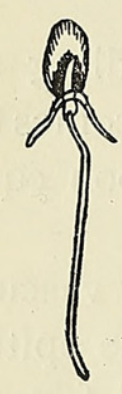

Fig. 25 .

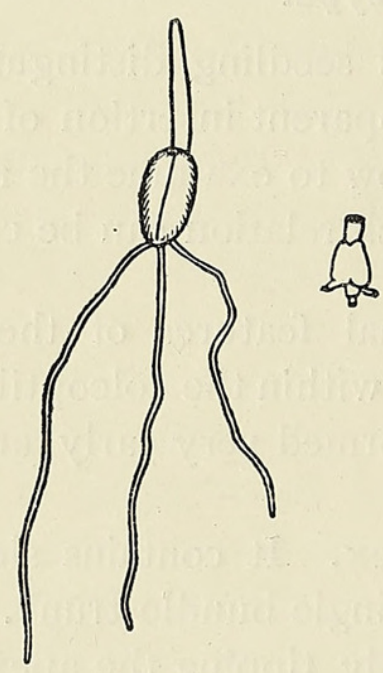

Fig. 26.

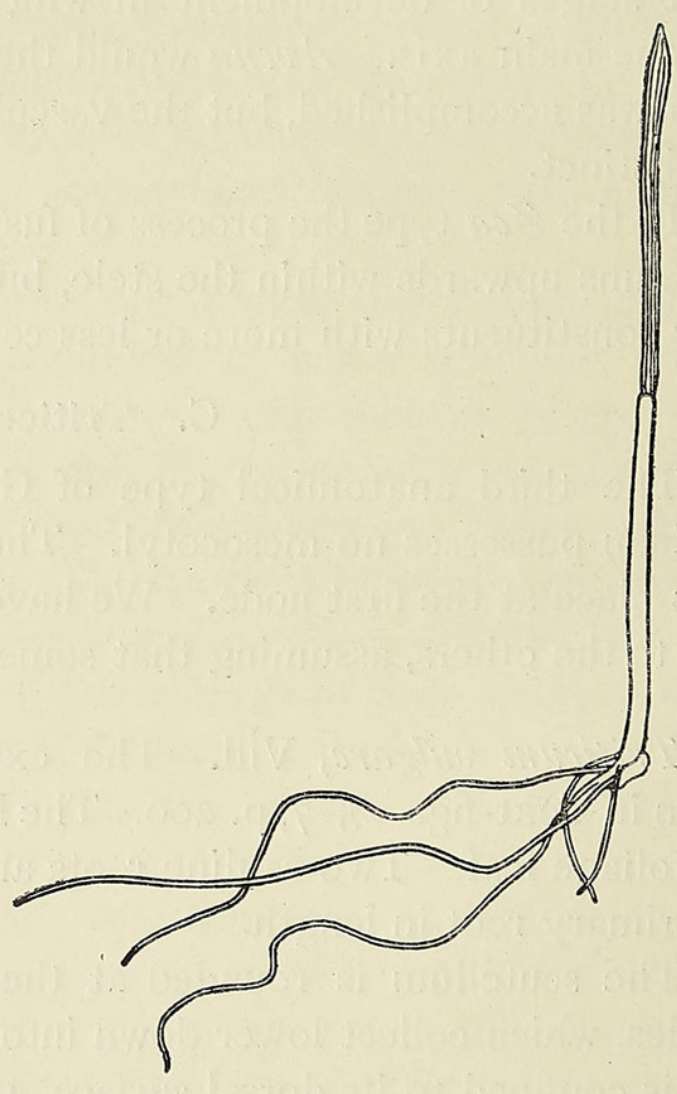

Fig. 27.

Text-Figs. 25-7. Triticum vulgare, Vill. 25. Outline of very young seedling, life-size. 26. Outline of older seedling, life-size. 27. Outline of still older seedling, life-size.

out. The following description of insertion and nodal structure is founded on those four seedlings only.

In the two younger seedlings the main bundle of the scutellum runs straight into the stele on entering the axis. But in the two older specimens it turns upwards, and is parallel to the stele for a short distance before entering it. Thus a few sections show the inverted scutellum trace side by side with the stele, just as in Avena. A mesocotyl can hardly be said to exist, for the vertical distance during which the inverted scutellum trace is distinct from the stele is very small. In our best specimen it does not exceed $0.05 \mathrm{~mm}$. The structure of the node is certainly clearer for this brief interval, however, and more readily comparable with that of Avena. 
Thus the first node can be distinguished from the entry of the scutellum bundle into the axis, although in the younger seedlings both occur together. For clearness we begin with one of the older seedlings in which the series is fairly complete and the preparations successful. The other is less clear, but the main points can be verified in it by comparison with the first.

After remaining distinct from the stele through a few sections, ${ }^{1}$ the phloem of the upward scutellum trace divides to right and left of the xylem. One half goes to form the coleoptile trace $P$, the other to form $P^{\prime}$. The xylem meanwhile splits into three parts; the lateral branches accompany the phloem, while the median elements enter the stele at the gap which faces the midrib trace $M$ (cf. II and III, Text-fig. 28, p. 202). They turn downwards at once, and do not, therefore, appear in Diagram I of Text-fig. 28.

So much for the behaviour of the scutellum trace on its upward course. A more complete view of the first node is gained by following the coleoptile and plumular traces downwards.

A little distance above the first node are eight well-marked plumular traces, besides several small ones. Seven of these belong to the first leaf. The eighth is the midrib of the second leaf, which divides just above the entry of the coleoptile bundles and inserts itself on two lateral traces. The coleoptile bundles enter by the gap thus left, which is opposite $M$, the midrib trace from the first leaf.

The terminations of the coleoptile bundles are sharply bent, one lying over the other, but quite distinct. They lie just under the apex of the coleoptile, and on the same side of it. A number of spiral tracheides are found at the angle of each. Their function is doubtless related to the occurrence of the large water-pores which are always found in their neighbourhood. Near the first node the bundles are not clearly double in transverse section, and they lie a little to one side of the line which bisects stele and axis symmetrically (I, Text-fig. 28). Nor do they meet within the stele as in Avena, but just outside it (II and III, Text-fig. 28, p. 202). The branching at this spot is, however, precisely that of Avena. The ingoing branches-a common xylem strand and two distinct phloem groups-enter the stele by the gap opposite $M$, and constitute the bundle $x$. The outgoing branches unite to form the inverted scutellum trace, sc. There is also a direct xylem connexion-as explained above-between the scutellum trace and $x$. In this respect again Triticum resembles Avena.

This vascular symmetry may be described as essentially that of an Avena seedling in which the mesocotyl has been reduced in length almost to vanishing point. In the two younger Triticum seedlings it 
has disappeared altogether, and the insertion of the scutellum bundle takes place at the first node.

The process may be shortly described from above downwards. The coleoptile bundles meet outside the stele, but the external branches go to form the main bundle of the scutellum itself, not merely an inverted trace.

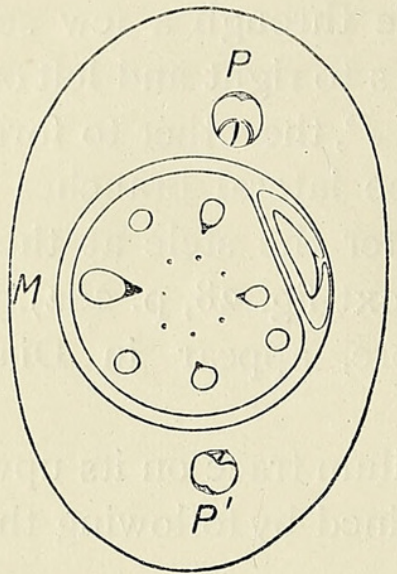

I.

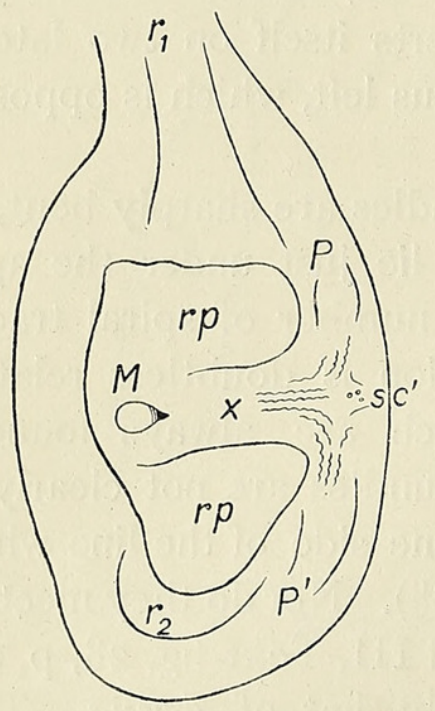

III.

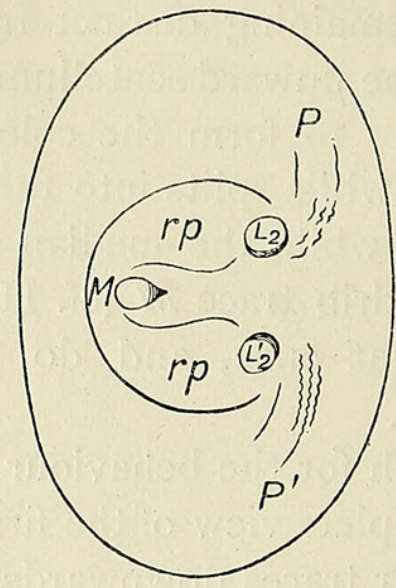

II.

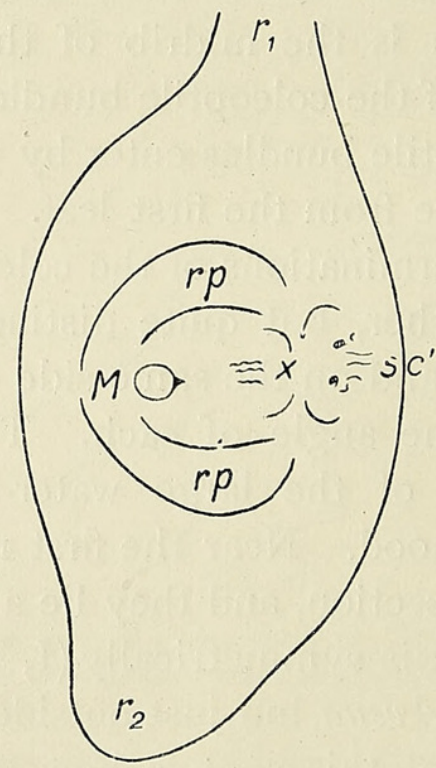

IV.

TEXT-FIG. 28. Triticum vulgare, Vill. Four diagrams of axis in transverse section. I. Base of first internode; bud in axil of coleoptile. II. Top of first node; $r p ., r p .$, root-plates. III. Middle of first node. IV. Base of first node; $s c^{\prime}$., scutellum trace.

The internal branches form a compact bundle which is prolonged downwards below insertion level, and can be recognized until the stele becomes root-like. There is a direct connexion by xylem arch between this trace and the scutellum bundle. In both the seedlings we are now considering the cauline roots are rudimentary, but the root-plates are present below the first node, and effectually mask the transition to root-structure. In the 
younger of the two seedlings very little tissue is lignified in this region, and this adds to the obscurity in structure.

We have already remarked that the chief difference in vascular symmetry between the seedlings of Avena and Triticum, besides the absence of a mesocotyl in the latter, lies in the insertion of the coleoptile bundles. In Avena each enters between two lateral traces from the first leaf, and unites with both. The root-plates depend chiefly on traces from the second and third leaves. In Triticum the lateral traces of the first leaf go bodily into the root-plates, and the coleoptile traces enter the stele in the by-gap between those plates. The difference can be appreciated most easily comparing Diagram II in Text-fig. I6, p. I74, with II in Text-fig. 28. The younger seedlings of Triticum, in which the root-plates are not differentiated at that level, show the insertion of one lateral leaf-trace on either coleoptile bundle.

This anatomical distinction is no doubt correlated with the single root-system of the Triticum seedling. In Avena the first leaf is supplied with water through the mesocotyl from the lower root-system, which includes the lower set of cauline roots as well as the primary root. The first leaf is therefore mainly connected with the traces which run down the mesocotyl. But in Triticum there is only one system of cauline roots. They correspond to the upper or nodal root-system of Avena. While the first leaf draws water from the primary root by its midrib, it must also be in direct connexion with the nodal roots through their insertion-plates.

Hordeum vulgare, $\mathrm{L}$. In external characters the seedling resembles that of Triticum, but the cauline roots are more numerous. In all the seedlings examined anatomically, the first leaf is still enclosed in the coleoptile.

The scutellum has two main bundles symmetrically placed. Each resembles the single bundle of Triticum in being a trunk, built up of the slender branches which ramify in the apical region of the scutellum. When first formed, both trunks are nearly or quite amphivasal: lower down, the xylem in each becomes a ventral crescent. Just above their insertion on the axis the xylem groups are much extended laterally, and each is bisected by a group of protoxylem elements.

The dual symmetry of the scutellum simplifies the ground-plan of its insertion. For when the two bundles run into the axis, the phloem of each turns outwards, and passes into the adjacent coleoptile trace. The greater part of the xylem of each bundle accompanies the phloem, but the inner xylem elements are in contact with each other, and go straight to the stele, where they meet other elements from the incoming coleoptile bundles. All this xylem turns downwards, and forms a massive strand within the stele for a short distance below the node. It is soon lost in the tangled anatomy of root-insertions. 
These changes in structure are more readily compared with those recorded in Triticum and Avena when they are described in the inverse order, that is, from above downwards.

Seven traces from the first leaf and two bundles from the coleoptile enter the first node from above. This does not include the midrib trace $m$ from the second leaf, which is commonly present at the beginning of the first node. But as it splits into two branches which unite with two lateral traces from the first leaf before the first node ends, it is not considered as having a course distinct from theirs. Some traces-usually unlignified at this age-which represent the lateral bundles of the second leaf, also enter the first node; and in the older seedlings examined, certain strands on either side of $m$ can be traced back to the bud in the axil of the coleoptile. Sooner or later all these traces are absorbed in the root-plates (I and II, Text-fig. 29).

The midrib trace $M$ from the first leaf remains distinct throughout the node, and is always opposite the gap left by the defection of $m$. Lower down this gap is filled by the temporary union of the two coleoptile traces $P$ and $P^{\prime}$; and a branch from each trace turns downwards into the stele while they are still in contact. Their phloem groups are distinct at first, but soon form a crescent external to the common xylem group, which contains, besides the two xylem branches from the coleoptile traces, some central elements from the scutellum bundles (III, Text-fig. 29).

Thus, at the base of the first node, we find within the stele a single bundle $M$ facing a compound bundle $x$, built up of branches from $P$ and $P^{\prime}$, together with xylem elements from the scutellum traces. These bundles $M$ and $x$ are separated from each other on either side by a plate of xylem and phloem $\left(r p, r p^{\prime}\right)$, derived from the lateral traces of the first and second leaves (IV in Text-fig. 29). This very definite structure is completely obliterated a little lower down by the insertion of four cauline roots, and when the confusion introduced by them has disappeared, the main stele of the axis is found to be root-like.

This accounts for the internal branch from each coleoptile trace. But the larger portion of each trace pursues its course through the cortex of the axis, and enters the scutellum. Turning sharply upwards, each coleoptile segment becomes one of the two bundle-trunks described above $\left(s c_{1}, s c_{2}\right.$, II and III, Text-fig. 29).

The Hordeum seedling differs from that of Triticum chiefly in two points : in the presence of two scutellum bundles, and in the absence of any approach to a mesocotyl. We might have attributed the second character to the youth of the Hordeum seedlings examined, but by the kindness of Mrs. Taylor we have been able to compare our series with another cut by her from an older specimen. This corresponds in age with the older 
Triticum seedlings described by us. As in our younger specimens, the scutellum bundles do not turn upwards in the axis before joining the stele, but enter the coleoptile traces at once.

The cultivated species of Hordeum are said by Van Tieghem to have two bundles in the scutellum; the wild species to have but one. We have verified this in the wild species $H$. jubatum, $L$. Two interpretations of this

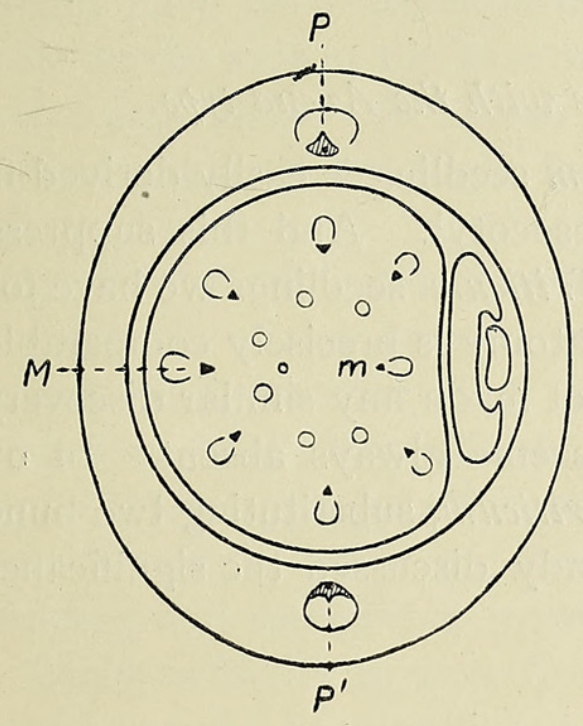

I.

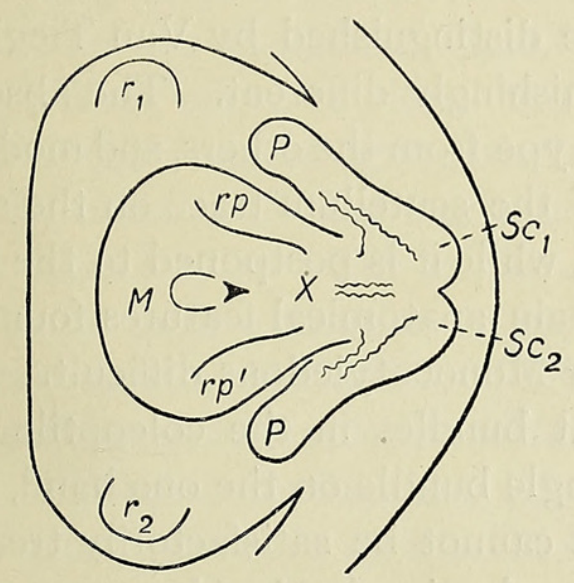

III.

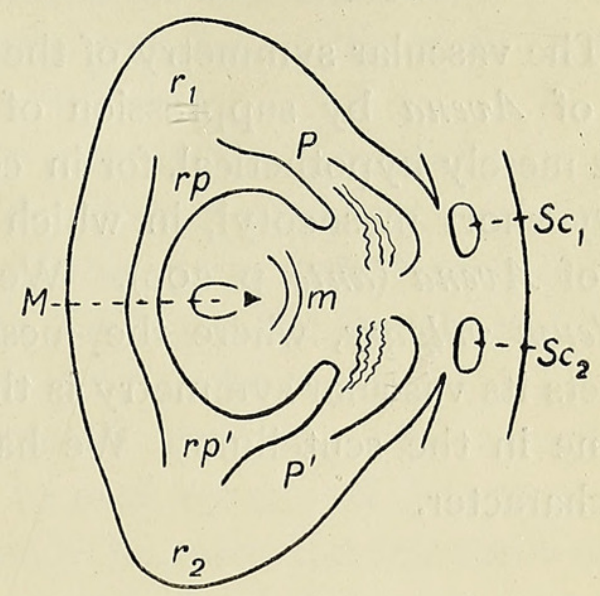

II.

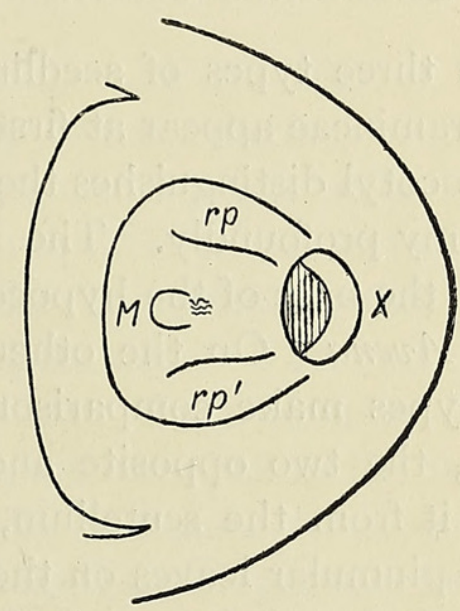

IV.

TEXT-FIG. 29. Hordeum vulgare, L. Four diagrams of axis in transverse section. I. Base of first internode; bud in axil of coleoptile. II. Top of first node and apparent insertion of scutellum ; $s c_{1}, s c_{2}$, scuteilum bundles. III. Middle of first node and real insertion of scutellum. IV. Just below insertion of scutellum.

distinction are possible. The cultivated varieties may be derived from an ancestral form with two bundles, now extinct. We might then regard the dual symmetry of the scutellum as a primitive character. Or the ancestral scutellum may have had but one bundle as in the wild species which survive. In that case the doubling of the bundle in cultivated forms is probably adaptive, a response to the demand for more vascular tissue. The 
ready splitting of the bundle-trunk to correspond with the twofold structure of the coleoptile might indeed suggest reversion to an originally dual symmetry. Otherwise the increase in mass of vascular tissue might perhaps have been effected by the division of the bundle-trunk into three or four ; or by the more vigorous branching of a single trunk. We cannot, however, attach much weight to this argument, considering our ignorance of the laws of adaptation.

\section{Comparison of the Triticum type with the Avena type.}

The vascular symmetry of the Triticum seedling is easily derived from that of Avena by suppression of the mesocotyl. And this suppression is not merely hypothetical, for in certain Triticum seedlings we have found a very short mesocotyl, in which the anatomy is precisely comparable to that of Avena (ante, p. 200). We have not made any similar discovery in Hordeum vulgare, where the mesocotyl seems always absent. In other respects its vascular symmetry is that of Triticum, substituting two bundles for one in the scutellum. We have already discussed the significance of this character.

\section{The Anatomy of Certain Other Monocotyledonous SEEDLINGS COMPARED WITH THAT OF THE GRASSES.}

The three types of seedling structure distinguished by Van Tieghem in the Gramineae appear at first sight astonishingly different. The absence of a mesocotyl distinguishes the Triticum type from the others, and modifies its anatomy profoundly. The insertion of the scutellum trace on the stele occurs at the base of the hypocotyl in Zea, while it is postponed to the first node in Avena. On the other hand, certain anatomical features found in all the types make comparison with other Monocotyledons difficult. For example, the two opposite and equivalent bundles in the coleoptile distinguish it from the scutellum, with its single bundle on the one hand, and from the plumular leaves on the other. It cannot be satisfactorily treated either as the cotyledon or as the first leaf. Again, the double structure of the coleoptile bundles-particularly plain in Avena, Sorghum, and Zea, and very clearly indicated in Triticum-can hardly depend on the double character of the scutellum trace, since only one-half of the latter reaches each coleoptile bundle. Finally, in all the types the coleoptile bundles appear to arise at the first node, partly from the scutellum trace, and partly from the stele of the mesocotyl.

These features are explicable if all three types are derived from an imaginary ancestor $X$, with the seedling skeleton suggested in Text-fig. 7 , p. I66. We have already considered the modifications of structure necessary to convert that ancestor into a seedling of the Avena type (pp. 168-9). None of 
them are improbable. Fusion between two distinct and adjacent members occurs very commonly in all parts of the plant ; there is no morphological reason why the stalk of the cotyledon should not unite with the hypocotyl to form the mesocotyl. More or less complete fusion of two separate bundles within the cotyledon is frequent among Monocotyledons, and may be supposed to occur in the sucker and stalk of type $X$. When these two changes have been accomplished, the sucker of the cotyledon will appear sessile on the axis at the base of the mesocotyl, while its trace runs upwards to the first node. In Avena the inversion of this trace, and its double character, suggest its origin from the two bundles of the stalk in a form such as $X$.

A third modification is necessary to convert the sheath of type $X$ into the coleoptile of the Avena type. The double scutellum trace, representing the two stalk bundles of $X$, divides at the node, and if each half-trace behaved as in $X$, it would run nearly to the top of the sheath, and turning sharply down again join the mesocotylar stele at the first node. The more acute the angle made by the half-trace on itself, the nearer would the ascending and descending segments lie to each other. If they approached so closely as finally to unite from first node to apex, the coleoptile bundles of Avena would be reproduced. That such fusion between two lengths of the same bundle may actually occur is shown in the sheath of Tigridia (Text-fig. 8, p. I68, and Pl. X, Fig. I5).

The two sheath-bundles of type $X$ finally enter the stele of the hypocotyl from opposite sides, and presumably remain distinct within it. In Avena the descending segments of the coleoptile bundles unite in the stele of the mesocotyl-the fourth modification required to convert type $X$ into the Avena type. But in the Zea type, best represented in this respect by Coix, no such alteration in structure is demanded. The coleoptile halftraces remain distinct in the stele; separated from each other by the ascending scutellum trace, which in this type is included within it.

We have implied throughout this discussion that the Avena type is the most primitive of the three described by Van Tieghem. Indeed, this conclusion follows from our conception of the mesocotyl. For if it represents the hypocotyl of a remote ancestor united with the stalk of its cotyledon, the two types possessing a mesocotyl are nearer to that ancestor than the third which has none. And in the Avena type the ancestral stalk is represented by a separate trace, which in the Zea type is absorbed in the stele of the hypocotyl. Thus on our hypothesis the vascular skeleton of the Avena seedling represents the ancestral type $X$ more completely than that of Zea or Sorghum.

But though, on the whole, the seedling skeleton of Avena sativa has more points which suggest the imaginary type $X$ than that of any other species we have examined, yet certain isolated characters are better repre- 
sented elsewhere. Thus the formation of the scutellum trace from the coleoptile bundles is better shown in Zizania aquatica, their double structure in Sorghum vulgare, and the coleoptile traces within the stele retain their identity longer in Coix Lacryma-Fobi.

Nor is it strictly accurate to say that the Triticum type can be derived from the Avena type in one way, and the Zea type in another. Our hypothesis is better formulated thus: the seedling skeleton of the common ancestor from which are descended all the genera we have examined probably resembled the Avena type in the possession of a mesocotyl, and in the less complete union of the two members from which it is derived. A greater number of the structural variations depending on these characters are found in the Avena type than in the others, and it may be called primitive with regard to them, since it approaches more nearly to our conception of an ancestral form within the Gramineae.

This ancestral form, which may be referred to as $G$, is not to be confused with type $X$ figured in Text-fig. 7, p. I66. $X$ has none of the anatomical features characteristic of the Gramineae, but illustrates a skeleton from which such features might be readily derived on the one hand, while on the other it has the seedling characters of a hypogeal Monocotyledon.

We shall now describe the seedling structure of certain Monocotyledons which approach more or less closely to the imaginary type $X$, in order to justify our use of that construction in explaining the anatomy of the Grass seedling. Before entering on this subject, however, we must explain the absence of any reference to the Cyperaceae. We naturally expected that the seedling structure of this family would throw light on that of the Grasses. But the vascular skeleton of the species we have examined is too much reduced to be significant. Even the seedlings of the comparatively robust Cyperus alternifolius, L., and C.natalensis, Hochst., are as small and tender as those of an aquatic plant.

We have already stated that Van Tieghem considered the mesocotyl to represent an elongated node, whereas we look on it as a fusion of the hypocotyl with part of the cotyledon. On either hypothesis the coleoptile of the Grass seedling is identified with the upper or stipular sheath.

An upper sheath is not universal even among hypogeal Monocotyledons, and cases in which it contains vascular tissue are comparatively rare outside the Glumiflorae. Such cases are, therefore, likely to be instructive, and we have already referred to some of them. We propose to discuss these and others in greater detail, beginning with the seedlings of Elettaria Cardamomum and its allies. 


\section{Zingiberaceae.}

Seedlings in spirit belonging to three genera from this family were sent from Kew in 1898 to one of us : Elettaria Cardamomum, Maton, Amomum angustifolium, Sonner, and Renealmia racemosa, A. Rich. Preparations from these species were made by Miss E. N. Thomas in the Reigate laboratory, and she also worked out the course of the bundles in the upper sheath, which is uniform in all three. Our thanks are due to her for permission to use her preparations and notes, including some drawings of the seedlings. We have since confirmed and extended her observations by cutting fresh seedlings of Elettaria, and also by examining Roscoea purpurea, Sm., Alpinia calcarata, Rosc., and Brachychilum Horsfieldii, O. G. Petersen. These seedlings we grew in a hothouse at Reigate, from seeds most kindly supplied by Mr. Lynch from the Botanic Garden at Cambridge. Thus we were able to examine and draw them in the fresh condition, besides pickling the important parts, the sheath and hypocotyl, in Merkel's solution. Material so treated gives far better results when microtomed than that preserved in spirit only.

Elettaria Cardamomum, Maton. The course of the bundles in the cotyledon is very characteristic. Text-fig. 30 (I), p. 210 , is a drawing of stalk and sheath from spirit material examined under the simple microscope. The course of the bundles in the sheath can be quite well followed by this method, and they are traced in the drawing. It will be seen at once that part of the sheath is above the insertion of the stalk, and part below it.

The stalk of the cotyledon contains two exarch collateral bundles, both of which enter the sheath. Their course within it is asymmetrical, for one bundle $(P)$ travels nearly to the top of the sheath before turning downwards, while the other $\left(P^{\prime}\right)$ turns down at once. We possess a complete series downwards, from the top of the same sheath which is drawn in I (Text-fig. 30), and can therefore reconstruct its vascular skeleton with certainty. The critical sections (II-V in Text-fig. 30) occur at the levels $a-\delta$ in $\mathrm{I}$.

Sections cut between the levels $\alpha$ and $\beta$ pass through bundle $P$ twice; once in its upward, and once in its downward course. Near a the two sections of this bundle lie close together, while lower down they move apart until they are separated by an angle of about $90^{\circ}$. Just below $\beta$, the bundle $P^{\prime}$ comes in, and in the following sections $P$ and $P^{\prime}$ are each cut twice: once in the sheath, and once in the stalk. From $\delta$ onwards the stalk has disappeared, and then the two sheath-sections only of $P$ and $P^{\prime}$ remain (V, Text-fig. 30 ).

Elettaria possesses a real hypocotyl; a region of appreciable length below the first node, in which the stele is stem-like. The hypocotyl varies 


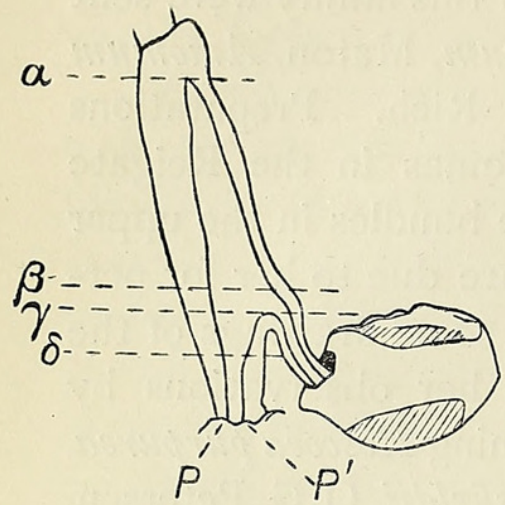

I.

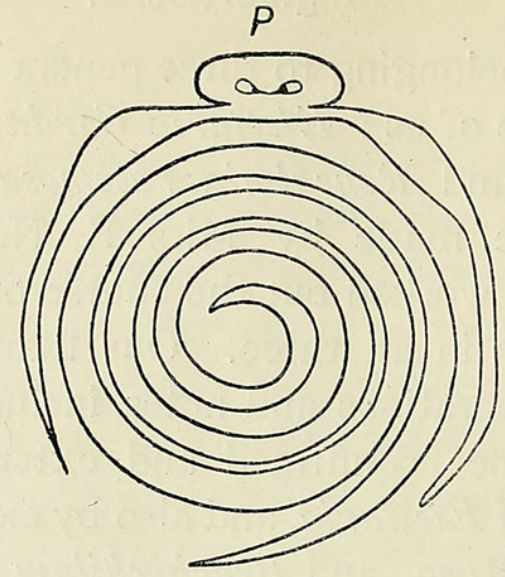

II.

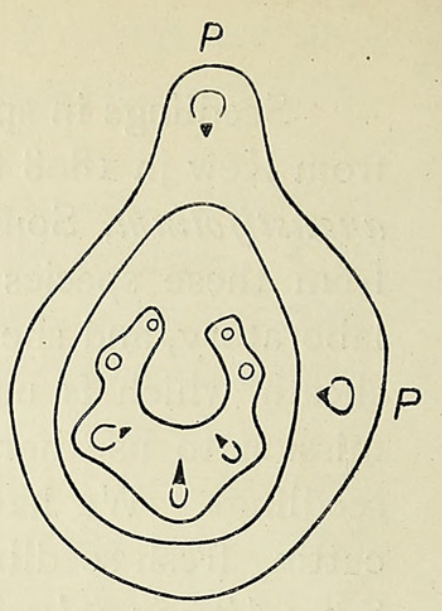

III.
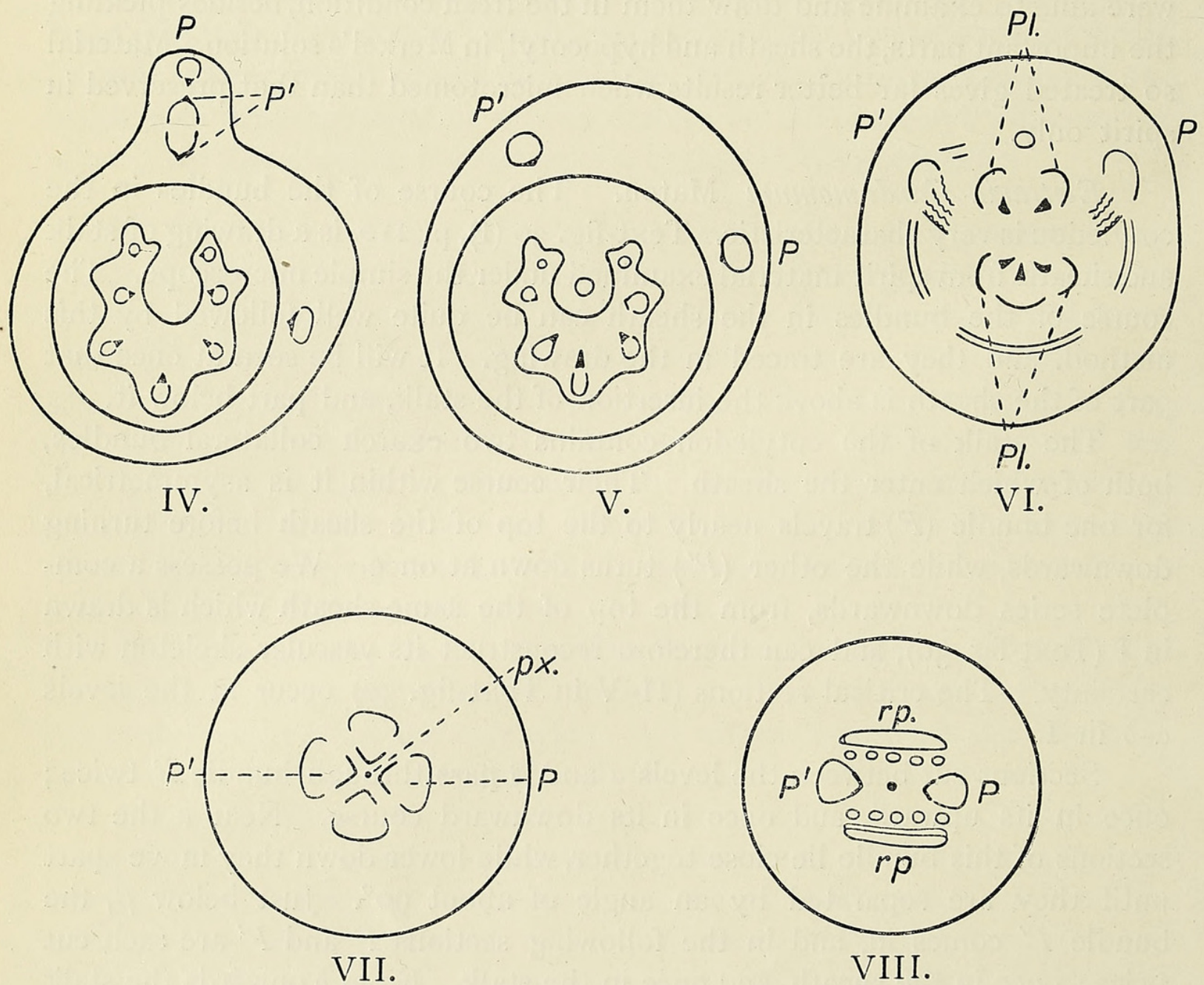

Text-Fig. 30. Elettaria Cardamomum, Maton. Structure of sheath and hypocotyl. I. Seed and sheath enlarged, showing course of cotyledonary bundles. II. Diagram of sheath at level $\alpha$. III. Diagram of sheath at level $\beta$. IV. Diagram of sheath at level $\gamma$. V. Diagram of sheath at level $\delta$. VI. Diagram of first node. VII. Diagram of hypocotyl (top). VIII. Diagram of hypocotyl (base). 
in length from $0.8 \mathrm{~mm}$. to about $\mathrm{I} .5 \mathrm{~mm}$. in the three seedlings from which we have fairly complete series.

In seedlings of the age shown in Text-fig. 30 , the first leaf has seven traces. The five larger run inwards at the second node, but each gives off one or two slender downward spurs before doing so. Hence a circle of seven or eight strands outside the stele of the first internode, in which the gap opposite the midrib is filled by the two marginal traces from the first leaf. These are still in their original position near the periphery of the section. They may unite to form a larger trace.

The traces in the stele just above the first node are reduced to five, arranged in two groups. The cotyledonary traces run in from either side between these two groups. But as they do so, each strand or trace in the outer circle extends itself tangentially, in such a way that the two cotyledonary traces are included in a vascular girdle which is concentric with the stele, but quite distinct from it. This girdle is shown in process of formation in VI, Text-fig. 30. In the Elettaria seedling on whose structure these diagrams are founded, the xylem of the girdle is unlignified except at one point, but we have found a girdle much better differentiated in Amomum (Pl. X, Fig. I3), and here the xylem is very well represented. The function of this girdle is probably to give rise to cauline roots, and its presence may indicate the approaching formation of a tuber.

At the top of the hypocotyl, as soon as all traces of the first node have disappeared, there are four massive phloem groups, each very distinctly triangular in transverse section. Two of these are cotyledonary, and they are diagonally opposite to each other. The two groups which separate them are derived from the plumule. The arrangement of xylem is characteristic. All the protoxylem elements form a little group in the centre of the stele. The internal angles of the four triangular phloem groups are bordered by metaxylem for some distance up each side. In the oldest seedling examined, the xylem has the form of a four-rayed star. Each ray is double, for it consists of metaxylem border from each of two adjacent phloem groups, separated by a strip of medullary tissue. Even in this seedling it is clear that the metaxylem bordering the plumular phloem is formed of elements larger and better lignified than that which borders the cotyledonary groups. This difference is more clearly marked in the younger seedlings, where much cotyledonary xylem is still unlignified.

Lower down, the symmetry of the stele alters, to provide for the insertion of cauline roots. The double rays become single by suppression of the medullary intervals, and then two parallel root-plates are formed from them. These root-plates are divided from each other by the cotyledonary bundles, which retain little or no metaxylem, but are each represented by a triangular patch of phloem and a small internal group of xylem elements, 
The two groups of plumular phloem are extended in strips, each external to a xylem plate (VIII, Text-fig. 30 ).

At a level very little below the formation of root-plates, the stele of the axis is completely masked by the repeated insertion of cauline roots. We could not determine in the descending series whether any one of the roots, all cut more or less obliquely, represented the primary root. It may perhaps never develop at all ; its functions being taken over at once by the cauline roots.

Amomum angustifolium, Sonner. Two seedlings were examined, both about the same age. That drawn by Miss Thomas in Text-fig. $3^{I}$ was cut

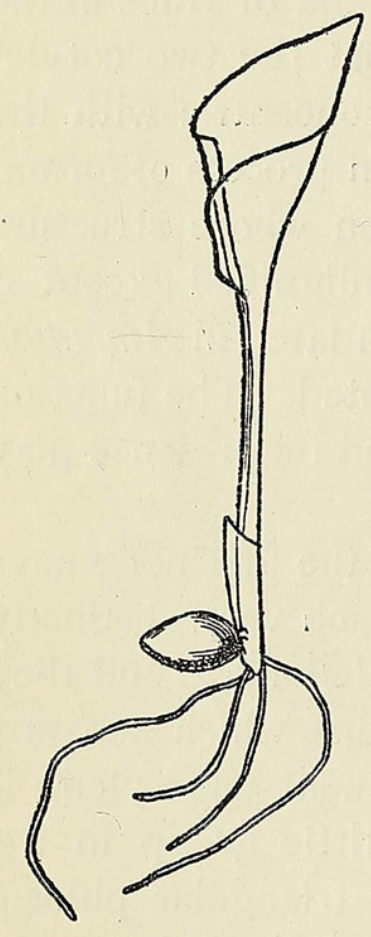

TeXT-Fig. 3 I. Amomum angustifolium, Sonner. Outline of seedling, slightly enlarged. by hand. The bundles of the cotyledonary sheath were previously traced by her under the simple microscope. From the other she cut a complete series of sections, beginning half-way down the upper sheath, and ending with the tangled insertions of cauline roots at the base of the hypocotyl.

The cotyledon of Amomum possesses two large bundles in its stalk; one of them runs nearly to the top of the upper sheath and then turns downwards, while the other hardly enters it. The vascular skeleton of stalk and sheath, indeed, is precisely that of Elettaria, and might be represented by Diagrams $\mathrm{I}-\mathrm{V}$, Text-fig. 30 , with a few alterations in matters of detail.

The cotyledonary bundles $P$ and $P^{\prime}$ enter the stele of the axis in the same way at the first node. The vascular girdle is better developed, perhaps because the seedlings are older than in Elettaria; and it seems as if $P$ and $P^{\prime}$ took an active share in its formation by branching to meet the cortical traces (Pl. X, Fig. I3). At the top of the hypocotyl, the formation of a xylem star with double rays is even clearer than in Elettaria (P1. X, Fig. I4); but it passes over into the single-rayed form more quickly, and this persists longer. The formation of root-plates is obscure; before they are well defined, the stele is lost among cauline root-insertions. We could not determine whether the primary root was undeveloped, or whether it existed but was hopelessly lost in the series among the sections of cauline roots.

Renealmia racemosa, A. Rich. Two seedlings were cut by Miss Thomas from spirit material. The series from the first is fairly complete from insertion of stalk downwards, but the xylem is very little lignified. 
The second series is very incomplete, but serves to confirm the first, and in some cases to explain it, as the tissues are better differentiated.

The bundles of the upper sheath behave as in Elettaria and Amomum. The lower sheath is comparatively short. The cotyledonary traces $P$ and $P^{\prime}$ enter the stele of the hypocotyl as usual from either side. In this species the plumular traces seem to form three groups in place of two. In both the seedlings examined there were five traces at the top of the hypocotyledonary stele; in one of them the fivefold symmetry was retained throughout, in the other it became fourfold lower down. The protoxylem forms a single group in the centre. No well-marked root-plates are formed. The cauline roots arise from the base of the hypocotyl.

Roscoea purpurea, Sm. The cotyledon in this species differs from that of Elettaria in the structure of its sheath. Of the three seedlings examined by us, we find two with no lower sheath, and the third with a very short one. The upper sheath is very well developed in all three seedlings, and its vascular skeleton corresponds exactly with that of the upper sheath in Elettaria.

The vascular structure of the hypocotyl and first node differ in the two genera, but the points of difference are clearly correlated with the presence or absence of a lower sheath. Thus in that seedling of Roscoea which has a lower sheath, though a very short one, and is therefore nearest to the Elettaria type, there are about a hundred sections in which the upper sheath corresponds in structure to Diagram III in Text-

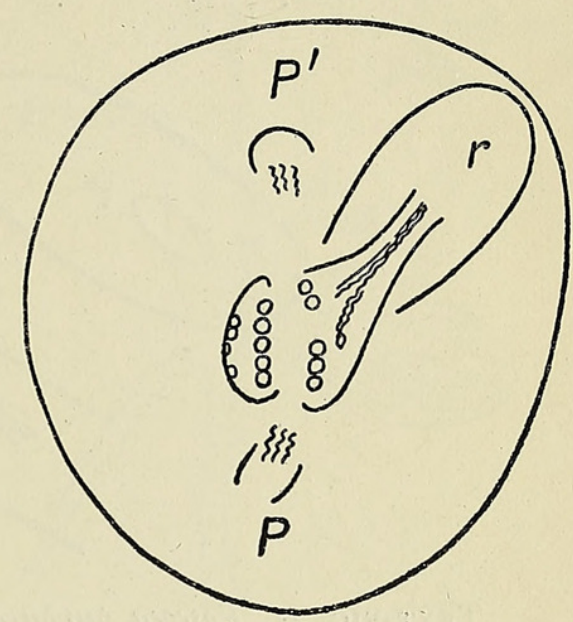

TeXT-FIg. 32. Roscoea purpurea, $\mathrm{Sm}$. Diagram of first node in one seedling, corresponding to level VI in Text-fig. 30 .

fig. 30 , except that in the lower ones the bundles are separated more widely. But whereas in Elettaria only the first leaf is enclosed by this region of the sheath, in Roscoea we find sections of the plumular axis. The length enclosed is about I mm.; it begins at the base of the plumular bud, and ends in the first internode. The single sheath section which corresponds to IV, and the few below it which represent V, still enclose sections of the first internode. In Roscoea cauline roots are formed above the first node, and they penetrate the sheath in region $\mathrm{V}$.

Thus the cotyledonary traces $P$ and $P^{\prime}$ run into a stele which is already giving off cauline roots, and has formed root-plates. In place of Diagram VI in Text-fig. 30 we have Text-fig. $3^{2}$. There is no level in this seedling which corresponds to VII. In the intervals between the insertion of cauline roots, the stele of the hypocotyl resembles VIII in structure, though the 


\section{Sargant and Arber.-The Comparative Morphology of}

orientation is different. For in Elettaria the bundle $P^{\prime}$ travelled through an angular distance of about $90^{\circ}$ in the sheath before running into the stele. Taking the insertion of the stalk on the sheath as a fixed point, and making the diameter of the section which passes through it vertical, the cotyledonary traces $P$ and $P^{\prime}$ in VIII lie on the horizontal diameter. But in Roscoea the trace $P^{\prime}$ runs straight into the stele from the stalk, and $P$ travels round to the opposite extremity of the vertical diameter before entering the stele.

In the two other Roscoea seedlings there is no lower sheath at all, which leads to greater modification in the vascular skeleton. The insertion of the upper sheath coincides with level IV, and the section of $P^{\prime}$ which appears in

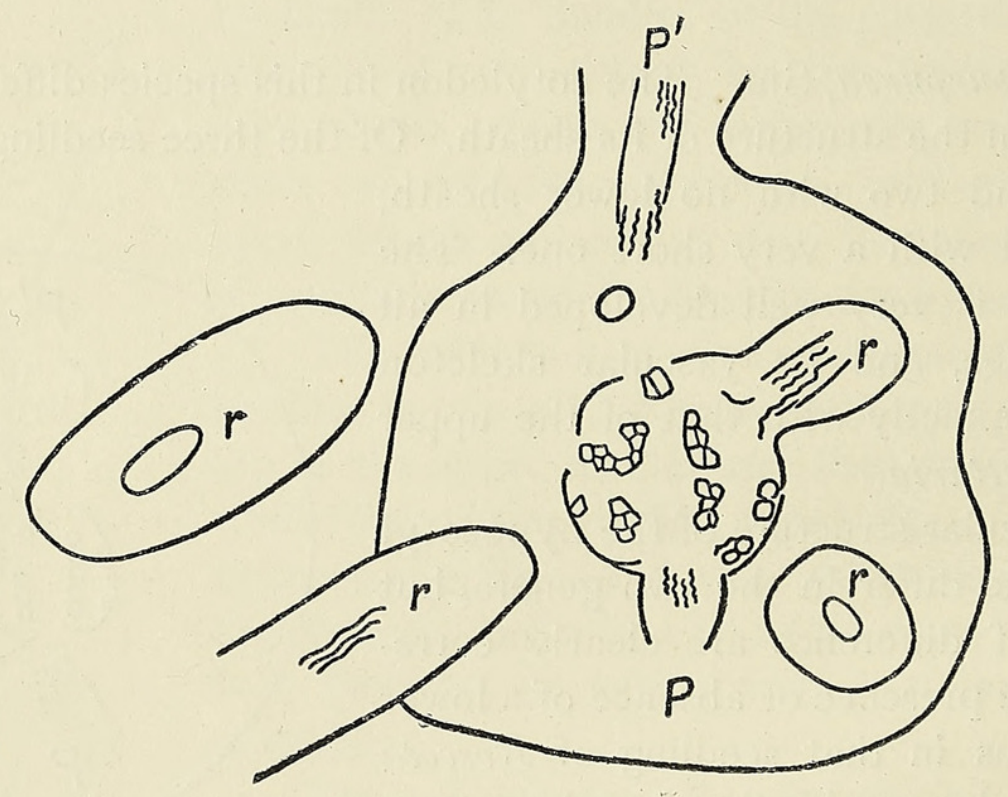

TeXT-FIG. 33. Roscoea purpurea, Sm. Diagram of first node in two other seedlings.

the sheath is already running into the stele of the axis (Text-fig. 33). Root-plates are formed early, to correspond with the great development of cauline roots at the node $(r, r, r, r)$. In one seedling the plates are found above the node; in the other they begin just below it. Between root-insertions the root-plates sometimes break up. Sections can be found which suggest the symmetrical arrangement of VII in the Elettaria diagrams.

Though we have used Diagrams VII and VIII from Elettaria to explain the structure of Roscoea, there is one great difference between the two genera. In all three Roscoea seedlings the central group of protoxylem is absent. Each root-plate and each cotyledonary trace retains its own protoxylem, which is more or less definitely internal to the other elements.

Alpinia calcarata, Rosc. We have made preparations from four seedlings, and drawings of five. They are small compared with those of Elettaria. The cotyledonary sheath is short, and the plumule very soon 
emerges from it. The first foliage leaf of the plant is the second in order on the axis, for the first is reduced to a mere sheath.

Two distinct bundles enter the stalk of the cotyledon from the sucker. ${ }^{1}$ The stalk is inserted rather above than below the junction of sheath with axis. There is no true lower sheath. In three seedlings the upper bundle $P$ runs a little way into the upper sheath before it turns down to join the axis. In the remaining seedling, the youngest, $P$ runs up from the stalk, and continues its course through the sheath into the axis. The second bundle, $P^{\prime}$, commonly enters the axis from the stalk below the apparent insertion. Since $P$ and $P^{\prime}$ enter the stele from opposite sides, one or other of them must skirt it for some distance before turning in.

The stele of the hypocotyl is cut so obliquely in the three older seedlings, that its structure cannot be deciphered. In the youngest seedling, the traces settle down to three endarch bundles, which seem to correspond in position to the midrib and lateral bundles of the second leaf. They are separated by three rays of medullary tissue, forming angles of about $120^{\circ}$ with each other. $P$ enters by one of the two rays which border the midrib of the second leaf, and $P^{\prime}$ by the other. The third ray remains clear. Below this level the stele of this seedling too is bent, and the sections of it hopelessly oblique. Apparently there would be five bundles at the top of the hypocotyl, as in Renealmia.

Brachychilum Horsfieldii, O. G. Petersen. Preparations were made from five

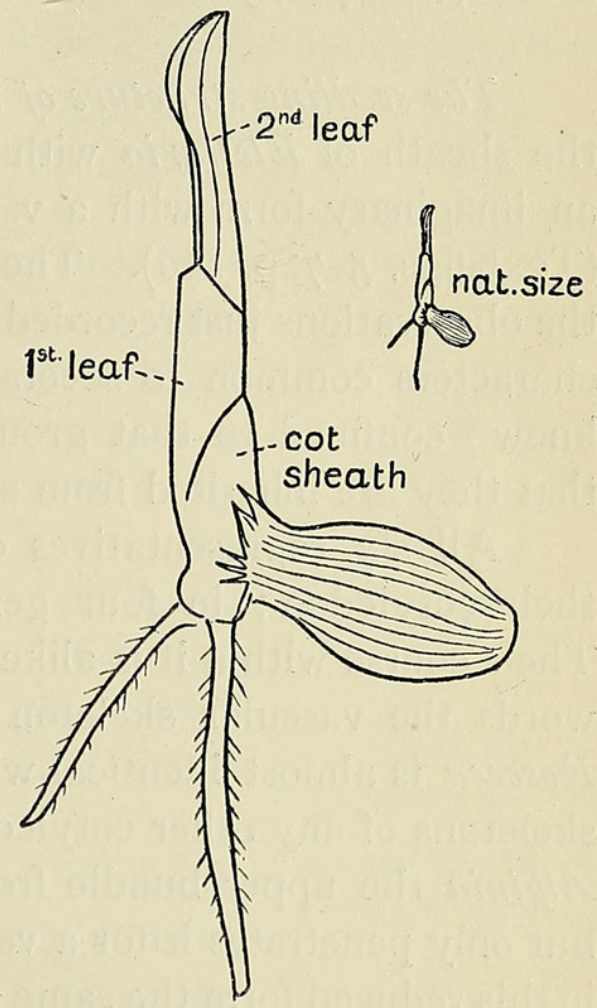

TeXT-FIg. 34. Brachychilum Horsfeldii, O. G. Petersen. Outlines of seedling, life-size and enlarged. seedlings by one of us, including complete series through the cotyledonary sheath in four of them. The cotyledon is inserted partly on the sheath and partly on the axis as in Alpinia. The first leaf is reduced to a mere sheath (Text-fig. 34).

There are two distinct bundles in the apex of the cotyledon, and they run side by side through the stalk into the axis. In three seedlings neither bundle enters the sheath at all; in the fourth, one trace $(P)$ lies rather above the other, and it curves upwards into the base of the sheath, just entering it before turning back into the axis. The short upper sheath,

1 For apparently mesarch structure of stalk-bundles in Alpinia, Brachychilum, and Roscoea, see E. M. Berridge in Ann. of Bot., vol. xxiv, p. 485 , I9 Io. 


\section{I6 Sargant and Arber.-The Comparative Morphology of}

indeed, may be said to be without vascular tissue even in this case. In the others, $P$ and $P^{\prime}$ alike run upwards from the stalk of the cotyledon into the stele, diverging as they penetrate the axis in order to enter the stele at different points.

In two seedlings the stele of the hypocotyl is cut transversely where $P$ and $P^{\prime}$ enter it. In both cases the three plumular bundles correspond in position to the principal traces of the second leaf. The cotyledonary traces enter on either side of the midrib. Thus there are five traces at the top of the hypocotyl, but they cannot be followed downwards in any series of preparations which we possess, partly because the hypocotyl is always curved, and partly on account of the numerous root-insertions.

The seedling structure of the Zingiberaceae. We have already compared the sheath of Elettaria with the coleoptile of Avena, and have constructed an imaginary form with a vascular skeleton intermediate between the two (Text-figs. 5-7, p. I66). The force of this comparison is much increased by the observations just recorded on five other genera of the Zingiberaceae. For characters common to several genera within a family, and-so far as we know-confined to that group, are probably ancient. The presumption is that they are inherited from a common ancestor.

All six representatives of their genera have two distinct bundles in their cotyledon; in four genera these bundles enter the upper sheath. Their course within it is alike in all four, and very characteristic. In other words the vascular skeleton of the sheath in Amomum, Renealmia, and Roscoea is almost identical with that of Elettaria, and is different from the skeletons of any other cotyledonary sheaths which we have examined. In Alpinia the upper bundle from the cotyledon sometimes enters the sheath, but only penetrates it for a very short distance before turning back. Even in this reduced form the same asymmetric type of skeleton can be recognized. In Brachychilum the short upper sheath contains no bundles.

These genera have other anatomical characters in common. The first node is alike in all of them. The cotyledonary traces enter the stele of the axis from opposite sides, making an angle of at least $120^{\circ}$ with each other. They take their place among the two or three plumular traces which are continued downwards. In all the species examined, except Roscoea purpurea, a common group of protoxylem is found in the centre of the hypocotyledonary stele, which recalls the common group formed by the junction of $P, P^{\prime}$, and $M$ in the mesocotylar stele of Coix. This afterwards breaks up into the groups $p x_{1}$ and $p x_{3}$ (p. I98).

Cauline roots are given off freely in the neighbourhood of the first node, and sometimes lower down. The well-defined root-plates found in the hypocotyl of Elettaria (Text-fig. 30, VIII), Amomum, and Roscoea recall the root-plates in the mesocotyl of Avena and other Grasses. 
The upper sheath in the Zingiberaceae, when it contains any vascular tissue at all, is stiffened by one of the bundles which enter it from the stalk of the cotyledon. After running obliquely upwards, this bundle turns sharply down, and enters the axis from the base of the sheath. No part of such a bundle passes directly from stalk to axis. The second bundle may do so (Roscoea, Alpinia), or it may just enter the upper sheath on the side opposite the first bundle, and then turn downwards through the lower sheath to the axis (Elettaria, Amomum, Renealmia). But all the bundles found in the upper sheath enter it from the stalk of the cotyledon, and leave it on their way to the hypocotyl. The same is true of Tigridia (Text-fig. 8, p. I68) and of Commelina coelestis, which we are about to describe. But this form of vascular skeleton is not universal in the upper sheath of Monocotyledons. We shall describe the seedling of Colchicum autumnale as an example of another type.

Commelina coelestis, Willd. The lower sheath is long, and consists of the cylindrical base of the cotyledon enclosing the plumule. Above it is the upper sheath, which forms a hood and seems to have arisen from a sharp twist in the stalk of the cotyledon, just where it was spreading out into a simple sheathing base (Text-fig. 35 ). Two main bundles enter the sheath from the stalk, and behave very much like those of Elettaria. The upper bundle $(P)$ travels nearly to the top of the hood before bending back to the axis, while the lower one $\left(P^{\prime}\right)$ turns down almost as soon as it enters the sheath. ${ }^{1}$ One or two additional bundles are sometimes found in sheath or stalk, but they are slender and end blindly, and are

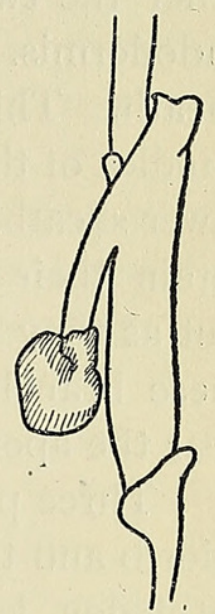

TEXT-FIG. $\quad 35$. Commelina coelestis, Willd. Outline of sheath and adjacent parts ; enlarged. probably mere mechanical stiffenings, produced where they are needed.

In Commelina the asymmetrical course of the two main bundles is probably due to the distortion of the originally simple sheath. After they have traversed the lower sheath, they approach the stele of the axis from opposite sides as in Elettaria. Two plumular traces are present at the first node, but there the resemblance ends. The plumular traces insert themselves on $P$ and $P^{\prime}$, each of which becomes double. These double bundles face each other throughout the rather long hypocotyl, and ultimately form a tetrarch root. The anatomy of the hypocotyl is precisely that of some Dicotyledons, as for example Althea. ${ }^{2}$ The details of transition to a rootstructure are masked by the insertion of cauline roots.

1 Attention has been drawn to the asymmetrical behaviour of the two bundles in the cotyledon sheath of another species of this genus by Martha H. Hollinshead: Notes on the Seedling of Commelina communis, L. Contributions from the Botanical Laboratory of the University of Pennsylvania, vol. iii, No. 3, p. 275 , I9I I.

${ }^{3}$ Gérard, R.: Ann. des sci. nat., sér. vi, Bot., t. xi, P1. XVI, Fig. 23, I88I. 
Colchicum autumnale, L., is an example of a hypogeal Monocotyledon in which the very well developed upper sheath is stiffened by branches from the cotyledonary bundles, and not by the bundles themselves. We have examined two seedlings of this species. The upper sheath is stiff, long, and sharply pointed. The lower sheath is cylindrical and of some length. The primary root is stout and long ; cauline roots do not appear early.

We have complete series of sections from both seedlings, beginning in the upper sheath, and passing downwards, through the insertion of the stalk and the lower sheath, to the junction of sheath and axis, and the formation of the primary root. The only anatomical difference between the two seedlings is that in one of them there are two distinct bundles in the stalk of the cotyledon, each surrounded by its own endodermis, and that in the other the two stalk-bundles are in contact, and surrounded by a common endodermis. In fact, they form a typical double bundle as they enter the sheath. This difference is not so great as it may seem, for the distinct bundles of the first seedling also form a double bundle when they enter the lower sheath. In both seedlings the stalk bundles turn into it at once, and retain their characteristic double appearance until they enter the axis. But as they turn, each gives off a slender branch to the upper sheath, and these branches divide again on their upward way. They all end blindly near the apex of the sheath which they serve to stiffen.

Three plumular traces are found at the first node. They represent the midrib and two lateral traces from the first leaf. The double bundle of the cotyledon is inserted on them, but it does not affect the symmetry of the triarch root-stele. The transition to root structure is extremely rapid, and the plumular phloem groups retain their position throughout.

\section{General Conclusions from Part II.}

In the introduction to this Part (pp. 206-8) we considered how far the evidence given in Part I could be used to support our interpretation of the Grass embryo and seedling. That interpretation has been outlined at the beginning of this memoir (pp. 164-9). It is illustrated there by the construction of an imaginary type $X$, linking the Avena type, which we consider as the most primitive of the three distinguished by Van Tieghem in the Gramineae, with the seedling skeleton of a real hypogeal Monocotyledon, Elettaria.

The evidence given in Part I refers to the structure of Grass seedlings only. In discussing it, we have tried to show that all Van Tieghem's types could be derived from the imaginary skeleton $X$, without any unprecedented or even improbable changes in structure. In Part II we have described seedlings from other families, whose vascular structure approaches that of $X$, and this evidence, too, must be summed up. 
The examination of monocotyledonous seedlings with a well-developed upper sheath shows that this sheath does not always contain vascular tissue. Among the species that do, we find two forms of vascular skeleton. The bundles entering the upper sheath may be branches from those which pass from cotyledon to hypocotyl, and then they end blindly near the top of the sheath (Colchicum). Or the bundles from the cotyledon may themselves enter the sheath, and after a longer or shorter course within it, turn down through the lower sheath to the axis (Elettaria, Commelina, Tigridia). We have described many more examples of the second form than of the first, because the second approaches the imaginary type $X$ from which the vascular skeleton of the coleoptile can be derived. In particular, this form of sheath is found in several genera within the Zingiberaceae. ${ }^{1}$ We may conclude that this form of vascular skeleton is inherited from some ancestor common to at least some of the genera within the Zingiberaceae. This is the more probable, as the structure of the first node and hypocotyl is also fairly uniform in these genera.

The resemblance between the embryo of Canna and that of the Grasses, already pointed out by Hegelmaier ('74, p. 669), is interesting in this connexion, since the Cannaceae are closely related to the Zingiberaceae.

The geographical distribution of the Zingiberaceae indicates that it is an ancient group, ${ }^{2}$ and the type of seedling skeleton which is primitive within it probably goes back to an early form of Monocotyledon. This makes the resemblance to the skeleton of Grass seedlings more suggestive, particularly as the likeness extends to first node and hypocotyl.

Schumann points out the remarkable similarity in vegetative characters between the Zingiberaceae and the Gramineae, ${ }^{3}$ but he does not therefore assume any genetic connexion. The Scitamineae on the one hand, ${ }^{4}$ and the Glumiflorae on the other, ${ }^{5}$ are generally considered as natural divisions of the Monocotyledons, without clear affinities to other groups. Both are probably related to the Liliiflorae. ${ }^{6}$

Even if no simple degree of relationship through a common ancestor should be discovered to explain the characters which the Zingiberaceae have in common with the Gramineae, it does not therefore follow that the sheath structure of one group may not illustrate that of the coleoptile in the other. More than one descendant from the prototype of the Liliiflorae may have stiffened its upper sheath by the entrance of whole bundles from the sucker

1 In the six we have cut, the only exception is Brachychilum, in which the sheath contains no vascular tissue at all.

${ }^{2}$ Schumann, K. : Engler's Pflanzenreich, iv. 46 ; Zingiberaceae, p. 27 , 1904.

${ }^{3}$ Schumann, K.: 1. c., p. 3.

${ }^{4}$ Petersen, O. G. : Engler's Pflanzenfamilien, ii, Abth. 6, p. 38, 1889.

${ }^{5}$ Hackel, E.: Engler's Pflanzenfamilien, ii, Abth. 2, p. I6, I887.

${ }^{6}$ Wettstein, R. : Handb. d. syst. Bot., Aufl. 2, p. 782, I9I I. 


\section{Sargant and Arber.-The Comparative Morphology of}

and stalk of the cotyledon, on their way to join the stele of the hypocotyl. The Zingiberaceae may represent one of those forms, the Gramineae another ; and the comparatively simple sheath of Elettaria may still serve to indicate the manner in which the coleoptile of Avena was evolved through a distinct line of descent.

The sheath of Commelina may represent an early stage in the evolution of the coleoptile, demonstrating how it might be derived from the simple sheathing base of the cotyledon, in the most usual form of epigeal germination (Allium, Anemarrhena, \&c.). And in this genus, too, interest is at once aroused and baffled by the existence of apparently primitive characters. We have already remarked on the anatomy of the hypocotyl, which is that of a typical Dicotyledon. Solms-Laubach has shown that the stem apex in the embryo of Commelina is terminal like that of a Dicotyledon, while in the typical Monocotyledon it is lateral. ${ }^{1}$

In conclusion, we think that the key to the morphology of the Grass embryo lies in the morphology of its seedling, as interpreted by comparison with the seedlings of other Monocotyledons. This comparison is not easy, for the anatomy of the Grass seedling is complicated, and very distinct variants are found within the family. We have shown that all these variants can be derived from an imaginary type $X$ (Text-fig. 7, p. I66). The scutellum then represents the sucker of the $X$ cotyledon, and the coleoptile its sheath, and in both cases this is the most natural interpretation of their anatomy. The vascular skeleton of $X$ is that of a hypogeal Monocotyledon, and is sufficiently near that of the Zingiberaceae to be derived from it without difficulty. But to derive the vascular skeleton of the Avena type from that of $X$ requires one considerable assumption; that the stalk which should connect scutellum with coleoptile has become united with the hypocotyl.

We maintain that the mesocotyl is more likely to have arisen in this way than as the elongated node, which Van Tieghem suggested ('72). The latter hypothesis does not explain the presence of the inverted trace found within the mesocotyl of certain forms by previous observers. ${ }^{2}$ On our view this trace represents the stalk, and is the last vestige of its independence.

1 Wettstein (1. c., p. 8II) remarks on the affinities of the Enantioblastae, including the Commelinaceae, with the Liliiflorae on the one hand and the Gramineae on the other.

2 Miss Lewin ('87, p. 22 and Pl. III, Fig. 46); Bruns ('92, p. 23); Schlickum ('96, p. $5^{8}$ and P1. V, Figs. 147,157$)$. 


\section{List in Chronological Order of the Principal Papers Relating to the Embryo and SeEdling of the GRAmineae Which have APPEARED SINCE I 872.}

Van Tieghem, Ph. ('72): Observations anatomiques sur le cotylédon des Graminées. Ann. des sci. nat., sér. v, Bot., t. xv, pp. $236-76,2$ pl., 1872.

Hegelmaier, F. ('74) : Zur Entwicklungsgeschichte monokotyledoner Keime, nebst Bemerkungen über die Bildung der Samendeckel. III. Triticum vulgare. Bot. Zeit., xxxii, pp. 657-68, I pl., I874.

Warming, E. ('79-'80): Forgreningen og Bladstillingen hos Slægten Nelumbo. Videnskab.

- Meddell. fra den naturh. Foren. Kjöbenhavn, I879-80, pp. 444-55, I pl., I text-fig. (The anthor's views regarding the Grass embryo are explained in a footnote to pp. 446-8.)

KLEBS, G. ('85): Beiträge zur Morphologie und Biologie der Keimung. Untersuchungen aus dem Botanischen Institut $z u$ Tübingen, Bd. i, Heft 4, pp. 536-635, 24 text-figs., I 885 .

Lewin, M. ('87) : Bidrag till Hjertbladets Anatomi hos Monokotyledonerna. Bihang till K. Svenska Vet.-Akad. Handlingar, Bd. xii, Afd. iii, No. 3, 28 pp., 3 pl., I 887 (for I 886 ).

Hackel, E. ('87): Gramineae, in Die natürl. Pflanzenfamilien, von A. Engler und K. Prantl. Teil ii, Abth. ii, pp. I0-I 4,1887 .

Tschirch, A. ('90): Die Saugorgane der Scitamineen-Samen. Sitzungsber. d. k. preuss. Akad. d. Wissenschaften zu Berlin, Jahrg. 1890, Erster Halbband, pp. 13I-40, I890.

Bruns, E. ('92) : Der Grasembryo. Flora, Bd. lxxvi (Ergänzungsband zum Jahrg. I892), pp. I-33, $2 \mathrm{pl}, \mathrm{1} 892$.

Schlickum, A. ('96) : Morphologischer und anatomischer Vergleich der Kotyledonen und ersten Laubblätter der Keimpflanzen der Monokotylen. Bibliotheca Botanica, Bd. vi, Heft 35, 88 pp., 5 pl., I 896.

Celakovský, L. J. ('97): Ueber die Homologien des Grasembryos. Bot. Zeit., lv, Abth. I pp. I4I-74, I pl., I 897 .

Van Tieghem, Ph. ('97): Morphologie de l'embryon et de la plantule chez les Graminées et les Cypéracées. Ann. des sci. nat., sér. viii, Bot., t. iii, pp. 259-309, I897.

Sargant, E., and Robertson, A. ('05) : The Anatomy of the Scutellum in Zea maïs. Ann. of Bot., vol. xix, pp. I1 5-123, I pl., I 905 .

Kirchner, O. von, LOEW, E., and Schröter, C. ('08-'12) : Lebensgeschichte der Blütenpflanzen Mitteleuropas. Bd. i, Abt. ii, Bogen I-I8. Gramineae, pp. I-288, 399 text-figs., I908, 1909, I9I2.

\section{EXPLANATION OF FIGURES IN PLATES IX, X.}

Illustrating the paper by Miss Sargant and Mrs. Arber on the Comparative Morphology of the

Embryo and Seedling in the Gramineae.

The lettering throughout the Plates is uniform: sc., main bundle of scutellum; $s c^{\prime}$., trace of scutellum in axis ; $P, P^{\prime}$, coleoptile bundles; $M$, midrib of first leaf; $L_{1}, L_{2}, L_{3}$, lateral traces from first leaf on one side of $M ; L_{1}^{\prime}, L_{2}^{\prime}, L_{3}^{\prime}$, lateral traces from first leaf on other side of $M$; $r$., $r$., cauline roots ; $r x$., root-xylem; $r p$., $r p$., root-plates.

\section{PLATE IX.}

Avena sativa, $\mathrm{L}$.

Fig. I. Coleoptile bundle from transverse section through young seedling, in which plumule is entirely enclosed within coleoptile. The phloem groups are deeply stained because they are full of proteids, and they are quite distinct ( $\left.p h_{.}, p h_{.}\right)$. One group of protoxylem $\left(p x_{0}\right) . \quad \times 25^{\circ}$. 
Fig. 2. Transverse section of coleoptile bundle from older seedling. Two groups of metaxylem (met., met.), and scattered $p x$. elements between them. $\quad \times 250$.

Fig. 3. Transverse section of first node from same seedling as Fig. 2. Xylem of $P$ and $P^{\prime}$ is branching : the outward branches will form xylem of $s c^{\prime}$; the inward branches that of the coleoptile trace within the stele $\left(x_{0}\right) . \quad \times$ I 55 .

Fig. 4. Mesocctyl of same seedling a little below the first node. Traces $M$ and $x$ face each other in the stele; they are bordered by a well-defined root-plate on either side. The inverted scutellum trace $\left(s c^{\prime}\right)$ is quite distinct from the stele. $\times 64$.

Fig. 5. Stele and scutellum trace more highly magnified a little below Fig. 4 in the same seedling. Scutellum trace with two distinct phloem groups, two groups of metaxylem, one of protoxylem. Root-plates very clear $(r p ., r p$.$) in stele. \times \mathrm{I}_{5} \mathrm{O}$.

\section{Zizania aquatica, L.}

Fig. 6. Drawing of seedling, life-size. A., grain; R., primary root; Ep., epiblast; Pl., plumule; col., coleoptile. The dotted line $A . A$. indicates level of Figs. 7 and 8.

Fig. 7. Diagram of first node from seedling drawn in Fig. 6. The section is taken at level A.A. (Fig. 6). Lettering as in Avena. $\times 40$.

Fig. 8. Detail of the space enclosed by dotted lines in Fig. 7. Letters as before. $\times 240$.

PLATE X.

\section{Zizania aquatica, L.}

Fig. 9. Vascular girdle from older seedling. The coleoptile traces $P$ and $P^{\prime}$ have not yet entered the stele. They are approaching it in direction indicated by arrows. Cauline root given off at $r . \times 66$.

$$
\text { Sorghum vulgare, Pers. }
$$

Fig. I0. Mesocotyl of young seedling drawn in Text-fig. 20, p. I86. Transverse section a little above insertion of scutellum. $\times 260 . p x_{1}$. , protoxylem of scutellum trace within stele; $p x_{2} .$, protoxylem of downward coleoptile traces ; $p x_{3}$., protoxylem of $M$, which is midrib of first leaf; $r x$., $r x$., 'sentinel vessels' of root-xylem.

Fig. II. Coleoptile bundle from older seedling. Two phloem groups very distinct. $\times 320$.

Fig. I2. First node, from same seedling as Fig. II. The xylem of the coleoptile bundles $P$ and $P^{\prime}$ forms a bridge across the stele. Some thin-walled elements of large lumen appear at periphery of stele (root-xylem). $\times 75$.

\section{Amomum angustifolium, Sonner.}

Fig. I3. Transverse section just above first node. $P$ and $P^{\prime}$ are branching to meet cortical traces. The xylem girdle is nearly complete on one side; on the other there is an isolated cortical bundle (c.), which links up with the girdle a few sections lower in the series. $\quad \times 190$.

Fig. I4. Hypocotylar stele of same seedling from same series, not far below first node. Large group of protoxylem, common to all the traces, in centre. The arrows $(m . r$.$) point to pathways of$ clear tissue dividing the traces, and partially bordered on either side by metaxylem. $\times$ I 90.

\section{Tigridia Pringlei, S. Wats.}

Fig. I 5. Transverse section through bundle of cotyledonary sheath in upper part of its course. It has doubled on itself, and its protoxylem is cut twice ( $p x$., $\left.p x_{\text {. }}\right)$, once going upwards, and a second time on its return. Lower down, the two segments separate. (Compare Text-fig. 8, p. I68.) $\times 260$. 
Anrals of Botany,
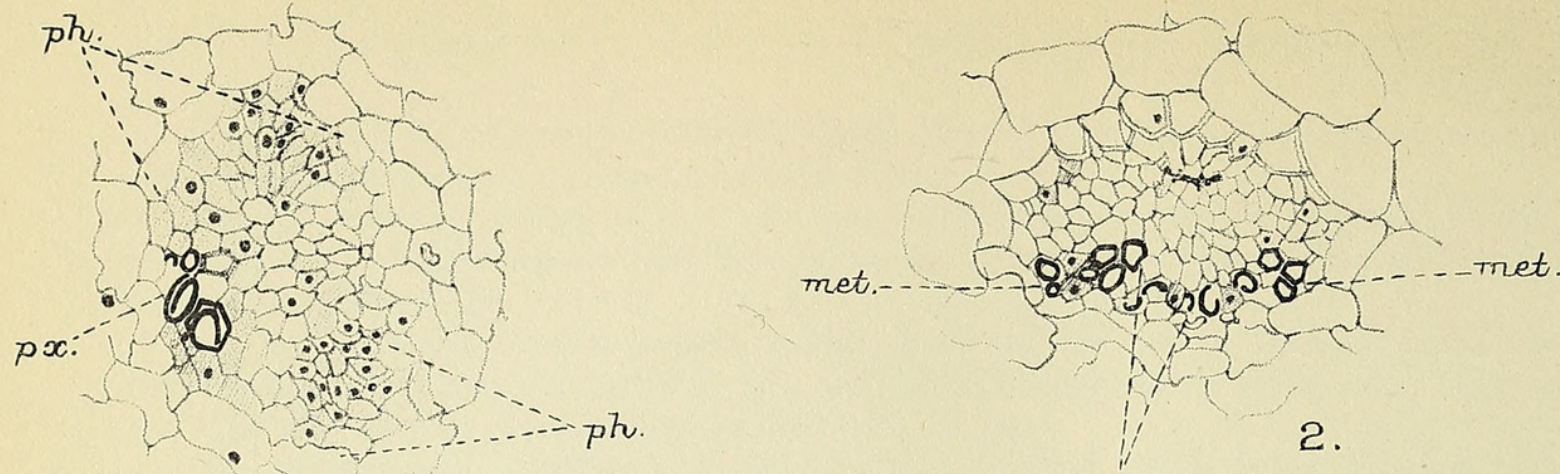

1.

2.

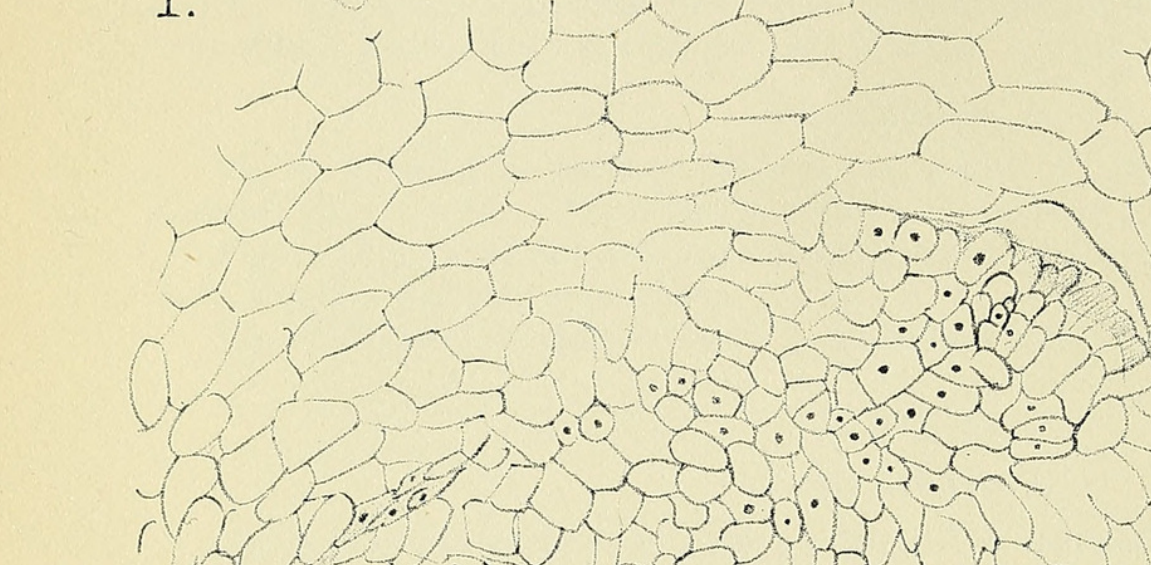

Ha 35

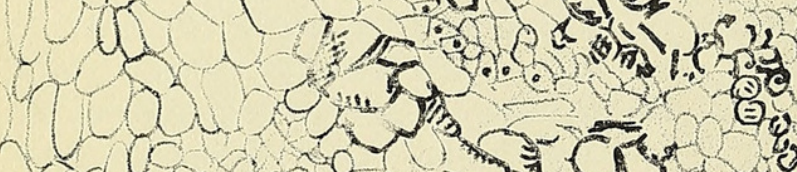

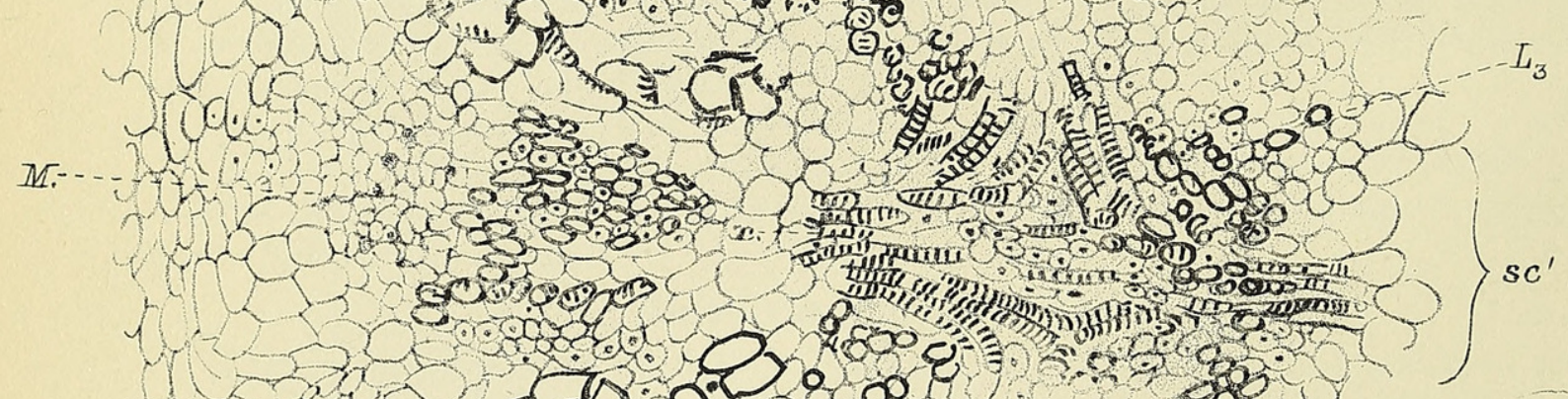

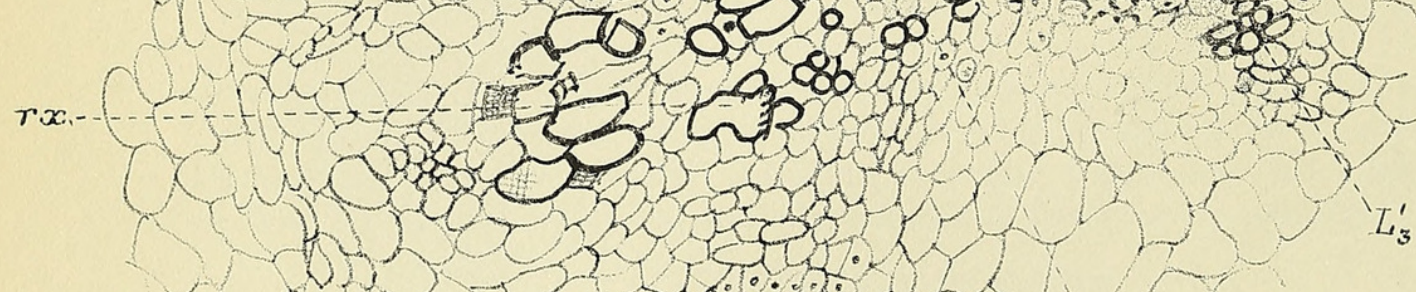

$I_{2}$

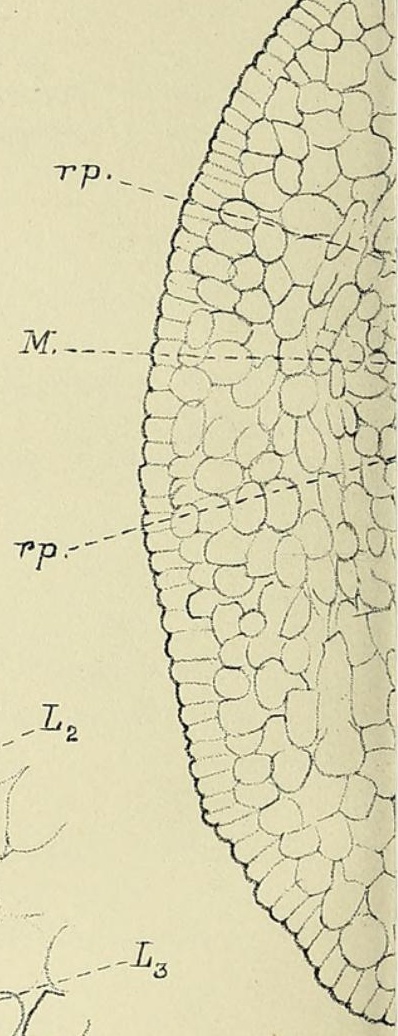


Anrals of Botany,

Vol. XXIX,Pl.IX.

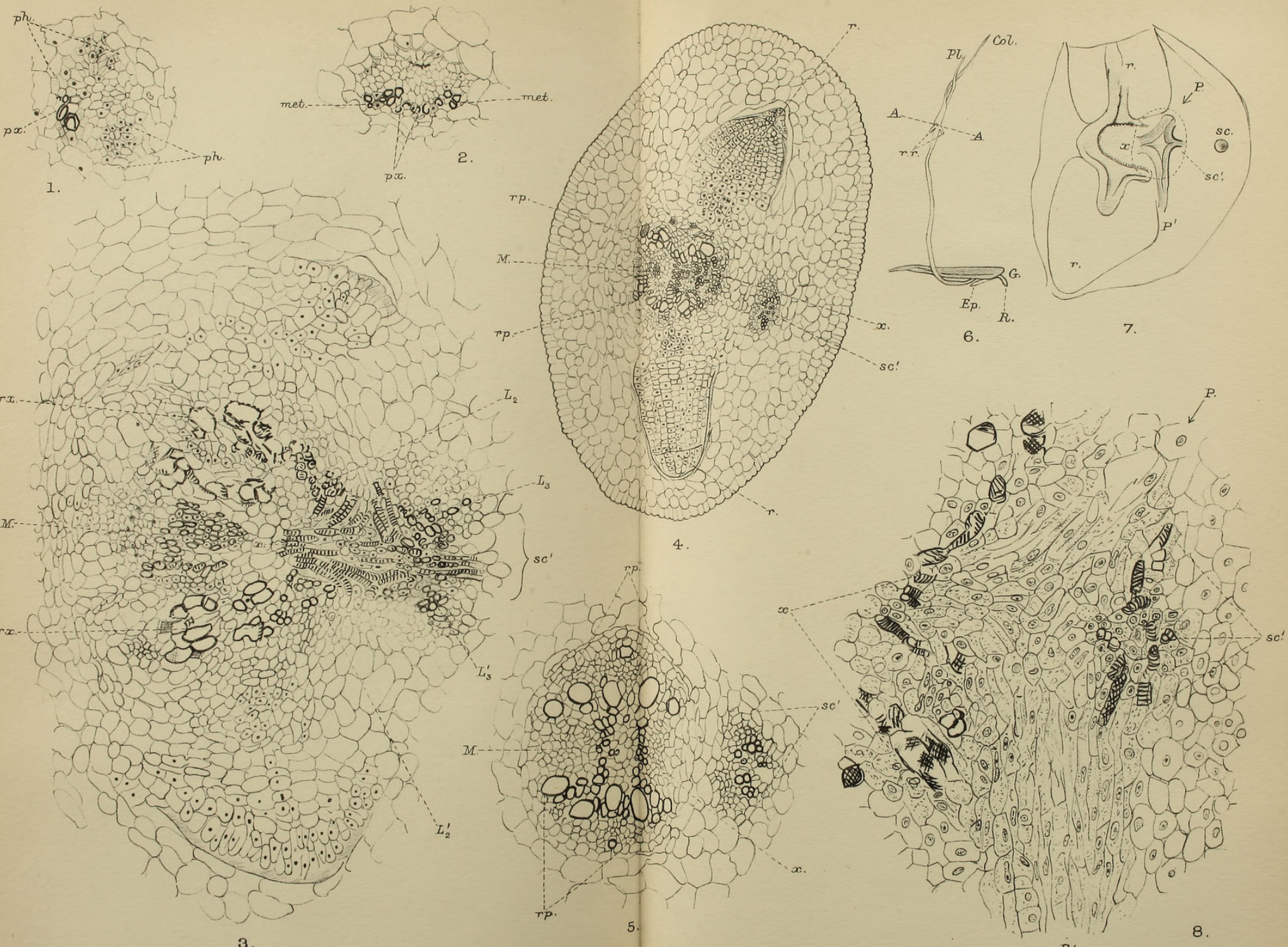

A.A.\&E.S. ad nat del. SARGANT \& ARBER - GRAMINEA.

$p^{\prime}$

Futh, lith ot imp. 
Annals of Botany,
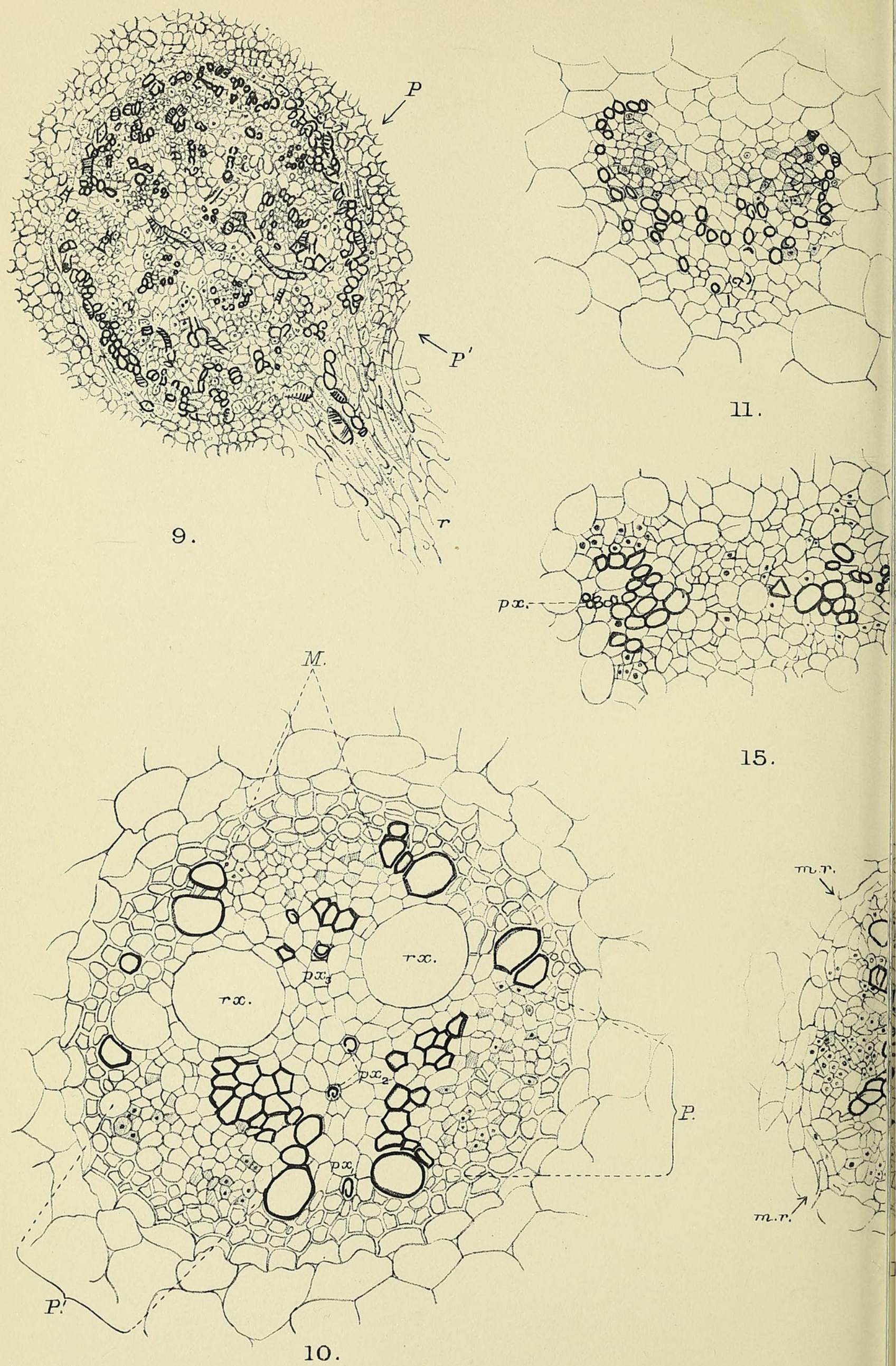

A.A. adnat del.

SARGANT \& ARBER - GRAMINEAE. 
Vol. XXIX,PZ.X.

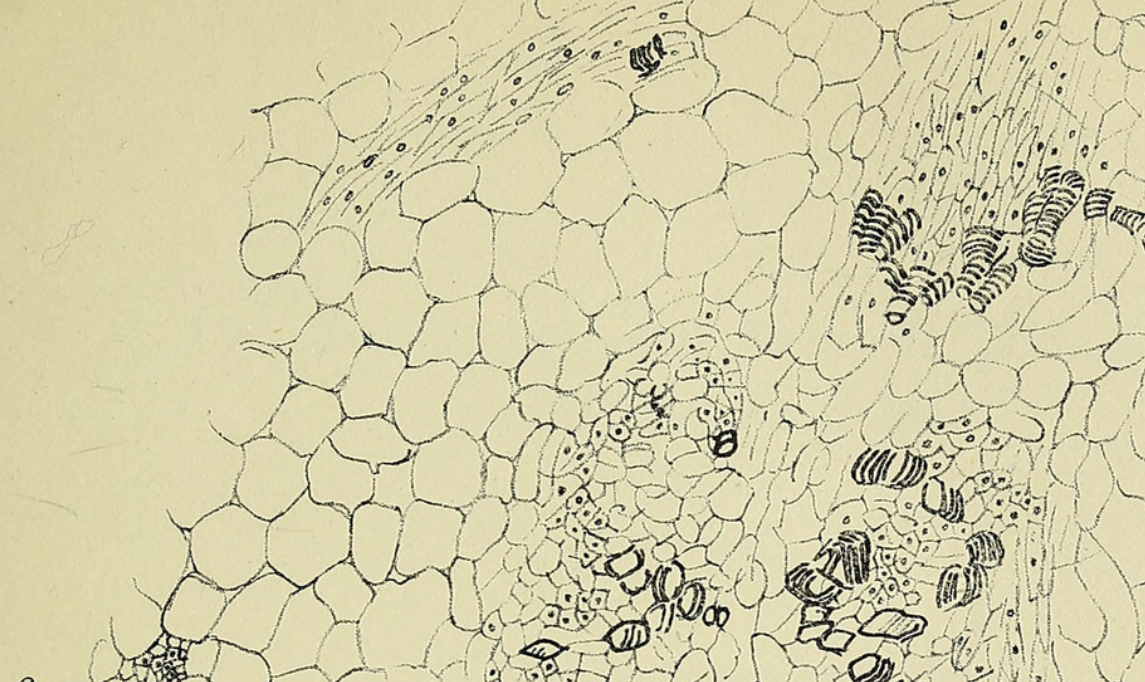

$--p x$

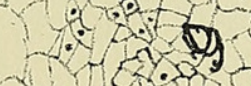

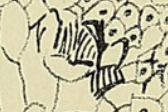

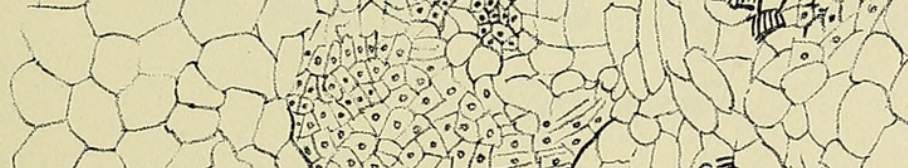

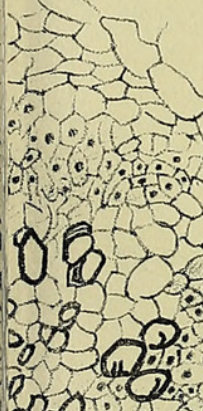

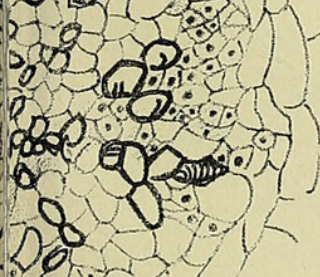

10 ,

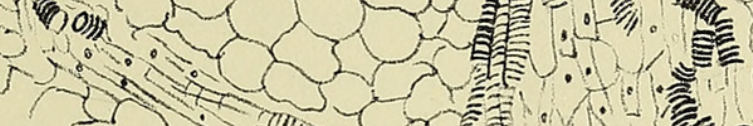
人

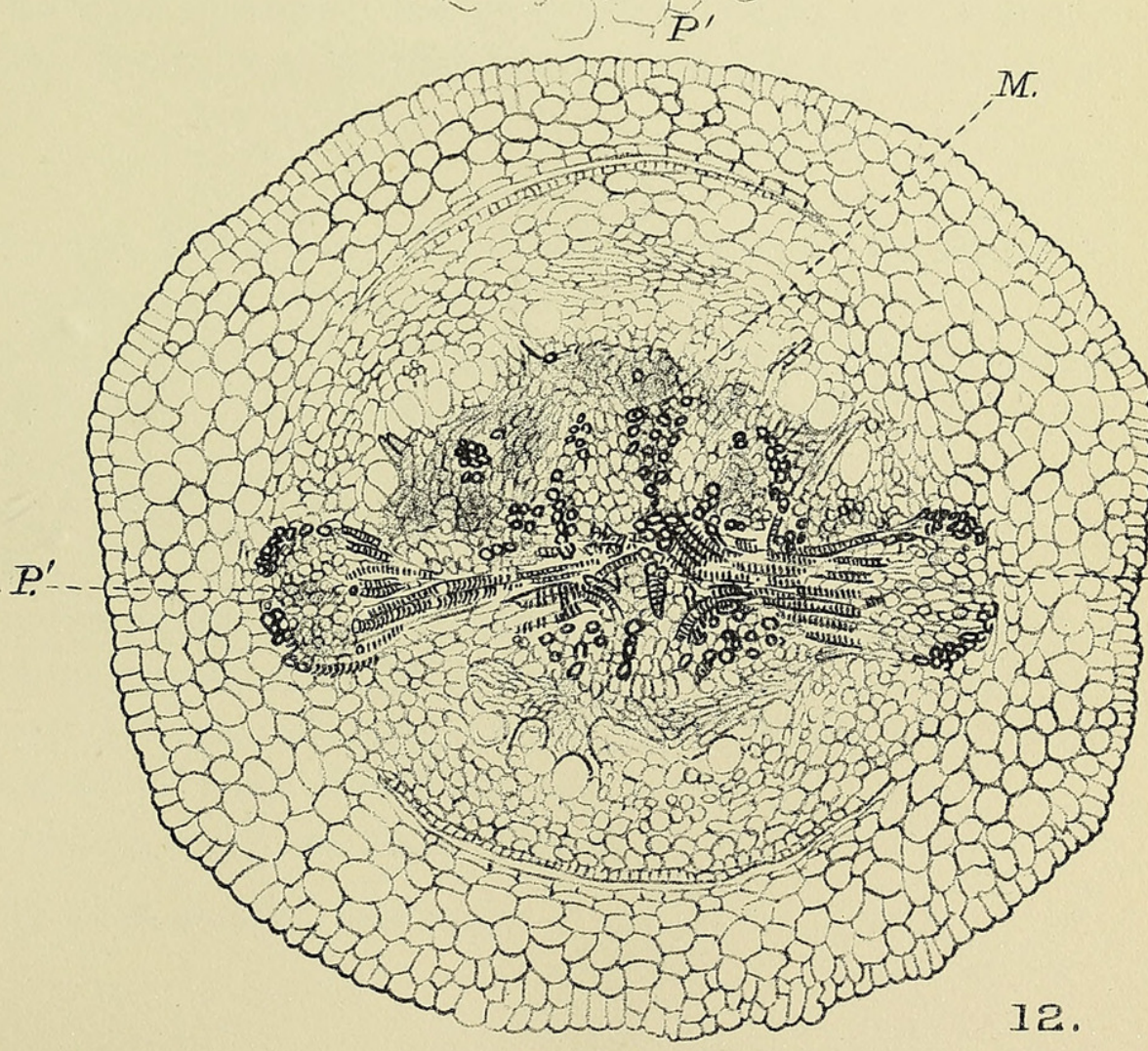

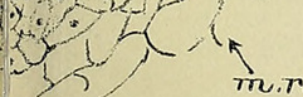

Erath Iith et imp 


\section{$2 \mathrm{BHL}$ Biodiversity Heritage Library}

Sargant, Ethel and Arber, Agnes Robertson. 1915. "The comparative morphology of the embryo and seedling in the Gramineae." Annals of botany 29, 161-222. https://doi.org/10.1093/oxfordjournals.aob.a089541.

View This Item Online: https://www.biodiversitylibrary.org/item/243629

DOI: https://doi.org/10.1093/oxfordjournals.aob.a089541

Permalink: https://www.biodiversitylibrary.org/partpdf/320058

\section{Holding Institution}

Smithsonian Libraries

\section{Sponsored by}

Biodiversity Heritage Library

\section{Copyright \& Reuse}

Copyright Status: Not in copyright. The BHL knows of no copyright restrictions on this item.

This document was created from content at the Biodiversity Heritage Library, the world's largest open access digital library for biodiversity literature and archives. Visit BHL at https://www.biodiversitylibrary.org. 